\title{
MICROSTRUCTURE AND PROPERTIES OF FINE GRAINED Cu-Cr-Zr ALLOYS AFTER TERMO-MECHANICAL TREATMENTS
}

\author{
A. Morozova, R. Mishnev, A. Belyakov and R. Kaibyshev
}

Belgorod State University, Pobeda 85, 308015 Belgorod, Russia

Received: June 13, 2018

\begin{abstract}
Cu}-\mathrm{Cr}-\mathrm{Zr}$ alloys provide an excellent combination of strength and electric conductivity and are frequently used as engineering materials in various electric/electronic devises. The present review deals with the microstructural design of $\mathrm{Cu}-\mathrm{Cr}-\mathrm{Zr}$ alloys, their alloying concept, thermo-mechanical processing based on technique of severe plastic deformation, physical mechanisms responsible for high strength and electric conductivity. The influences of microstructure and a dispersion of secondary phases on the mechanical properties and electric conductivity are discussed in detail. First, precipitation sequences during aging that leads to depletion of $\mathrm{Zr}$ and $\mathrm{Cr}$ solutes from $\mathrm{Cu}$ solution are critically reviewed in close connection with interaction mechanisms between dislocations and particles. Then, the main structure-property relationships of $\mathrm{Cu}-\mathrm{Cr}-\mathrm{Zr}$ alloys are considered. Finally, the strengthening of $\mathrm{Cu}-\mathrm{Cr}-\mathrm{Zr}$ alloys through severe plastic deformation by means of submicrocrystalline/nanocrystalline structure and increasing dislocation density as well as the effects of post-deformation heat treatment on the mechanical and electric properties are discussed.
\end{abstract}

\section{INTRODUCTION}

Current progress in electric power systems including railway contact wires, integrated circuit lead frame, and electrode of resistance welding, intelligent systems involving the computing system miniaturization and the development of connectors for electrical microelectronic devises requires the upgrade of materials for electrical conductors. In addition, such heat transfer elements as thin walled diverter plates for high heat flux require a heat sink material with a high strength. Today, the most commonly used materials for electrical engineering applications are aluminum, copper and its alloys due to the high conducting characteristics. Strength and electrical/thermal conductivity are the key properties of electrical engineering materials. These properties, however, are frequently achieved by opposite approaches, The strength can be increased owing to increasing density of lattice defects such as solutes, dislocations, grain boundaries or dispersoids, while the conductivity decreases due to electron scattering on vacancies, impurities, dislocations and grain boundaries. Thus, materials may be strong or exhibit high electrical/thermal conductivity. However, high electrical and/or thermal conductivity and high mechanical strength are simultaneously required in numerous applications.

Aluminum and its alloys are frequently used in various applications because of the low price and high specific strength. In contrast, copper and its alloys are used for critical elements that require a beneficial combination of mechanical and functional properties. The main advantages of copper over aluminum is high conductivity (electrical conductivity of aluminum achieves $62 \%$ of electrical conductivity of pure copper (\%IACS) and strength (ultimate 


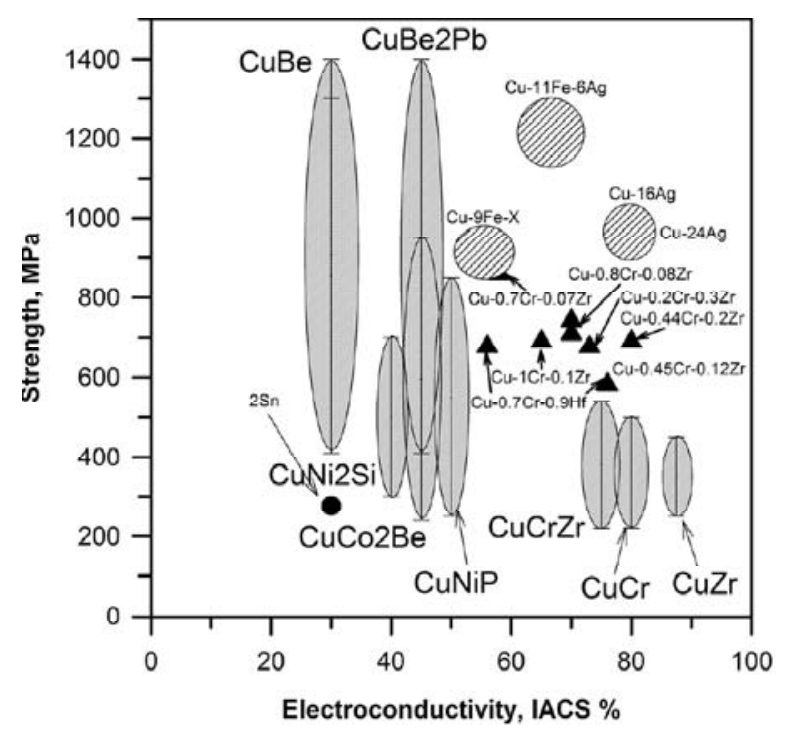

Fig. 1. Strength and electrical conductivity of copper alloys, data from [3-5,11].

tensile strength of pure aluminum is about half of that of copper) $[1,2]$. However, specific strength of $\mathrm{Cu}$ is lower than that of $\mathrm{Al}-\mathrm{Mg}-\mathrm{Si}$ and $\mathrm{Al}-\mathrm{Zr}$ alloys due to high density $\left(8.96 \mathrm{~g} / \mathrm{cm}^{3}\right)$. An appropriate alloying and suitable thermo-mechanical treatment can significantly harden the copper alloys [2]. For example, the strength of beryllium bronze can reach $2000 \mathrm{MPa}$ (Fig. 1) [3-5]. On the other hand, an increase in alloying extent degrades the functional properties, the electrical conductivities of beryllium bronzes are about $10-20 \%$ IACS [3-5]. Therefore, the fundamental problem of copper alloys is the selection of the optimal alloying systems that provide a combination of high strength and electrical/ thermal conductivity. Alloying philosophy for $\mathrm{Cu}$ alloys consists in using such defects, which can enhance the strength, but do not decrease the conductivity. Nanoscale dispersoids are valuable for an increase in strength of $\mathrm{Cu}$ alloys without remarkable decrease in conductivity. The alloying by substitutional solutes leads to inevitably decrease in conductivity with small increase in strength. Therefore, a Cu alloy exhibiting high electrical and/or thermal conductivity and high mechanical strength has to be a dispersion strengthened alloy with pure $\mathrm{Cu}$ matrix containing traces of solutes and nanoscale particles.

Cu-Ag alloys exhibit outstanding strength and electrical conductivity (Fig. 1). However, the expenses of $\mathrm{Ag}$ additions limit commercial production and use of these alloys. The best candidate for electrical engineering and heat transfer applications can be $\mathrm{Cu}-\mathrm{Cr}-\mathrm{Zr}$ alloys combining reasonable cost with high strength and conductivity (Fig. 1) [6-27]. The
Cu-Cr-Zr alloys possess high strength and electrical conductivity, which result from precipitation of dispersed particles (Fig. 2) [28-33].

$\mathrm{Cu}-\mathrm{Cr}-\mathrm{Zr}$ alloys are age-hardenable materials. Heat treatment including solution treatment followed by quenching and aging provides significant increase in strength of these alloys. The aged $\mathrm{Cu}-\mathrm{Cr}, \mathrm{Cu}-\mathrm{Zr}$ and $\mathrm{Cu}-\mathrm{Cr}-\mathrm{Zr}$ alloys possess high electric conductivity due to insignificant electron scattering on solutes. Electron scattering on $\mathrm{Cr}$ - and $\mathrm{Zr}$-containing dispersoids decreases electrical conductivity to about $80 \%$ IACS (Fig. 1) [14,26].

In spite of low solubility of $\mathrm{Cr}$ in $\mathrm{Cu}$ [30-34], up to 0.78 at. $\% \mathrm{Cr}$ can be solved in $\mathrm{Cu}$ at $960{ }^{\circ} \mathrm{C}$ [35]; and the highest equilibrium solubility is 0.89 at.\% (0.71 wt.\%) at $1070^{\circ} \mathrm{C}[14]$. Cu-Cr supersaturated solid solution can be obtained through rapid solidification or severe plastic deformation dissolving the Cr particles [34,36-41]. In contrast, the Zr solubility is quite small of approx. $0.1 \mathrm{wt} . \%$ even at pre-melting temperature [30-32]. Optimal contents of $\mathrm{Cr}$ and $\mathrm{Zr}$ in $\mathrm{Cu}-\mathrm{Cr}-\mathrm{Zr}$ alloys are limited by 0.67 and 0.12 wt.\%, respectively. As it will be shown below the strength characteristics of $\mathrm{Cu}-\mathrm{Cr}-\mathrm{Zr}$ alloys are attributed to a dispersion of secondary particles and increasing volume fraction of $\mathrm{Cr}$ - and $\mathrm{Zr}$-containing dispersoids is an attractive way to enhance the yield strength. The highest content of $\mathrm{Cr}$ and $\mathrm{Zr}$ in $\mathrm{Cu}-\mathrm{Cr}$ $Z r$ alloys is controlled by solubility of these elements during solidification. The primary precipitates from liquid during solidification decrease the strength of $\mathrm{Cu}-\mathrm{Cr}$-Zr alloys [40]. The upper limit for $\mathrm{Cr}$ and $\mathrm{Zr}$ content in Cu-Cr-Zr alloys is about 2 and $0.5 \mathrm{wt} . \%$, respectively, for thin ribbon produced by rapid solidification [38,39] and 0.8 and $0.2 \mathrm{wt} . \%$, respectively, for rods with a diameter of approx. $10 \mathrm{~mm}$ or sheets with a thickness of $5 \mathrm{~mm}$ produced by semicontinuous casting [1]. Specific routes of heat treatment without solution treatment were applied to $\mathrm{Cu}$ $\mathrm{Cr}$-Zr alloys with $\mathrm{Cr}$ and $\mathrm{Zr}$ content higher than equilibrium solubility of these elements at $1000^{\circ} \mathrm{C}$ to achieve high strength, although small dimensions of these products restrict their commercial use by microelectronic devises. Thus, the highest contents of $\mathrm{Cr}$ and $\mathrm{Zr}$ in the most commercial $\mathrm{Cu}-\mathrm{Cr}$-Zr alloys are lower than the solubility of these elements.

The strength of $\mathrm{Cu}-\mathrm{Cr}-\mathrm{Zr}$ alloys can be significantly increased by thermo-mechanical processing (TMP) $[5,10,14,16,19,21-26,42-72]$. Plastic deformation by drawing, cold rolling or rolling at cryogenic temperature, equal channel angular pressing (ECAP) increases strength due to dislocation strengthening and grain boundary strengthening $[51,72,73]$. The main advantage of TMP is its little effect on electri- 

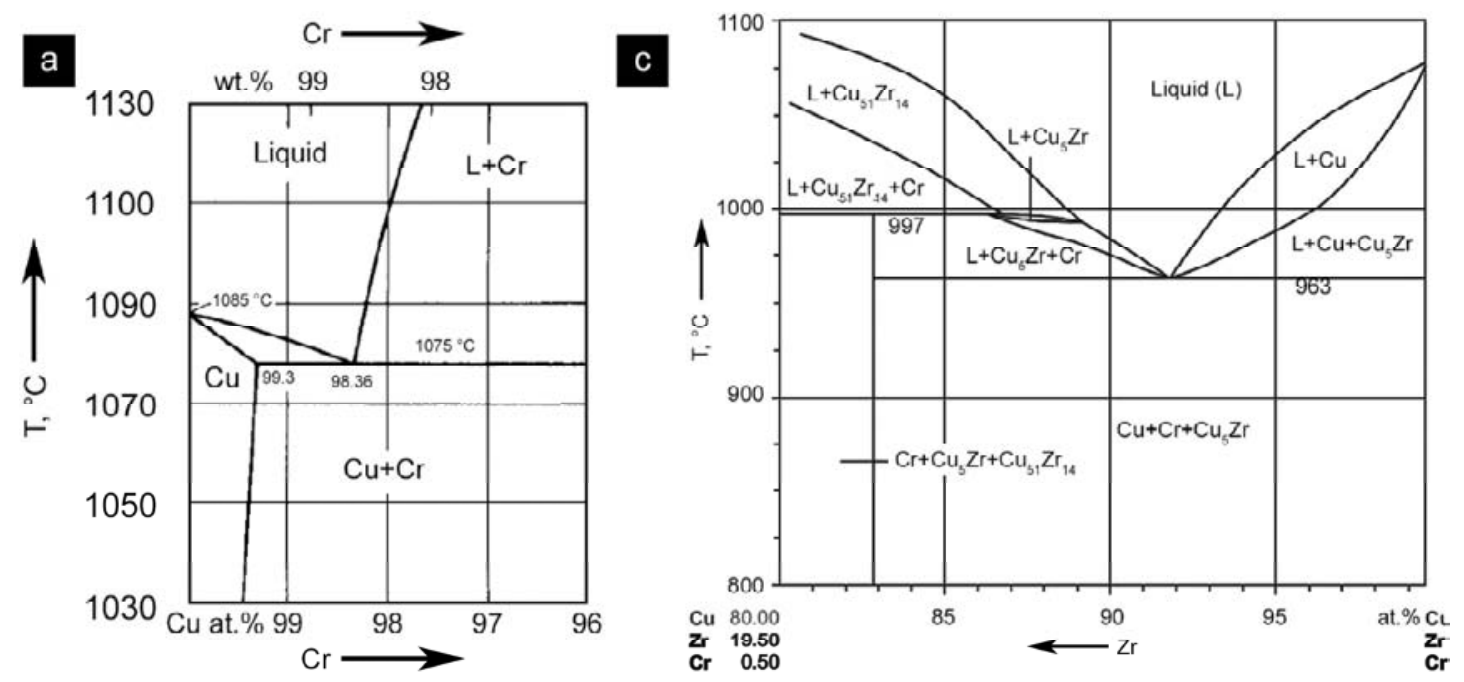

b
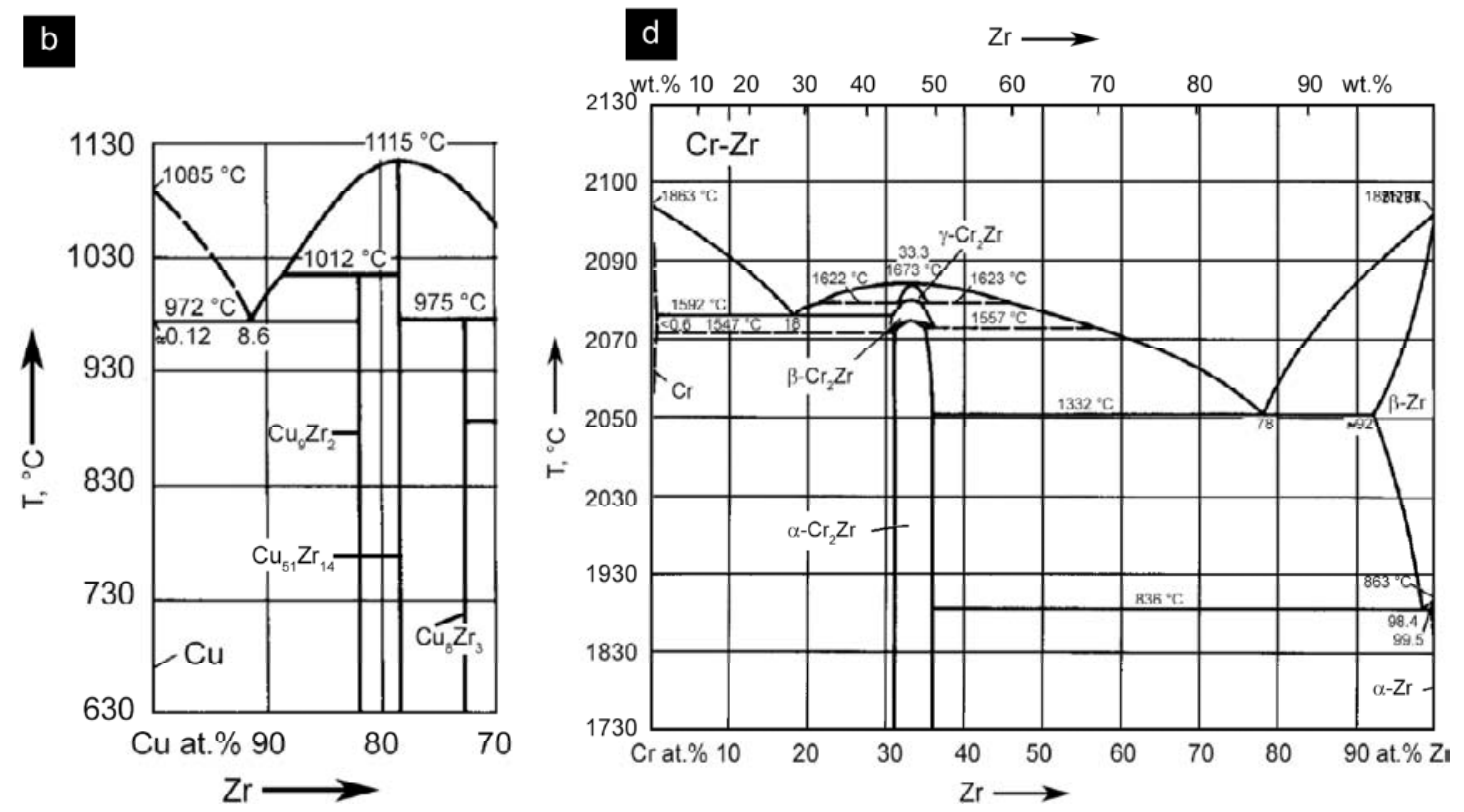

Fig. 2. Phase equilibrium diagram of the binary $\mathrm{Cu}-\mathrm{Cr}(\mathrm{a}), \mathrm{Cu}-\mathrm{Zr}$ (b), $\mathrm{Cr}-\mathrm{Zr}$ alloys (d) and ternary system of Cu- $0.5 \% \mathrm{Cr}-\mathrm{Zr}$ (c), adapted from Refs. [31-33].

cal conductivity, since electron scattering on dislocations and grain boundaries is insignificant [74]. As a result, $\mathrm{Cu}-\mathrm{Cr}-\mathrm{Zr}$ alloys retain electrical conductivity above $70 \%$ IACS even after severe plastic deformation $[14,19,24,25,48,51,52,55,56,58,68$, $69,75,76]$.

The present review is devoted to consider the modern concepts of microstructural design, TMP and their effect on microstructure and properties of $\mathrm{Cu}-\mathrm{Cr}$-Zr alloys. The overview consists of three main sections. Firstly, the phase contents/transformations in the $\mathrm{Cu}-\mathrm{Cr}$-Zr alloys during solidification, solution treatment and aging are considered. The second part of the paper discusses the effects of chemical composition, phase contents and microstructures on strength, ductility, electrical conductivity and wear resistance. Special attention is paid to mecha- nisms of dispersion strengthening. In the third part, the influence of TMP on the microstructure and distribution of secondary phases is considered in relation with their effects on the strength and electrical conductivity. Finely, optimal microstructural design and chemical/phase composition of these alloys are outlined.

\section{PHASE TRANSFORMATIONS IN Cu-Cr-Zr ALLOYS}

Binary $\mathrm{Cu}-\mathrm{Cr}$ and $\mathrm{Cu}-\mathrm{Zr}$, and ternary $\mathrm{Cu}-\mathrm{Cr}$-Zr alloy phase equilibrium diagrams are well developed (Fig. 2) [28-33]. In the present study, we consider Curich corner, only, since as it was shown above the content of $\mathrm{Cr}$ and $\mathrm{Zr}$ content in $\mathrm{Cu}-\mathrm{Cr}$-Zr alloys produced by ingot metallurgy does not exceed $\sim 2$ and 
$\sim 0.5 \mathrm{wt} . \%$, respectively. There are two terminal solid solutions in the $\mathrm{Cu}-\mathrm{Cr}-\mathrm{Zr}$ ternary system and two intermetallic compounds with negligible homogeneity ranges [32]: the solution of $\mathrm{Cr}$ and $\mathrm{Zr}$ in fcc-Cu with a lattice parameter of $a=0.3615 \mathrm{~nm}$, denoted (Cu); the solution of $\mathrm{Cu}$ in bcc-Cr with a lattice parameter of $a=0.2895 \mathrm{~nm}$, denoted ( $\beta-\mathrm{Cr}$ ) [18]; the eutectic intermetallic compound with a fcc structure of the $\mathrm{AuBe}_{5}$ type $(\mathrm{F} \overline{4} 3 \mathrm{~m})$ and a lattice parameter of 0.687 $\mathrm{nm}$, denoted $\left(\mathrm{Cu}_{5} \mathrm{Zr}\right)[13,77,78]$; the congruent compound of $\mathrm{Cu}_{51} \mathrm{Zr}_{14}$, that is true stoichiometric composition, with a hcp structure of the $\mathrm{Ag}_{51} \mathrm{Gd}_{14}$ type $(\mathrm{P} 6 / \mathrm{m})$ and lattice parameters of $a=1.125 \mathrm{~nm}$ and $C=0.8275 \mathrm{~nm}[13,30]$. It is worth noting that the stoichiometry $\mathrm{Cu}_{9} \mathrm{Zr}_{2}$ is also accepted for $\mathrm{Cu}_{5} \mathrm{Zr}$ phase since the concentration of $\mathrm{Zr}$ in this phase is $\sim 24.3$ wt.\% by electron probe microanalysis, which is close to the $\mathrm{Zr}$ concentration of $24.18 \mathrm{wt} . \%$ for theoretical concentration in stoichiometric $\mathrm{Cu}_{9} \mathrm{Zr}_{2}[30$, 76]. Eutectic reaction $\mathrm{L} \rightarrow(\mathrm{Cu})+\mathrm{Cu}_{5} \mathrm{Zr}$ occurs at $\sim 1000{ }^{\circ} \mathrm{C}$ [30]. This phase melts congruently at $1100^{\circ} \mathrm{C}$ [30]. The formation of $\mathrm{Cu}_{51} \mathrm{Zr}_{14}$ phase was reported in $\mathrm{Cu}-0.31 \% \mathrm{Cr}-0.21 \% \mathrm{Zr}$ alloy during aging at $450^{\circ} \mathrm{C}[79]$. This phase may replace the $\mathrm{Cu}_{5} \mathrm{Zr}$ during aging due to lower Gibbs energy [30].

The precipitation sequences of decomposition of supersaturated solid solution (SSSS) remain a subject of debates despite of numerous studies devoted to the aging behavior. We will consider decomposition sequences in binary $\mathrm{Cu}-\mathrm{Cr}$ and $\mathrm{Cu}-\mathrm{Zr}$, separately. In summary, we will analyze the effect of $\mathrm{Zr}$ on precipitation sequence in binary $\mathrm{Cu}-\mathrm{Cr}$ alloys. The reported precipitation sequence in $\mathrm{Cu}-\mathrm{Cr}$ can be summarized as follows [18,35,56,59,80-85]:

$$
\begin{aligned}
& \text { SSSS } \rightarrow \text { GP zones } \rightarrow \text { ordered fcc Cr-rich } \\
& \text { phase } \rightarrow \text { coherent B2 phase } \rightarrow \beta \text {-Cr. }
\end{aligned}
$$

An aging at $450{ }^{\circ} \mathrm{C}$ for 5 minutes leads to partitioning of $\mathrm{Cr}$ atoms [80] followed by the formation of Guinier-Preston (GP) zones of round shape with a size of 1 to $2 \mathrm{~nm}$ [81-83]. The GP zones exhibit coffee bean contrast on transmission electron microscopy images, suggesting high anisotropic coherent stress fields [81-83]. In addition, GP zones give streaks along $\langle 110\rangle_{\mathrm{Cu}}$ direction around every fcc reflection from Cu matrix on selected area electron diffraction (SAED) patterns. Therefore, the GP zones consists of multiple layered structure of $\{110\}_{\mathrm{Cu}}$ planes enriched by $\mathrm{Cr}$ and alternating along $\langle 110\rangle_{\mathrm{Cu}}$ direction. TEM did not reveal any other diffraction spots except those from the $\mathrm{Cu}$ matrix $[81,82]$. These precipitates are fully coherent with the Cu matrix.
An increase in the aging duration from $5 \mathrm{~min}$ to $\sim 4 \mathrm{~h}$ leads to coarsening of the $\mathrm{Cr}$-rich GP zones up to $5 \mathrm{~nm}$ and their direct transformation to ordered fcc structure with cube-on-cube orientation relationship (OR) $[18,35,56,81-83,86]$. The precipitates of ordered fcc $\mathrm{Cr}$-rich phase retain spherical shape of GP zones. The corresponding SAED pattern with $\langle 110\rangle_{C u}$ zone axis shows the extra superlattice reflection of $1 / 2<022>_{p}$ from the ordered fcc precipitates at midway between $\{220\}_{\mathrm{Cu}}$ spots $[18,82]$. Therefore, fcc ordered Cr-phase consists of alternating $\{110\}_{\mathrm{Cu}}$ planes. It is apparent that the most probable superstructure of ordered fcc $\mathrm{Cr}$-rich phase is following. Pure $\mathrm{Cu}$ layer is separated by pure $\mathrm{Cr}$ layer along $\langle\overline{1} 10\rangle_{\mathrm{Cu}}$ direction since the $\mathrm{Cr}$ concentration is $\sim 50$ at.\% in the spherical precipitates [35]. The atomic radius of $\mathrm{Cu}$ is $0.1278 \mathrm{~nm}$, the atomic radius of $\mathrm{Cr}$ is $0.1249 \mathrm{~nm}$ [87]. The larger $\mathrm{Cu}$ atoms are dissolved in the $\mathrm{Cr}$ phase and the interplanar distance and the lattice parameter of $\mathrm{Cr}$ increases to 0.408 [82], 4.183 [18] or $0.4219 \mathrm{~nm}$ [88]. Thus, the lattice parameter of the ordered fcc $\mathrm{Cr}$-rich phase is larger than that of the fcc Cu matrix. The surrounded Cu matrix is strained towards the $\mathrm{Cr}$ layers as a result of the smaller size of the $\mathrm{Cr}$ atoms compared to the $\mathrm{Cu}$ atoms that induces coffee bean contrast along $\langle 110\rangle_{\mathrm{Cu}}$ direction. A spherical shape of ordered fcc $\mathrm{Cr}$ precipitates with a cube-on-cube OR with the Cu matrix should grow with resulting from isotropic distortions. The strainfield contrast of these particles is attributed to a large misfit of $\sim 15 \%$ [18]. This is why the nanoscaled fcc $\mathrm{Cr}$-rich precipitates induce large lattice distortions in Cu matrix that make difficult their examination by BF-TEM technique [35].

The nucleation barrier for the ordered fcc Cr particles with coherent interfaces is reportedly lower than that for bcc $\mathrm{Cr}$ particles with incoherent interfaces by a factor of $\sim 100$ [81] due to a low energy of coherent interfaces $\left(86 \mathrm{mJm}^{-2}\right)$ and high energy of incoherent interfaces $\left(626 \mathrm{mJm}^{-2}\right)[35,82]$. Therefore the most probable mechanism for transformation of ordered fcc $\mathrm{Cr}$-rich particles to bcc $\mathrm{Cr}$ ones is step-by-step in situ transformation of crystal lattice [82]. There is no doubt that in situ transformation of fcc ordered $\mathrm{Cr}$-rich phase is the main mechanism for the formation of the B2 phase. It should be noted that an evidence for independent homogeneous nucleation of bcc $\mathrm{Cr}$ particles has also been reported [35].

The coherent B2 (CsCl-type ( $\mathrm{Pm} 3 \mathrm{~m}))$ phase exhibits a well-known Nishiyama-Wassemann (NW) OR with Cu matrix of $\{111\}_{\mathrm{Cu}} / /\{011\}_{\mathrm{B} 2}$ and $\langle 011\rangle_{\mathrm{Cu}} / /$ 
$\langle 100\rangle_{\mathrm{B} 2}$. These particles may exhibit Moiré fringes on TEM images [35, 82]. The lattice parameter of B2 phase is $\sim 0.280 \mathrm{~nm}$ [82], which is close to that of $\beta$-Cr. Elipsoidal shape of B2 particles is attributed to a small misfit of $2.3 \%$ along the $\langle 111\rangle_{\mathrm{Cu}}$ ll $<011\rangle_{\mathrm{B} 2}$ direction and a large misfit of $15.45 \%$ along the $\langle 110\rangle_{\mathrm{Cu}} / \mid\langle 100\rangle_{\mathrm{B} 2}$ direction $[35,82]$. As a result, these particles grow favorably along the small misfit direction acquiring ellipsoidal shape [35]. Typical dimensions of major and minor axis of ellipsoid are $\sim 10$ and $\sim 3 \mathrm{~nm}$, respectively, for the B2 phase dispersoids after prolonged aging. In general, the transformation of ordered fcc Cr-rich particles to B2 phase is accompanied by tenfold increase in their average volume [35]. The $\mathrm{Cr}$ concentration is $~ 50$ at.\% in the B2 phase. It is apparent that solubility of $\mathrm{Cr}$ in $\mathrm{Cu}$ solution being in thermodynamical equilibrium with transition B2 phase is relatively high. After aging at $440^{\circ} \mathrm{C}$ for $5 \mathrm{~h}, 0.14$ at.\% (0.11 wt.\%) $\mathrm{Cr}$ remains in solid solution providing $60 \%$ IACS [35].

Besides NW OR, the $\beta$-Cr dispersoids exhibit the Kurdjumov-Sachs (KS) OR of $\{111\}_{\mathrm{Cu}} / /\{011\}_{\beta-\mathrm{Cr}}$ and $\langle 110\rangle_{\mathrm{Cu}} / /\langle 111\rangle_{\beta-\mathrm{Cr}}[35,82,89]$. KS OR is characterized by two directions with small misfits of $2.3 \%$ along $\left.<111>_{\mathrm{Cu}} / /<011\right\rangle_{\beta-\mathrm{Cr}}$ (as for NW OR) and $2.2 \%$ along $\langle 110\rangle_{\mathrm{Cu}} / /\langle 111\rangle_{\beta-\mathrm{Cr}}[35]$. As a result, $\beta$-Cr dispersoids grow along two directions acquiring a plate-like shape and relatively large dimensions and volume [35]. The $\beta$-Cr dispersoids also exhibit Moiré fringes on TEM images [35,82]. Incoherent interfaces of $\beta$ - $\mathrm{Cr}$ have been reported in numerous works $[35,81,82,90]$. However, this statement could be argued by the following. It is well known that the $\beta$-Cr dispersoids nucleate homogeneously in $\mathrm{Cu}$ and the replacement of B2 precipitates occurs through Gibbs-Thomson schema [91]. Therefore, the nucleation of $\beta$ - $\mathrm{Cr}$ dispersoids with initially incoherent interfaces is almost impossible due to aforementioned large value of interfacial energy leading to a very high energy barrier [81]. Therefore, the homogeneous nucleation of $\beta-\mathrm{Cr}$ dispersoids with KZ OR may take place with coherent and/or semi-coherent interfaces. Small misfits provide coherency of interfaces along two directions up to their dimensions of $10 \mathrm{~nm}$. Therefore, $\beta-\mathrm{Cr}$ dispersoids retain coherency of their interfaces despite their growth at expense of the B2 dispersoids under prolonged aging [35]. The $\beta$-Cr dispersoids contain $~ 95$ at. $\% \mathrm{Cr}$ [35]. After aging at $440^{\circ} \mathrm{C}$ for $10 \mathrm{~h}, 0.02$ at. $\% \mathrm{Cr}$ retain in solid solution providing $76 \%$ IACS [35]. Therefore, the $\beta$-Cr dispersoids is a unique phase which could be useful for dispersion hardening of $\mathrm{Cu}-\mathrm{Cr}$ alloys since the precipitation of this phase and the corresponding depletion of $\mathrm{Cr}$ from $\mathrm{Cu}$ solid solution is quite favorable for electrical conductivity.

The atomic radius of $\mathrm{Zr}$ atom $(0.16 \mathrm{~nm})$ is $20 \%$ higher than that of $\mathrm{Cu}$ that causes the difference in precipitation sequence and equilibrium phases between binary $\mathrm{Cu}-\mathrm{Cr}$ and $\mathrm{Cu}-\mathrm{Zr}$ alloys. The following precipitation sequence in $\mathrm{Cu}-\mathrm{Zr}$ can be drawn [77, 92]:

$$
\text { SSSS } \rightarrow \text { GP zones } \rightarrow \mathrm{Cu}_{5} \mathrm{Zr} .
$$

The GP zones are disk-shaped monolayers of Zr-rich $\{111\}_{\text {Cu }}$ planes [92]. The diameter and thickness of the disks are $\sim 5$ and $\sim 1 \mathrm{~nm}$, respectively. Coarsening of the GP zones during aging is accompanied by their direct transformation to $\mathrm{Cu}_{5} \mathrm{Zr}$ phase [92]. Characteristic superlattice diffraction spots from $\mathrm{Cu}_{5} \mathrm{Zr}$ appear, when the disk diameter attains $\sim 10$ $\mathrm{nm}$ and the thickness ranges from 2 to $4 \mathrm{~nm}$. The $\mathrm{Cu}_{5} \mathrm{Zr}$ particles exhibit plate-like shape [77,92], their typical diameter and thickness are reported as $\sim 50$ $\mathrm{nm}$ and $\sim 8 \mathrm{~nm}$, respectively [92]. Growth of the platelets takes place along $\{111\}_{\mathrm{Cu}}$ planes. The $\mathrm{Cu}_{5} \mathrm{Zr}$ particles exhibit OR of $\{111\}_{\mathrm{Cu}} / /\{111\}_{\mathrm{Cu} Z \mathrm{r}}$ and $\langle 112\rangle_{\mathrm{Cu}} /$ $|<011\rangle_{\text {Cu5zr }}$ providing a small mismatch of $0.054 \%$ [93]. As a result, interfaces of $\mathrm{Cu}_{5} \mathrm{Zr}$ phase located along $\{111\}_{\mathrm{Cu}}$ habit planes retain coherency up to high dimensions. Precipitation of $\mathrm{Cu}_{5} \mathrm{Zr}$ phase yields almost full depletion of $\mathrm{Zr}$ from solid solution that provides $90 \%$ IACS. Therefore, this phase is also quite useful for dispersion strengthening of $\mathrm{Cu}-\mathrm{Cr}-\mathrm{Zr}$ phases. The particles of this phase are noneshearable despite of coherent or semi-coherent interfaces [50], since the shearing leads to the formation of anti-phase boundary within the sheared particle that provide a high shear resistance. Note here, the formation of $\mathrm{Cu}_{5} \mathrm{Zr}$ particles with $\{011\}_{\mathrm{Cu}}$ habit plane due to $\mathrm{B}$ additives to a $\mathrm{Cu}-\mathrm{Zr}$ alloy has been recently reported [94]. Also, $\mathrm{Cu}_{x} \mathrm{Zr}_{y}$ precipitates with intermetallic structure and ellipsoid shape have been observed in $\mathrm{Cu}-\mathrm{Cr}$ alloys concurrently with $\mathrm{Cu}_{5} \mathrm{Zr}$ particles. However, the origin of these precipitates remains unknown.

In ternary Cu-Cr-Zr alloys, the decomposition sequences of (1) and (2) may occur concurrently, providing an increased strength in comparison with binary alloys $[7,15,18,95-97]$. There are two main reasons for enhanced strength characteristics of the ternary alloys in comparison with binary alloys. First, an aging at a relatively low temperature of $450^{\circ} \mathrm{C}$ leads to precipitation of shearable $\beta$-Cr platelets and none-shearable $\mathrm{Cu}_{5} \mathrm{Zr}$ precipitates with disc and plate-like shapes having $\{111\}_{\mathrm{Cu}}$ habit plane in 

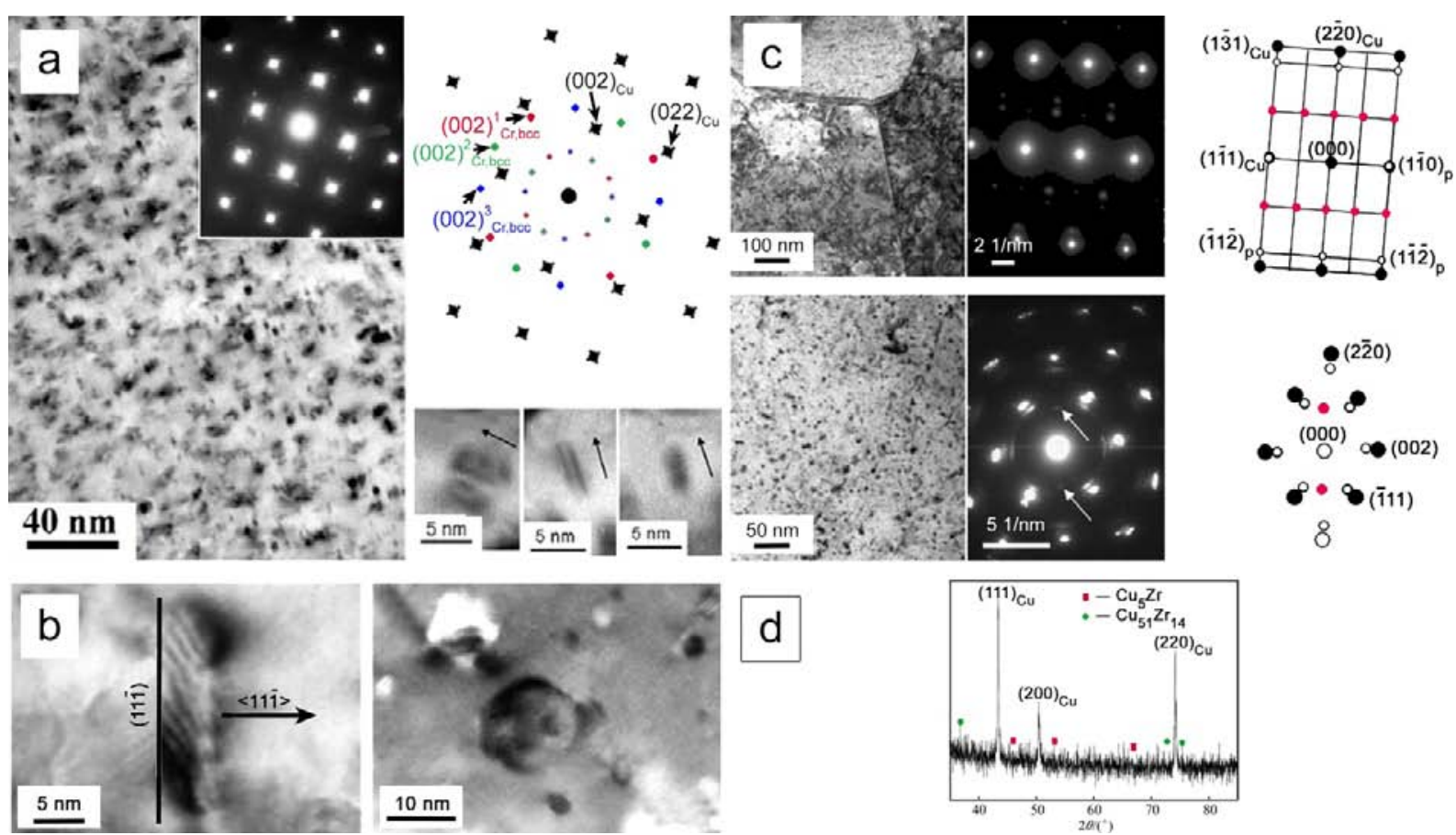

Fig. 3. Fine microstructures of Cu-Cr-Zr alloys with (a) Cr particles, (b) Cu5Zr-particles, (c) Guinier-Preston zones, and (d) X-Ray diffraction showing Cu51Zr14-phase, adapted from Refs. [35,82,97,100].

Cu-Cr-Zr alloys (Fig. 3). This dispersion of secondary phase particles provides higher strength comparing with that containing one type of dispersoids. Second, $\mathrm{Zr}$ atoms restrain a dispersion of b-Cr platelets due to segregations on periphery of $\mathrm{Cr}$-rich particles that restricts further diffusion of $\mathrm{Cr}$ atoms to these particles [94,98]. Since the atom radius of $\mathrm{Zr}$ is higher than that of $\mathrm{Cr}$, the $\mathrm{Zr}$ segregations at $\beta-\mathrm{Cr} / \mathrm{Cu}$ matrix interfaces highly enhance their coherency due to mutual compensation of mismatch in atomic radii. As a result, mismatch between $\beta-\mathrm{Cr}$ and Cu matrix decreases that releases elastic strain [98]. Therefore, minor Zr additions play a key role in restraining coherency of $\beta$-Cr particles and promote the contribution of these particles to dispersion hardening. An apparent contradiction between incoherent and coherent origins of these interfaces in binary $\mathrm{Cu}-\mathrm{Cr}$ alloys $[35,81,90]$ and ternary $\mathrm{Cu}-\mathrm{Cr}-\mathrm{Zr}$ alloys [51] can be attributed to the effect of $Z r$. Thus, $0.1 \mathrm{wt} . \%$ Zr provides coherent interfaces of $\beta$-Cr platelets that strongly increases their number density and hardening efficiency.

$Z r$ atoms modify sequence (1). The precipitation of ordered fcc $\mathrm{Cr}$-rich phase has been characterized by following OR, $\{\overline{1} 11\}_{\mathrm{Cu}} / /\{100\}_{\mathrm{tcCCr}}$ and $\{01 \overline{1}\}_{\mathrm{Cu}} /$ $/\{01 \overline{1}\}_{\mathrm{fcc} \mathrm{Cr}},\{211]_{\mathrm{Cu}} / /[011]_{\mathrm{fcC} \mathrm{Cr}}$ and $[100]_{\mathrm{Cu}} / /[111]_{\mathrm{fcC} \mathrm{Cr}}$ in Cu-0.8wt.\%Cr-0.2wt.\%Zr alloy [18]. These precipitates have the same crystal structure as ordered fcc $\mathrm{Cr}$, but exhibit ellipsoid shape due to a low mis- match of $0.07 \%$ at $\{111\}_{\mathrm{Cu}} / /\{100\}_{\mathrm{fcC} C \mathrm{Cr}}$ interfaces. In peak aged conditions, the Heusler phase of $\mathrm{CrCu}_{2}(\mathrm{Zr}$, $\mathrm{Mg}$ ) has been observed in $\mathrm{Cu}-\mathrm{Cr}-\mathrm{Zr}-\mathrm{Mg}$ alloys $[7,56,79,83,99,100]$. The Heusler phase has an fcc crystal structure of $\mathrm{Fe}_{3} \mathrm{Al}$ type $(\mathrm{Fm} 3 \mathrm{~m})$ with a large unit cell containing $8 \mathrm{Cu}, 4 \mathrm{Cr}$, and $4 \mathrm{Zr}$ or Mg atoms. This unit cell can be represented by $8 \mathrm{bcc}$ subcells with each subcell having a $\mathrm{Cu}$ atom at its center and the corner sites alternately occupied by $\mathrm{Cr}$ and either $\mathrm{Zr}$ or Mg. It is worth noting that diffraction patterns from Heusler phase and B2 phase are nearly the same [82]. Moreover, interfaces of Heusler phase are coherent or semi-coherent and shape is nearly elipsoid as that of $B 2$ phase $[7,56]$. As a result, some authors dispute the precipitation of Heusler phase in $\mathrm{Cu}-\mathrm{Cr}-\mathrm{Zr}$ alloys $[82,84,85]$. The Heusler phase precipitates have been shown in $\mathrm{Cu}$ $\mathrm{Cr}-\mathrm{Mg}$ alloy instead of the B2 phase. Prolonged aging may be accompanied by a replacement of Heusler phase by $\beta$-Cr precipitations [7].

Turchanin has studied a possibility of spinodal decomposition in the Cu-Cr alloys (Fig. 4) [101]. The supersaturated $\mathrm{Cu}-3 \mathrm{wt} . \% \mathrm{Cr}$ and $\mathrm{Cu}-5 \mathrm{wt} . \% \mathrm{Cr}$ solid solutions have been produced by mechanical alloying and studied using DSC, XRD and TEM. According to DSC results, all samples exhibit a broad exothermic double peak upon heating that mainly originates from the decomposition of the supersaturated solid solution. A decomposition 

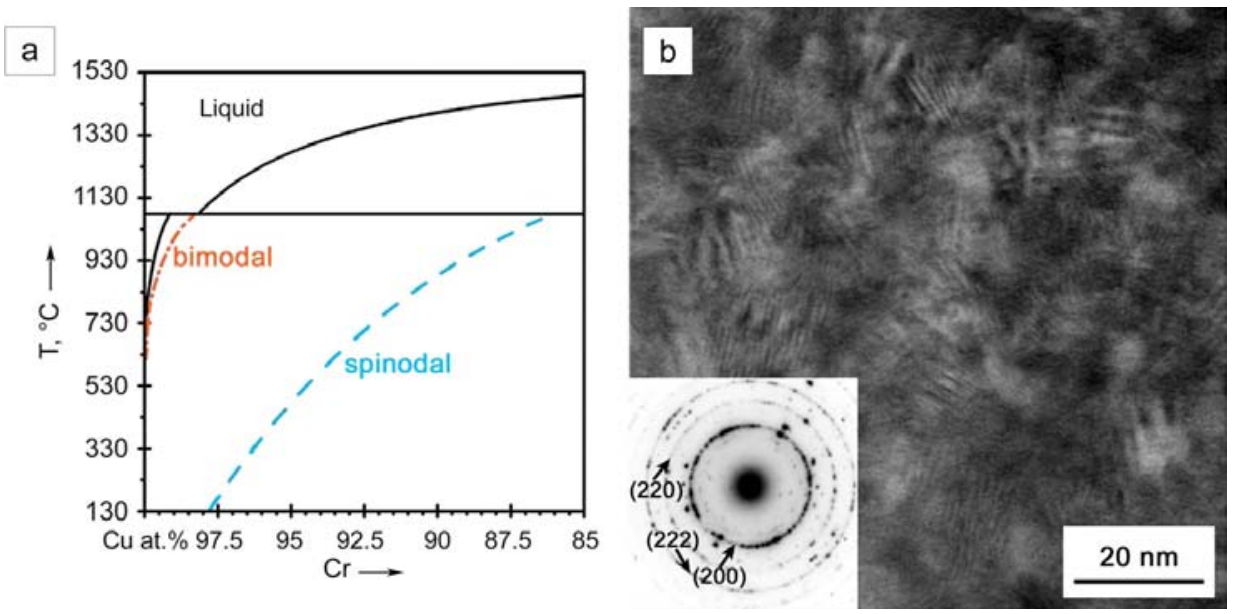

Fig. 4. $\mathrm{Cu}-\mathrm{Cr}$ binary phase diagram with metastable liquid miscibility gap (a) and TEM micrograph of aged sample exhibiting spinodal decomposition in a Cu-5\%Cr alloy (b), adapted from Ref. [102]. The binodal and spinodal lines are imposed on the diagram [101].
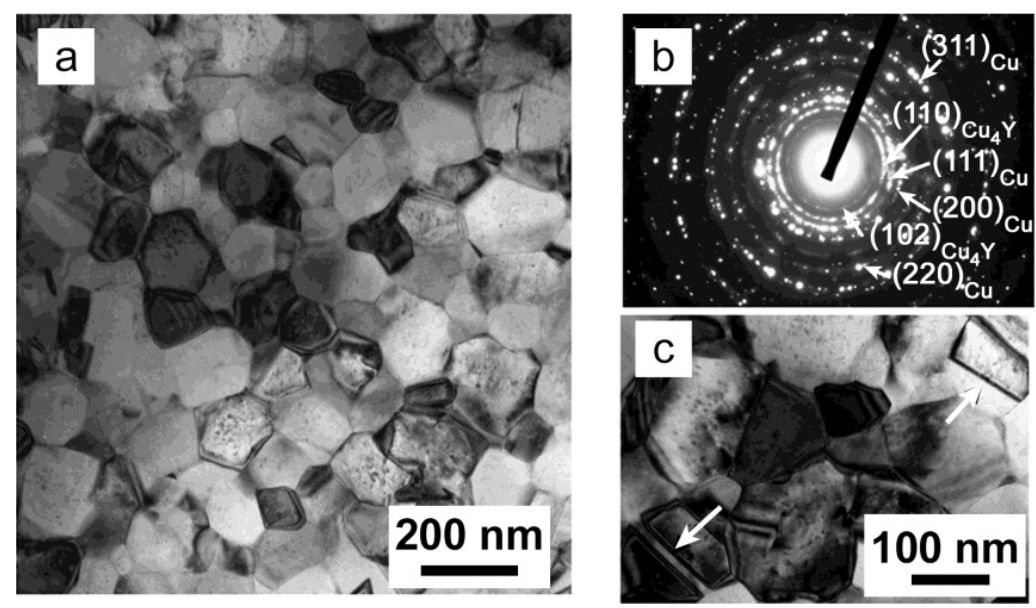

Fig. 5. TEM image (a), SAED pattern (b), and TEM enlarged image of the Cu- $0.8 \% \mathrm{Y}$ alloy. Interplanar distances corresponding to different diffraction rings in (b) are as follows (nm): 0.296 Cu4Y \{102\}, 0.247 $\mathrm{Cu} 4 \mathrm{Y}\{110\}, 0.209 \mathrm{Cu}\{111\}, 4: 0.180 \mathrm{Cu}\{200\}, 0.128 \mathrm{Cu}\{220\}, 0.109 \mathrm{Cu}\{311\}$ adapted from Ref. [105].

scheme, which begins with spinodal decomposition and ends with nucleation and growth as temperature increases is represented in Fig. 5 [102].

Alloying of Cu-Cr-Zr bronze by rare metal (RE), such as $\mathrm{Hf}, \mathrm{Y}, \mathrm{La}, \mathrm{Ce}$, have some advantages. For example, $\mathrm{Hf}$ may increase the thermal stability [103]. The $\mathrm{Cu}_{5} \mathrm{Hf}$ particles can precipitate in $\mathrm{Cu}$-rich ternary $\mathrm{Cu}-\mathrm{Cr}-\mathrm{Hf}$ alloy [22]. Therefore, the higher hardening effect can be expected after aging due to the larger amount of strengthening particles. The $\mathrm{Cu}_{5} \mathrm{Hf}$ particles are more effective for the age hardening than the Cr-based particles [42-46]. RE can remove harmful elements from pure copper and copper alloys, such as oxygen, sulfur, hydrogen and other impurities (e.g. Bi, Sn, $\mathrm{Pb}$ ), and refine cast microstructure [104]. Therefore, the solid solution was purified and the conductivity increased [104]. Small $\mathrm{Cu}_{4} \mathrm{Y}$ particles have been observed in copper alloys with small content of $\mathrm{Y} . \mathrm{Cu}_{4} \mathrm{Y}$ phase exhibits hex- agonal crystal structure with lattice parameters of $a$ $=0.496 \mathrm{~nm}$ and $c=0.824 \mathrm{~nm}$ [105].

\section{PROPERTIES OF Cu-Cr-Zr ALLOYS}

\subsection{Mechanical properties}

The strength is one of the most important mechanical properties of copper alloys [106]. The strengthening of $\mathrm{Cu}-\mathrm{Cr}-\mathrm{Zr}$ alloys can be achieved by alloying and thermo-mechanical treatment. Thus, the total strength of the alloy can be written in the following form.

$\sigma=\sigma_{0}+\sigma(\%)+\sigma(\varepsilon)$,

where $\sigma_{0}$ is the lattice friction or Pierls-Nabarro stress for pure copper, $\sigma(\%)$ is the strengthening by alloying, and $\sigma(\varepsilon)$ is the strengthening by plastic deformation. 
The chromium and zirconium are commonly characterized by small solubility at room temperature and significant solubility in high temperatures. This provides dispersion $\left(\sigma_{\text {part }}\right)$ and/or solid-solution $\left(\sigma_{\mathrm{sS}}\right)$ hardening:

$\sigma(\%)=\sigma_{\mathrm{ss}}+\sigma_{\text {part }}$.

The values of solid-solution and dispersion hardening are interrelated with each other and are determined by the thermal treatment and decomposition of the supersaturated solid solution. In general, notwithstanding the high solubility of chromium $(0.6 \%$ [14]) and zirconium $(<0.1 \%$ [30]) in copper at high temperatures $\left(900^{\circ} \mathrm{C}\right)$, the effect of solid-solution hardening in alloys is not large. The solid solution strengthening can be written as a function of concentration [106],

$\sigma_{\mathrm{sS}}=M G b \varepsilon_{\mathrm{SS}}^{3 / 2} c^{0.5}$,

where $M$ is the Taylor factor ( 3.06 for face-centered materials [106]), $G$ is the shear modulus of copper ( $48.6 \mathrm{GPa}$ [107]), $b$ is the Burgers vector of copper $\left(2.56 \times 10^{-10} \mathrm{~m}\right)$ [108], $\varepsilon_{\mathrm{ss}}$ is a misfit parameter $(0.03$ [106]). In this case, the hardening from the solid solution is $0.04 \mathrm{MPa}$. Therefore, the solid-solution strengthening is inefficient.

The dispersion hardening is of particular interest. The interaction of dislocations with particles can be realized by different mechanisms, depending on the density of the particle distribution, their size, the difference of the shear modulus and the type of interface boundaries. Due to lattice coherency of the precipitates with the copper matrix and volumetric misfit strains, an elastic stress field exists in the matrix surrounding the precipitates. The dislocation interaction with this stress field leads to an increase in the yield strength. According to Brown and Ham [109,110], for small precipitates, the strength increase caused by misfit strengthening can be evaluated as

$\sigma_{\text {coh }}=8 G \varepsilon^{1.5}\left(\frac{r f}{0.5 b}\right)^{0.5}$

where $\varepsilon$ is the linear misfit strain $\varepsilon=(2 / 3)(\Delta a / a), r$ is the particle radius, $f$ is the volume fraction of particles. For a misfit strain of $\varepsilon=0.015$, the strength increase in the $\mathrm{Cu}-\mathrm{Cr}-\mathrm{Zr}$ alloy caused by $\mathrm{Cr}$ particles with a diameter of about $5 \mathrm{~nm}$ and volume fraction of 0.001 amounts to $100 \mathrm{MPa}$. Such strength contribution must not be neglected in this type of alloy.

When a dislocation intersects a spherical precipitate with a shear modulus lower than the shear modulus of the matrix, a strengthening effect occurs due to the differences in dislocation line energies within the precipitate and the matrix. Russell and Brown [111] derived an equation for this modulus strengthening effect, following the argumentation of Brown and Ham [109,110], based on Foreman and Makin's [112] numerical solution for the critical stress, when a dislocation moves large distances through an array of obstacles. According to Russell and Brown, the strength increase is given with:

$\sigma_{\bmod }=M 0.055(\Delta G)^{\frac{3}{2}}\left(\frac{2 f}{G}\right)^{0.5}\left(\frac{r}{b}\right)^{\frac{3 m}{2}-1}$,

where $\Delta G$ is the difference in shear modulus between precipitate and matrix and $m=0.85$ is a constant [113]. For the Cu-Cr-Zr alloy in the peak hardening condition ( $d=5 \mathrm{~nm}, f=0.001)$, the strength increase by modulus mismatch hardening yields a value of $120 \mathrm{MPa}$.

The strength increase due to the coherent precipitates as determined by misfit strengthening and modulus mismatch hardening can be calculated according to Koppenaal and Kuhlmann-Wilsdorf [113-115] for particles with similar strength as follows

$\sigma_{p, \text { shear }}=\sqrt{\sigma_{\text {coh }}^{2}+\sigma_{c \text { mod }}^{2}}$.

According Eq. (8), $\sigma_{p, \text { shear }}$ for the Cu-Cr-Zr alloy specified above is $155 \mathrm{MPa}$.

The precipitate-dislocation interaction may change from shearing of soft precipitates to bypassing of hard particles by looping mechanism. In the presence of impenetrable particles, the dislocation interaction with precipitates can be described by the Orowan mechanism [113]. The strength increase in this case is given as:

$\sigma_{O R}=M \frac{0.4 G b}{\pi \sqrt{1-\vartheta}} \frac{\ln (2 \bar{r} / b)}{\lambda}$.

Here $v=0.32$ is Poisson coefficient [108]; $\bar{r}=\sqrt{2 / 3 r}$, with $r$ as the mean radius of the precipitates, $\lambda$ is the interparticle distance [115]. For the $\mathrm{Cu}-\mathrm{Cr}$-Zr alloy, in the overaging condition, when $r=50 \mathrm{~nm}$, the strength increase comprises $75 \mathrm{MPa}$. It can be concluded that dispersed particles can significantly strengthen the Cu-Cr-Zr alloys.

Plastic deformation can refine the grain size, leading to structural strengthening. Following the pioneer works by Hall and Petch, many experimental and theoretical studies have been conducted to 

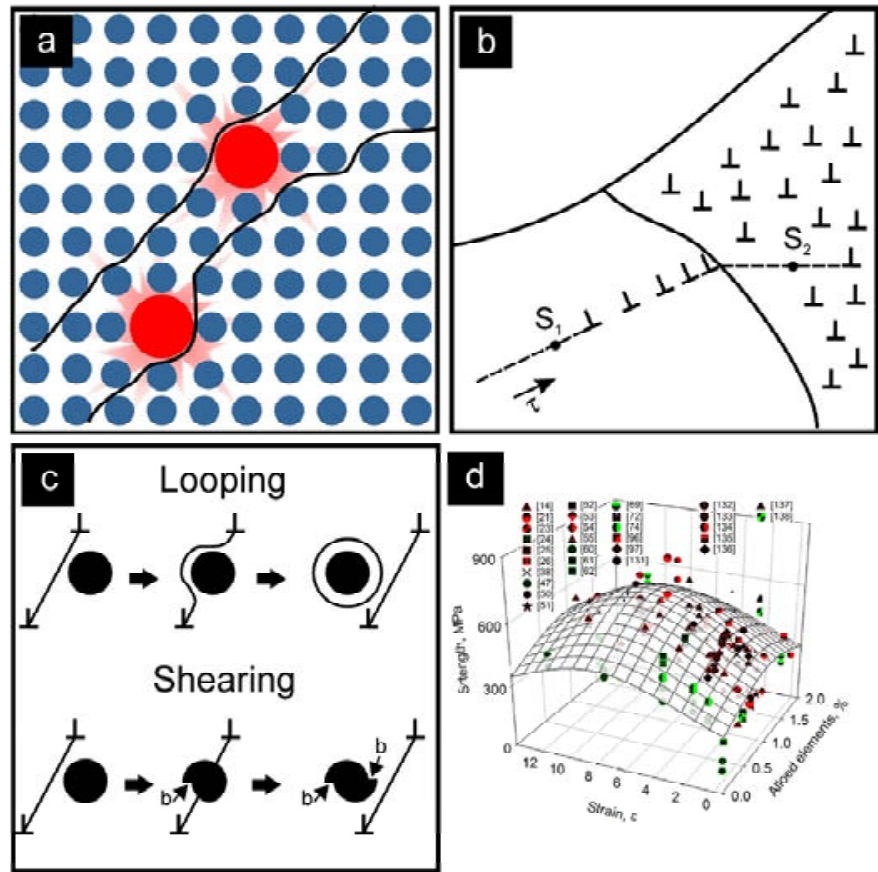

Fig. 6. Schematic illustration of dislocation interaction with structural defects, i.e., impurity atoms (a), dislocations and grain boundary (b), particles by shearing and Orowan model (c), and the relationship between strength, strain and alloyed elements (d), data taken from Refs. [14,21,23-26,38,47,50-55,60$62,69,72,74,96,97,131-138]$.

show the linear relationship between yield or flow stress and inverse square root of grain size [116,117]:

$\sigma_{Y S}=\sigma_{0}+k_{y} D^{-0.5}$,

where $\sigma_{Y S}$ is the yield or flow stress, $\sigma_{k y}$ is the HallPetch coefficient and $D$ is the grain size. This model is based on the idea of dislocation pile up at grain boundary as shown in Fig. 6 . The Hall-Petch relationship describes well the grain size dependence of strength properties in annealed materials, but is poorly suited for the strength prediction in work hardened states. Besides grain refinement, plastic deformation leads to an increase in the density of dislocations arranged in various dislocation substructures [118].

Generally, the strength-structure relationship can be discussed in terms of the grain boundary strengthening and the dislocation strengthening, assuming that these strengthening mechanisms are independent and linearly additive [119-130]. The structural strengthening, which is associated with the grain refinement, can be expressed by Hall-Petch relationship; and the substructural strengthening can be related to the dislocation density through Taylor equation [124]. Therefore, the strengthening by plastic deformation reads as

$$
\sigma(\varepsilon)=k_{y} D^{-1 / 2}+\alpha N G b \sqrt{\rho},
$$

where $\alpha$ is a constant depending on dislocation properties and arrangements.

The grain boundaries are effective obstacles to the movement of dislocations. It should be noted that the grain size strengthening evaluated by Eq. (11) for work hardened alloys depends remarkably on the choice of critical misorientation angle separating grain boundaries and subgrain boundaries. The deformed samples may be characterized by almost equal fractions of high-angle boundaries $(>15)$ and dislocation boundaries with misorientation angles in the range of $2-15^{\circ}$.

The most questionable term in Eq. (11) is the dislocation density, which should be taken into account. The deformation substructure contains free dislocations and dislocation tangles. Moreover, the dislocations can form various substructure ensembles, such as dislocation cells, dislocation subboundaries, dislocation forest, etc. Several methods were employed to evaluate the dislocation density, including direct TEM observations and indirect estimation from kernel average misorientations. Another source of dislocation strengthening originates from dislocation subboundaries. Corresponding dislocation density and strength contribution can be estimated as follows [119,121-122,47]:

$$
\Delta \sigma=\alpha M G\left(1.5 b S_{\text {LAB }} \theta_{\text {LAB }}\right)^{0.5} \text {, }
$$



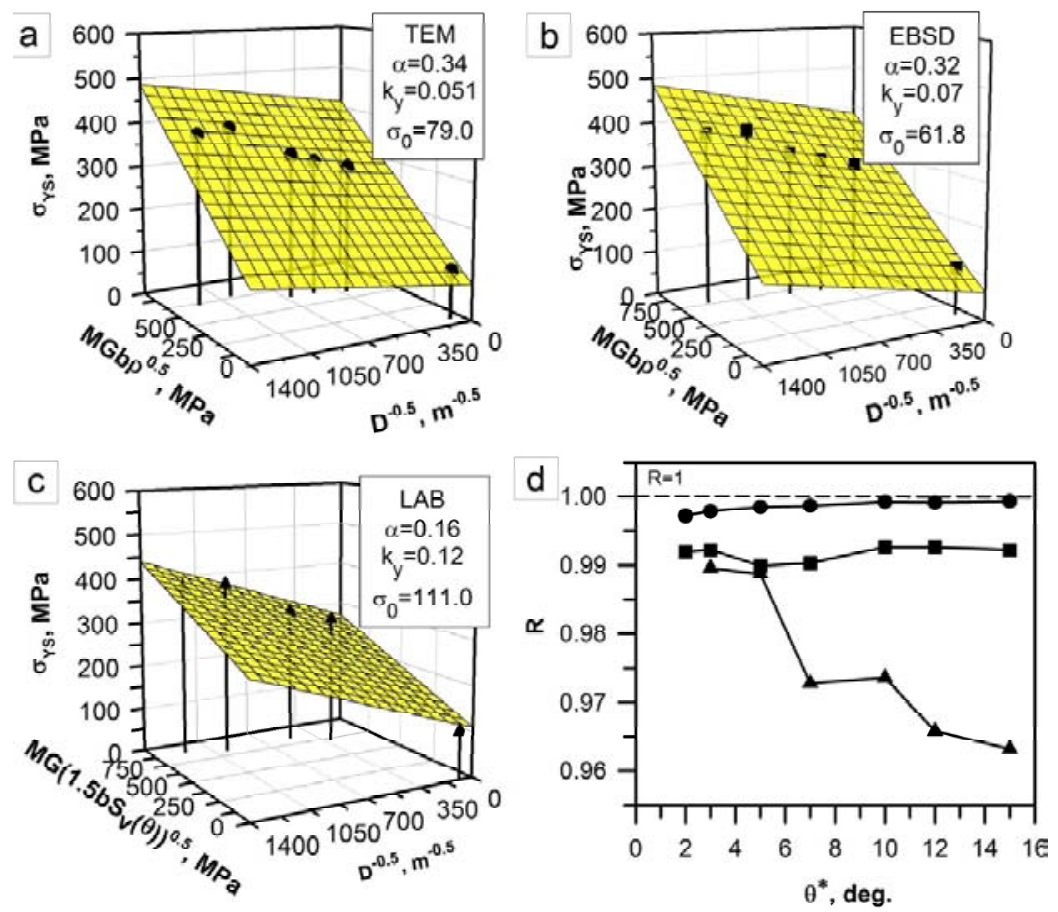

Fig. 7. Relationships between the yield strength, $\sigma_{\mathrm{YS}}$, the effective grain size, $\mathrm{D}$, as an average boundary spacing for critical boundary/subboundary separating misorientation of $\theta^{*}=15^{\circ}(\mathrm{a}),(\mathrm{b})$, (c), and the dislocation strengthening as calculated by means of TEM observation (a), kernel average misorientation (b), LAB misorientation (c); and the determination coefficient for the different critical misorientations (d), adapted from Ref. [47].

where $S_{L A B}$ and $\theta_{L A B}$ are the LAB area per unit volume and the average misorientation angle of $L A B$, respectively. The strength contribution from LABs, Eq. (10), also depends significantly on the critical misorientation angle $\left(\theta^{*}\right)$, which separates $\mathrm{HAB}$ and $L A B$ from point of view of operating strengthening mechanisms [119-122]. Note here that LABs with misorientations above $2-3^{\circ}$ were discussed as conventional grain boundaries in terms of their strength contribution [120].

The experimental data [47] can be fairly well described by the modified Hall-Petch relationship irrespective of $\theta^{*}$ ranging from $3^{\circ}$ to $15^{\circ}$ (Fig. 7). An almost perfect fit is obtained for the dislocation density measured by TEM and the correspondence between experimental and calculated strength increases with increasing the separating $L A B / H A B$ angle to $\theta^{*}=15^{\circ}$. The kernel average misorientation also gives a good agreement with experimental results irrespective of $\theta^{*}$. The worst fit is obtained for the dislocation strengthening calculated by Eqs. (10), assuming that all dislocations are associated with LABs. The variations of the reported factors of dislocation strengthening could be associated with different methods of the dislocation density measurement as well as inhomogeneity of dislocation distribution.
In general, strength-structure relationship for metals and alloys according to Eqs. (1)-(10) can be represented as $[47,124,130]$ :

$\sigma_{y S}=\sigma_{0}+\sigma_{\text {part }}+k_{y} D^{-1 / 2}+\alpha M G b \sqrt{\rho}$.

The experimental results including the data of different researches on the strain and alloying dependence of the strength for $\mathrm{Cu}-\mathrm{Cr}$-Zr alloys is shown in Fig. 6 [14,21,23-26,38,47,50-55,60$62,69,72,74,96-97,131-138]$. An increase of alloying is accompanied by the strengthening in all concentration range. The plastic deformation leads to significant strengthening, which attains a maximum at total strain of 4-8. Further deformation results in strength saturation and/or degradation. Combination of plastic deformation and alloying provide twofold strengthening as compared to annealed pure copper.

\subsection{Plasticity}

The plastic deformation is accompanied by an increase in the dislocation density. The dislocations interact with each other and with other microstructural defects like grain boundaries during plastic deformation, and dislocation cell or subboundaries develop. Thus, the plastic deformation reduces the 

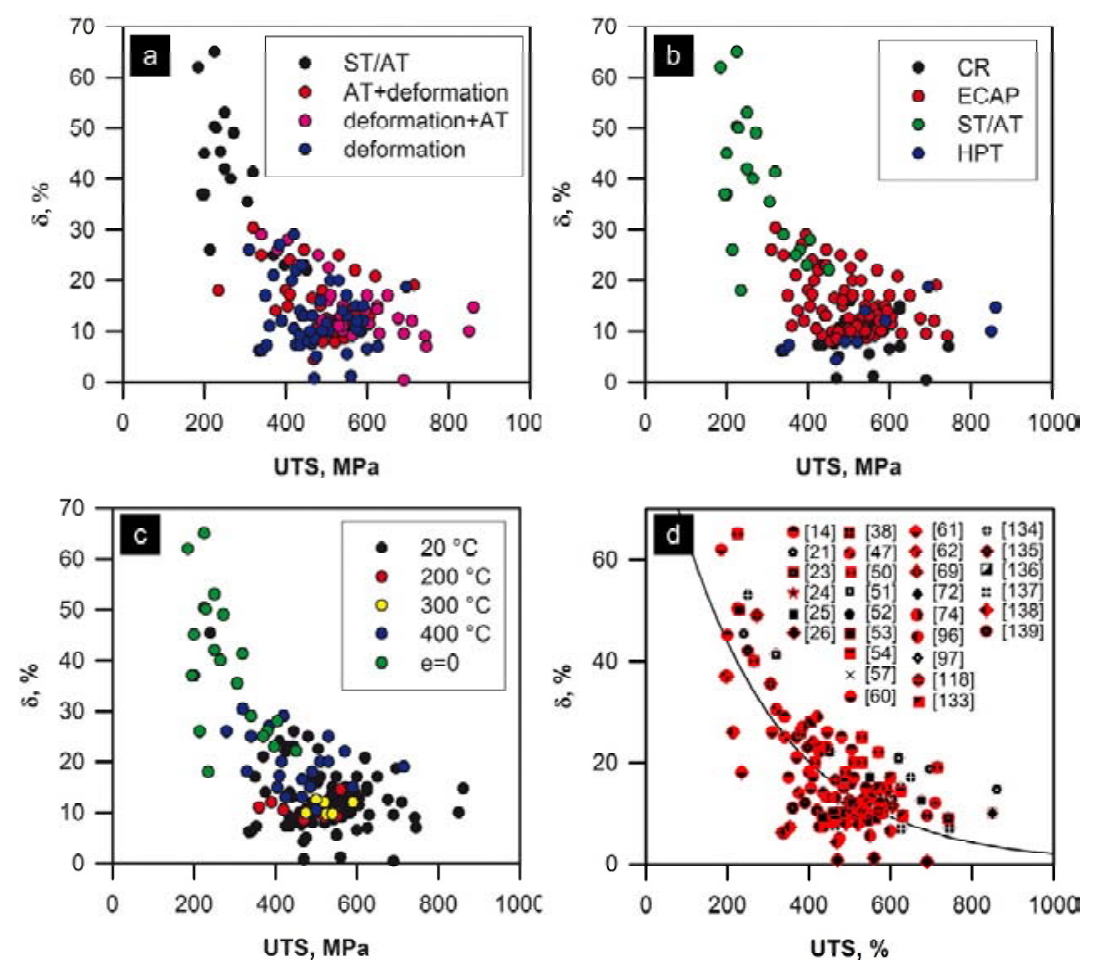

Fig. 8. The relationship between UTS and elongation to failure, $\delta$, of $\mathrm{Cu}-\mathrm{Cr}$-Zr alloys subjected to different aging (a), deformation methods (b), and deformation temperatures (c). The references are collected in (d), data taken from Refs. [14,21,23-26,38,47,50-54,57,60-62,69,72,74,96,97,118,133-139].

free path of dislocation and, accordingly, plasticity degrades.

The effect of different termo-mechanical treatments, deformation methods, deformation temperatures on UTS and elongation to failure, $\delta$, of $\mathrm{Cu}-\mathrm{Cr}-$ Zr alloys is shown in Fig. $8[14,21,23-26,38,47,50-$ $54,57,60-62,69,72,74,96,97,118,133-139]$. It clearly seen that the plastic deformation leads to a decrease in plasticity from $30-70 \%$ in the solution treated/ aged condition to $0.5-20 \%$. The aging of deformed material increases the elongation to $10-25 \%$ that can be associated with recovery or recrystallization $[69,140]$. The worst plasticity is observed after cold rolling and similar treatments that can be associated with the lamellar microstructure development [21,26,96,136-137]. In contrast, ECAP and high pressure torsion (HPT) result in almost equiaxed UFG microstructure, providing reasonable elongation [21]. The deformation temperature also influences the $\mathrm{Cu}-\mathrm{Cr}-\mathrm{Zr}$ alloy plasticity. Plastic deformation at $400^{\circ} \mathrm{C}$ allows higher elongation as compared with that at $20-300^{\circ} \mathrm{C}$. Dynamic recovery and the reorganization of dislocations in subboundaries can be realized in at elevated temperatures, leading to elongation increase $[47,50,51,141,142]$. The relationship between elongation and UTS can be estimated by an empirical exponential function, $\delta=95 \exp \left(-0.004 \sigma_{\mathrm{UTS}}\right)$.

\subsection{Electrical conductivity}

Electrical conductivity is the main functional property of the $\mathrm{Cu}-\mathrm{Cr}-\mathrm{Zr}$ alloys. These alloys are used in electrical engineering, so the Cu-Cr-Zr alloys should exhibit the maximum possible conductive characteristics. The required electrical conductivity depends on the purpose of electrical device. The electrical conductivity in high-strength copper wires should be above $80 \%$ ICAS to reduce an energy loss; and that of materials for contact welding electrodes should be more than $70 \%$ ICAS

The electrical conductivity reduction in copper and its alloys results from the scattering of moving free electrons by obstacles, i.e., structural defects. Schematic illustration of mechanisms of electron interaction with structural defects (with impurity atoms, dislocations, particles, grain boundaries) is shown in Fig. 9. Such structural defects can be classified as the point defects, i.e., interstitial, substitutional atoms and vacancies, the linear defects, i.e., dislocations, the surface defects, i.e., (sub)boundaries, interphase boundaries, and the volume defects like pores. These defects reduce the electron free path ( $40 \mathrm{~nm}$ in pure annealed copper). Consequently, additional scattering of electrons leading to an increase in the electrical resistance occurs in alloys when the interdefect distance is less than $40 \mathrm{~nm}$. 

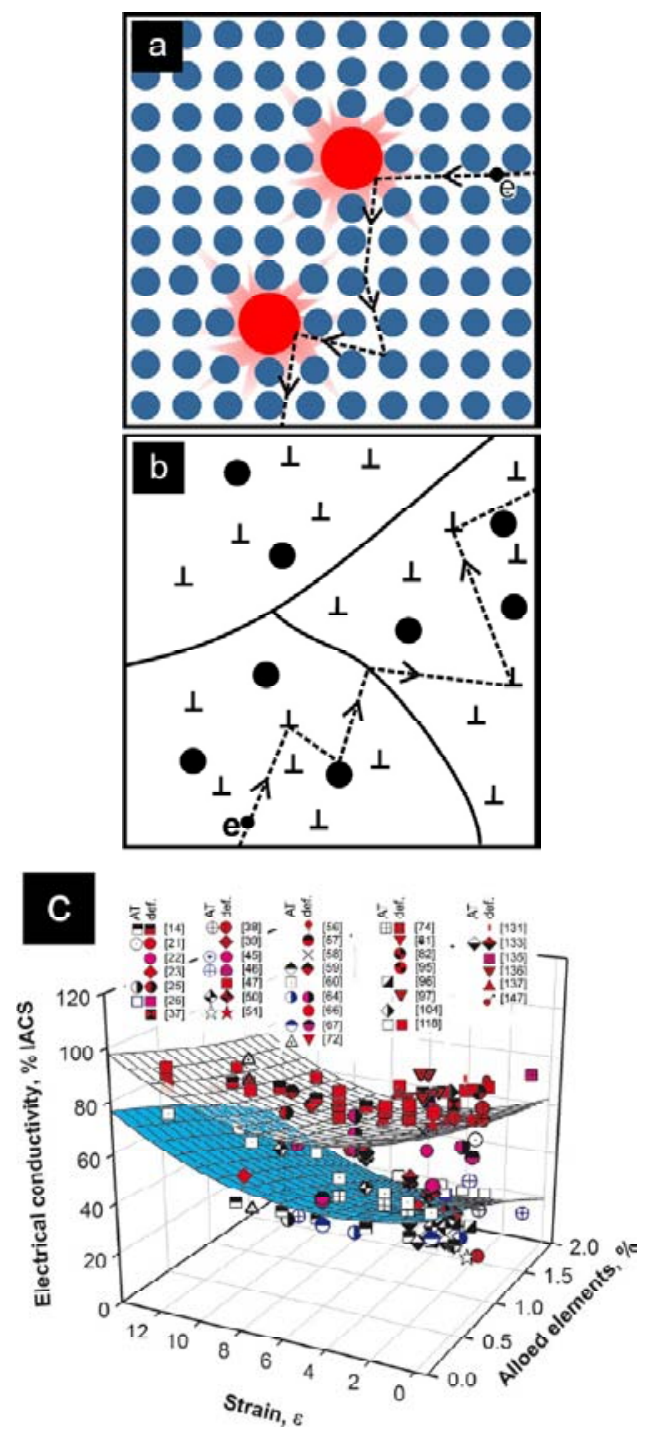

Fig. 9. Schematic illustration of mechanisms of electron interaction with structural defects (impurities atoms (a), dislocations, particles, grain boundary (b)). Relationship between electroconductivity, strain and alloying elements after different treatment (c), data taken from Refs. [14,21-23,25-26,37-39,45-47, 50-51,56-60,64,66-67,72,74,81-82,95-97, $104,118,131,133,135-137,147]$.
The critical concentration of point defects in the solid solution, the critical dislocation density, the critical size and volume fraction of the second phases particles, and the critical size of the sub (grains) corresponding to the 40-nm interdefect distance are shown in Table 1. It is seen in table 1 that the concentration of point defects in the solid solution, which does not affect the electrical conductivity, is very small and amounts about 0.008 at.\%. Therefore, the dissolution of foreign atoms in the copper matrix greatly affects the electrical conductivity. Experimental studies of the positron annihilation method have shown that the maximum vacancy density in copper subjected to intense plastic deformation reaches $10^{-5}$ (or $10^{-3}$ at,\%) [82]. Therefore, the effect of vacancies on the electrical conductivity is very small. The critical dislocation density is $2 \times 10^{14} \mathrm{~m}^{-2}$ that corresponds to a typical dislocation density for $\mathrm{Cu}-\mathrm{Cr}$-Zr alloy after plastic working $[47,50-51]$. The critical particle size at the $0.015 \%$ volume fraction (volume fraction for the peak aging conditions of $\mathrm{Cu}-0.3 \mathrm{Cr}-0.5 \mathrm{Zr}$ alloy [47]) is $1.3 \mathrm{~nm}$ that does not correspond to real particle size in the peak strength condition. Thus, the effect of scattering of electrons on particles in the maximal strength condition is small. The critical dimensions of (sub)grains of $40 \mathrm{~nm}$ are very small and are observed only in alloys after special treatments such as cryogenic deformation [26]. Therefore, the effect of electron scattering at the boundaries with a typical (sub)grains size about $100-500 \mathrm{~nm}$ is small.

Quantitative data for the effect of various defects on electrical conductivity can be obtained from the experimental relationships given below. According to $[143,144]$, the coefficient of resistivity increment for monovacancies in copper is $1.3 \mu \Omega^{*} \mathrm{~cm} /$ at.\%. Consequently, the contribution of vacancies to the electrical resistivity of copper is $0.0013 \mu \Omega \times \mathrm{cm}$ at vacancy concentration about $10^{-3}$ at, \%. Taking into account that the electrical resistivity of pure copper at $20^{\circ} \mathrm{C}$ is $1.72 \mu \Omega \times \mathrm{cm}$ [1], the contribution of va-

Table 1. The critical concentration of point defects in the solid solution, the critical dislocation density, the critical size and volume fraction of the second phase particles, and the critical size of sub (grains).

\begin{tabular}{lll}
\hline & Critical & Observed in real materials \\
\hline The concentration of point defects, at.\% & 0.008 & $>0.1$ \\
The dislocation density, $\mathrm{m}^{-2}$ & $2 \times 10^{14}$ & $(2-10) \times 10^{14}$ \\
The particles size, $\mathrm{nm}$ & 1.3 & $2.5-5$ \\
The sub(grains) size, $\mathrm{nm}$ & 40 & $100-500$ \\
\hline
\end{tabular}



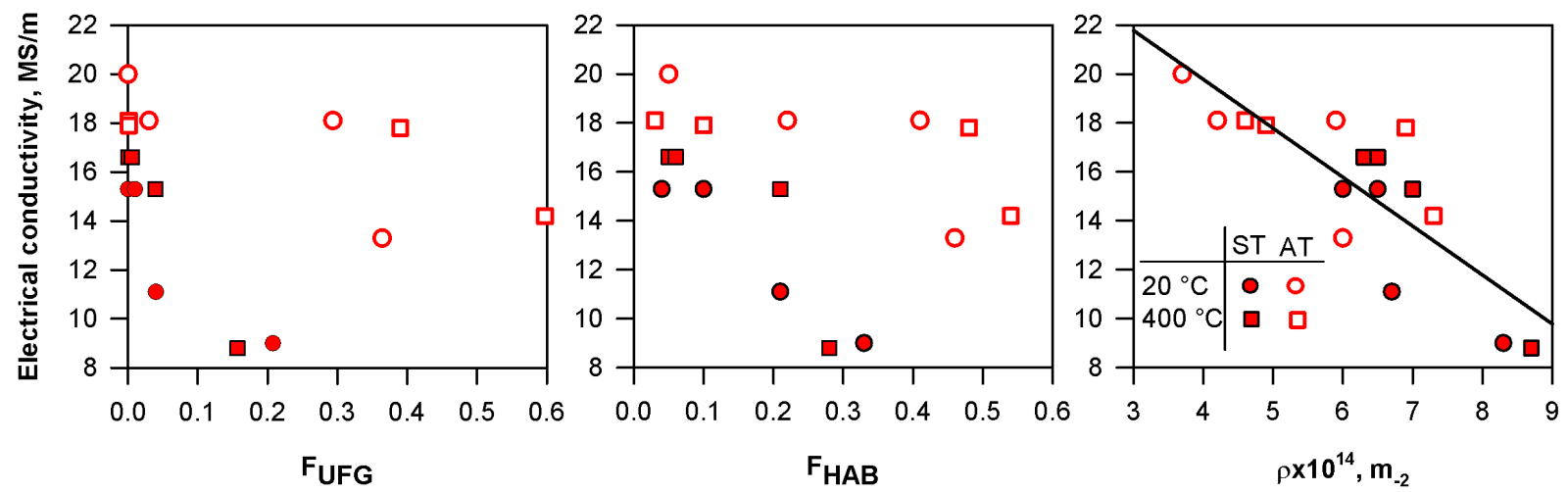

Fig. 10. Effects of the UFG fraction (FUFG), the HAB fraction (FHAB) and the dislocation density ( $\rho$ ) on the electric conductivity of $\mathrm{Cu}-\mathrm{Cr}-\mathrm{Zr}$ alloy, adapted from Ref. [59].

cancies to the resistivity at room temperature does not exceed $0.08 \%$.

The contribution of alloying elements to the electrical resistivity $\rho_{\mathrm{SS}}$ can be expressed by the following formula [144]:

$$
\rho_{\mathrm{ss}}=K_{\mathrm{ss}} C_{\mathrm{ss}} \text {, }
$$

where $K_{\mathrm{ss}}$ is the increment of the electrical resistivity by $1 \%$ (at.) of the alloying element, CSS is the concentration of the alloying element in at.\%. The influence of different alloying elements is additive. According to Eq. (14), the $\mathrm{Cu}-0.6 \% \mathrm{Cr}-0.1 \% \mathrm{Zr}$ alloy is characterized by $40 \%$ IACS when all $\mathrm{Cr}$ and $\mathrm{Zr}$ atoms locate in the solid solution. Dispersed particles do not affect the mean free path, because typical interparticle distance $(100-200 \mathrm{~nm})$ is greater than the free electron path.

The increment of the resistivity per unit density of randomly distributed dislocations $\rho_{\text {dis }}$ in pure copper is $K_{\text {disl }}=1.14 \times 10^{-13} \mu \Omega^{*} \mathrm{~cm}^{3}$ [144]. Consequently, the resistivity due to the electrons scattering by dislocations is:

$$
\rho_{\text {disl }}=K_{\text {disl }} \rho \text {. }
$$

An increase in the resistivity due to the presence of grain boundaries can be expressed by the formula [82]:

$$
\rho_{\mathrm{GB}}=K_{\mathrm{GB}}\left(S_{\mathrm{GB}} / V\right) \text {, }
$$

where $S_{\mathrm{GB}} / V$ is the area of (sub)grain boundaries per unit volume of the metal, and $\mathrm{K}_{\mathrm{GB}}$ is the increment of the resistivity per unit grain boundary density, which is $1.02 \times 10^{-12} \Omega \times \mathrm{cm}^{-2}$ in pure copper [1]. Assuming that the grain has the shape of a cube, the contribution of grain boundaries is $3.06 \times 10^{-3}$ $\mu \Omega \times \mathrm{cm}$, or $0.18 \%$ of the electrical resistivity of pure copper with an average grain size of $200 \mathrm{~nm}$.
Thus, it is expected that the main contribution to electrical resistivity in $\mathrm{Cu}-\mathrm{Cr}$ - Zr alloys is associated with solid solution $[144,145]$. The high electrical conductivity in the $\mathrm{Cu}-\mathrm{Cr}$ - $\mathrm{Zr}$ alloys can be obtained by a decomposition of supersaturated solid solution and precipitation of particles with $\mathrm{Cr}$ and Zr. Fig. 9 shows the effect of deformation processing, alloying, and heat treatment on the electrical conductivity of the alloys. It is clearly seen that the $\mathrm{Cu}$-Cr-Zr alloys after annealing treatment (AT) demonstrate high electrical conductivity as compared with cast or solution treated (ST) samples irrespective of strain and chemical composition [14,21-23,2526,37-39,45-47,50-51,56-60,64,66-67,72,74,81$82,95-97,104,118,131,133,135-137,147]$.

The effect of the dislocation density that evolves during multi-directional forging (MDF), on the electrical conductivity of a Cu-Cr-Zr alloy was studied in [59]. The effect of the UFG formation and the dislocation density on the electrical conductivity is represented in Fig. 10. It is clearly seen in Fig. 10 that UFG and high-angle boundaries (HAB) have only a marginal effect on the electrical conductivity. In contrast, the electric conductivity almost linearly decreases with increasing the dislocation density. These results suggest that the contribution of the dislocations to a decrease in the conductivity is significantly higher than that of the grain boundaries. Therefore, extensive grain refinement is an attractive method to achieve high strength and sufficient electrical conductivity in copper alloys. However, UFGs should contain a low dislocation density, which may be attained by an appropriate recovery annealing.

\subsection{Wear}

The combination of grain refinement and precipitation hardening is a well-established technique for 

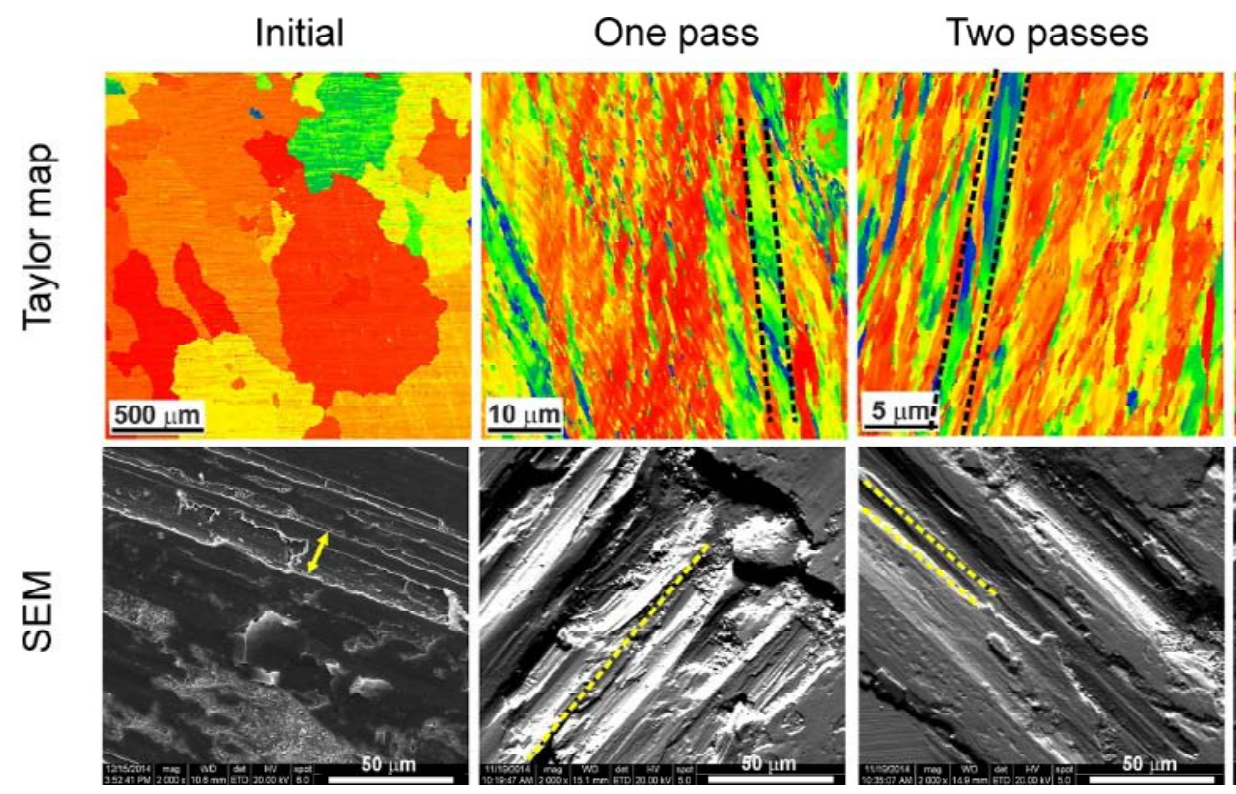

Fig. 11. EBSD-Taylor map and SEM micrographs of worn surfaces of an ECAP $0.3 \mathrm{Cr}-0.5 \mathrm{Zr}$ alloy in solution treated condition as a function of a number of ECAP passes, adapted from Ref. [151].

improving mechanical and functional properties, such as yield strength, electrical conductivity and wear resistance. Currently, the design of highly conductive materials for fusion, high-speed railroad or generation IV reactors is of extreme importance to accomplish industrial requirements [147,148]. For example, there is a demand to improve the strength and conductivity performance of the contact wire in the electric railways of high-speed trains $[59,84,148]$. In addition, a high wear resistance is a critical issue. In order to accomplish the above specifications, CuCrZr alloys are being considered as the best candidates for industrial application. According to the commonly used relationship $[149,150]$ the wear rate is reciprocal to the hardness of the contact materials:

$$
Q=K F L / H V \text {, }
$$

where $Q$ is the total volume of the wear debris produced, $K$ is a dimensionless constant, $F$ is the total normal load, $L$ is the sliding distance, $H V$ is the hardness of the softest contacting surface. Wear rate, $W$, follows from (17) as

$$
W=Q /(F L)=K / H V \text {. }
$$

The wear resistance of the Cu- $0.3 \mathrm{Cr}-0.5 \mathrm{Zr}$ (wt.\%) (0.3Cr-0.5Zr) alloy subjected to ECAP was investigated in detail [151]. A $0.3 \mathrm{Cr}-0.5 \mathrm{Zr}$ alloy in two initial conditions (after solution treatment (ST) and after age hardening (AT)) was subsequently processed by ECAP under an isothermal condition at $400^{\circ} \mathrm{C}$ to total strains of $\sim 1,2$, and 4 .
The EBSD maps for samples subjected to both treatments appear to be rather similar with some microbands revealed in the microstructure. The wear tracks in the right columns of Figs. 11 and 12 possess some specific strands that apparently correlate with the microbands highlighted in the EBSD maps. Moreover, the worn surfaces of the ST and AT specimens evolve in a similar way for the initial specimen and the ECAP samples processed by 1 , 2 , and 4 passes. On the contrary, the SEM micrographs for the specimens processed by one ECAP pass demonstrate heavily damaged surfaces, which occupied nearly the whole area of the micrographs for both ST and AT samples. The fracture surfaces are of a considerably brittle appearance. The specimens subjected to 2 and 4 passes of ECAP possess moderately damaged areas with noticeably decreased areas of worn strands (Figs. 11 and 12). Moreover, it is apparent that after four ECAP passes, the AT specimen undergoes a transition from brittle to ductile behavior, whereas the ST specimen retains the brittle fracture surface. The appearance of worn surfaces is in good correlation with the measured wear rates.

There is a clear trend showing a decrease in the mean friction coefficient with an increase in the accumulated strain for both ST and AT samples. The wear rate possesses a maximum for samples processed for one ECAP pass. This correlates well with the heavily worn surfaces shown in Figs. 11 and 12. As expected, the rate of dislocation accumulation (Fig. 13d) follows the same trend as the wear rate 

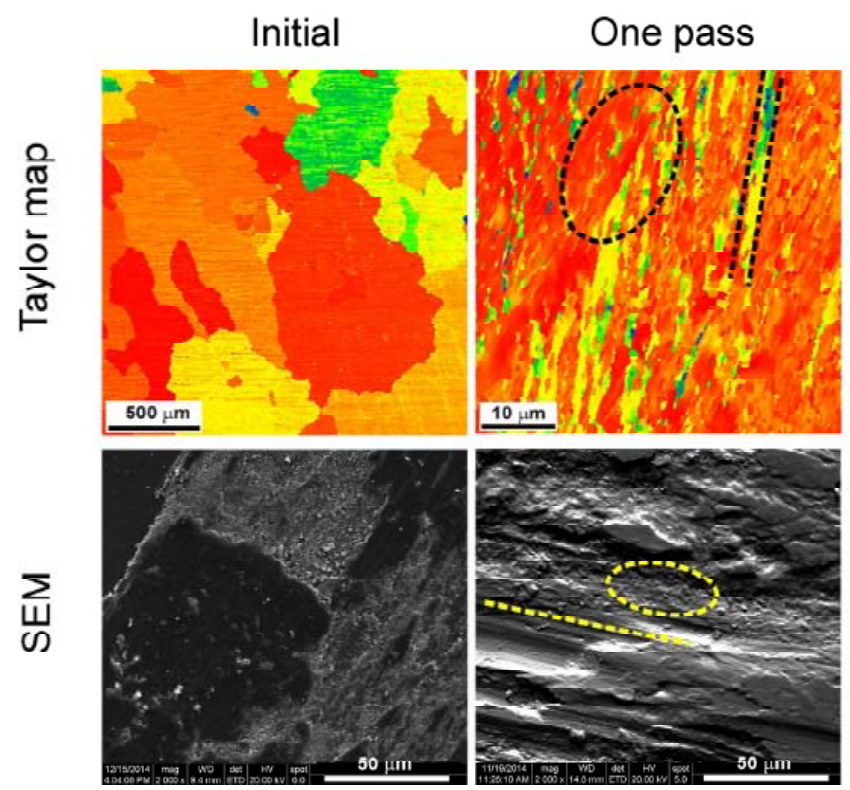

Two passes
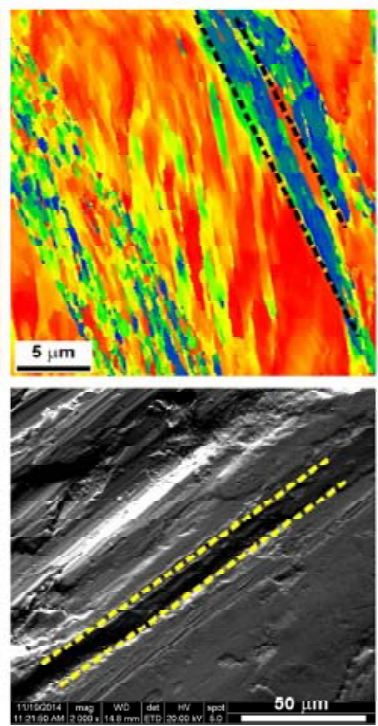

Four passes
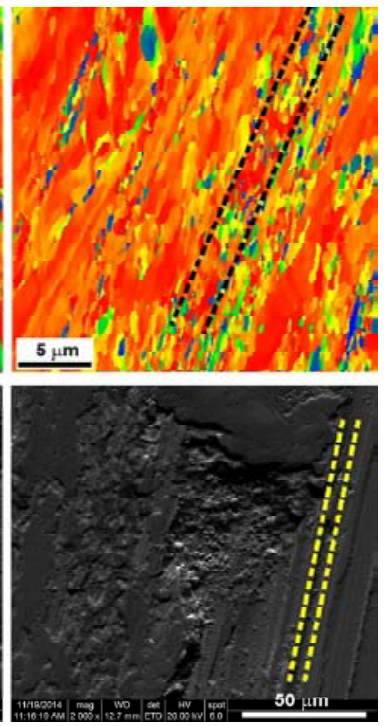

Fig. 12. EBSD-Taylor map and SEM micrographs of worn surfaces of an ECAP Cu-Cr-Zr alloy in aged condition as a function of a number of ECAP passes, adapted from Ref. [151].
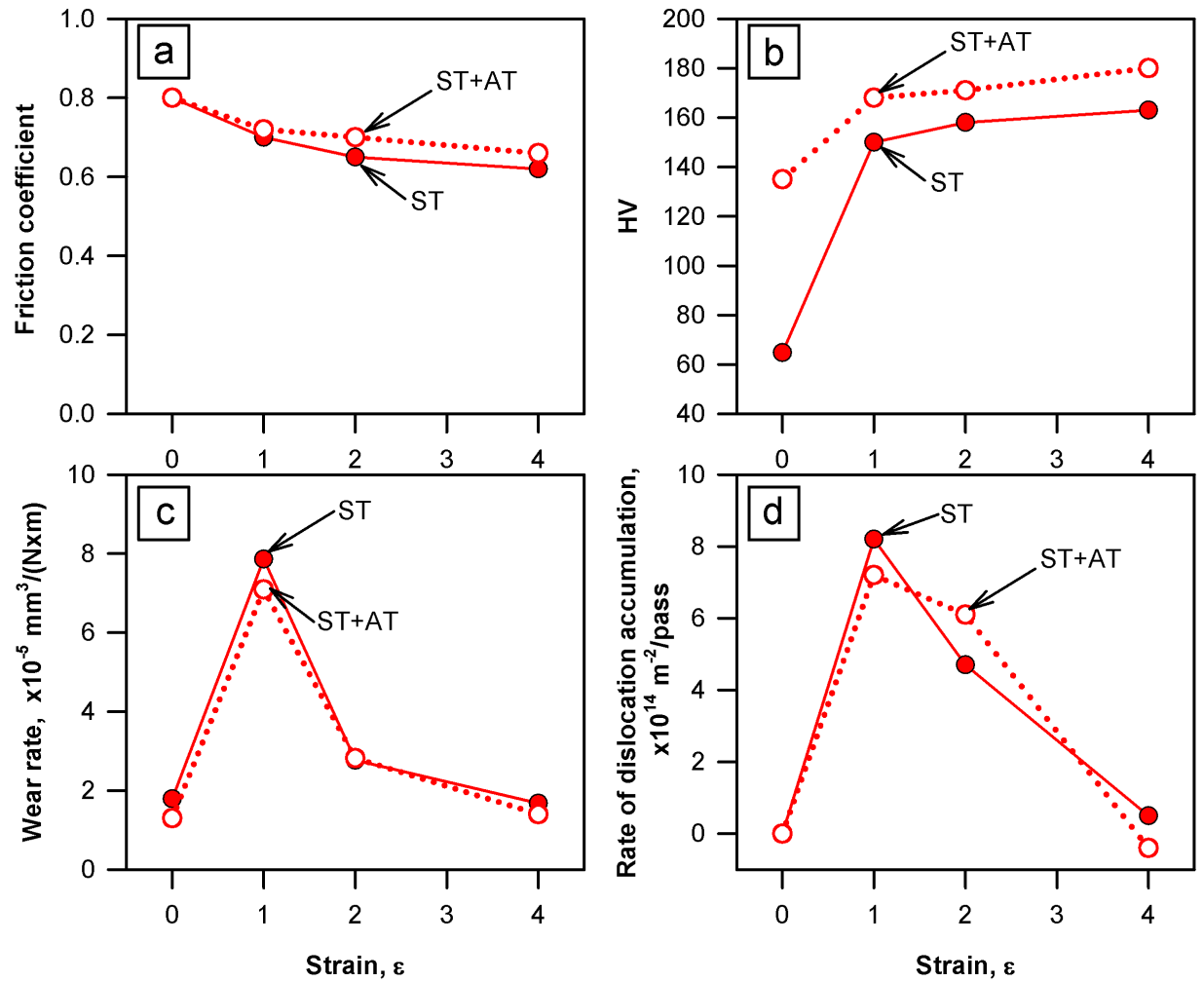

Fig. 13. Averaged friction coefficient (a), Vickers microhardness (b), wear rate (c) and rate of dislocation accumulation (d) for solution-treated and aged ECAP Cu-Cr-Zr alloys as a function of the accumulated strain or the number of ECAP passes, adapted from Ref. [151].

does (Fig. 13b). From all of the dependencies shown in Fig. 13, the wear rate does not obey Eq. (17). Apparently, the wear rate is dictated not by the hardness but rather by the type of damage. The initial material exhibits damage dominated by shear fracture that is attributed to a low material hardness
(Fig. 13e). The first pass provides more than a fourfold increase in the wear rate of the samples from both treatments, despite an increase in hardness. This phenomenon is attributed to the replacement of shear fracture as the dominant damage mechanism by brittle fracture and the crumbling of rela- 
tively large material areas along microbands. As straining by ECAP progresses to 2 passes, the microstructure of the $0.3 \mathrm{Cr}-0.5 \mathrm{Zr}$ alloys alters to thin lamellas separated by high-angle $\left(>15^{\circ}\right)$ or mediumangle $\left(>5^{\circ}\right)$ boundaries. As a result, the brittle fracture damage occurs through the crumbling of relatively thin areas (Fig. 11). In addition, the dislocation density increases with the accumulating strain that leads to an increase in the hardness (Fig. 13e). An approximately three-fold decrease in the wear rate takes place. It is evident that the change from the crumbling of large areas to one of thin bands strongly contributes to the decreased wear rate. After 4 ECAP passes, the lamellas were subdivided by transverse boundaries into crystallites of a nearly rectangular shape, and the mixing of thin layers that is responsible for decrease in the wear rate is rarely observed.

The large strain deformation leads to the microstructure refinement in the $0.3 \mathrm{Cr}-0.5 \mathrm{Zr}$ alloy with moderate and high-angle boundaries, which decrease the wear rate to the level of the initial state of the alloy. There is no clear difference in the wear properties of the ST and AT samples processed to the same strain by ECAP. The wear rate seems to sensitively depend on the character of the dislocation substructure. The microbands involve a high density of stochastic dislocation subboundaries, which were brought out by a moderate ECAP strain (i.e., one ECAP pass), resulting in a drastic degradation of the wear resistance. In contrast, the dislocation rearrangement leading to the subdivision of the microbands into new fine grains during subsequent ECAP passes remarkably improves the wear resistance. Therefore, extensive grain refinement is a necessity for the enhancement of the wear resistance of the $\mathrm{Cu}-\mathrm{Cr}-\mathrm{Zr}$ bronze with increased hardness that is attributed to deformation hardening. Merely hardening this material by severe plastic deformation may deteriorate the wear resistance, if coarse shear bands evolve.

\section{EFFECT OF LARGE PLASTIC DEFORMATION ON MICROSTRUCTURE AND PROPERTIES OF Cu-Cr-Zr ALLOYS}

The effect of severe plastic deformation on the microstructure and properties was examined in $0.1 \mathrm{Cr}, 0.9$ $\mathrm{Cr}$ and $\mathrm{Cu}-0.3 \% \mathrm{Cr}-0.5 \% \mathrm{Zr}(0.3 \mathrm{Cr}-0.5 \mathrm{Zr})$ alloys $[63,64,89]$. The samples were subjected to a solution treatment (ST) at $920^{\circ} \mathrm{C}$ with subsequent water quenching. Several samples after solution treatment were aged $(\mathrm{ST}+\mathrm{AT})$ at $450-550^{\circ} \mathrm{C}$. Then, the
$\mathrm{Cu}-\mathrm{Cr}-\mathrm{Zr}$ alloys were subjected to severe plastic deformation by equal channel angular pressing at $400^{\circ} \mathrm{C}$. The deformation microstructures that evolved during ECAP are presented in Fig. 14. The first ECAP pass results in the elongation of initial grains in the metal flow direction and the evolution of a large number of strain-induced subboundaries with low-angle misorientations $\left(\theta<15^{\circ}\right)$ followed by the development of deformation microbands. LAB form the well-developed substructure within the initial grains. Further processing is accompanied by the formation of separated UFGs along the deformation microbands and initial grain boundaries. The number of deformation microbands and new UFG increase with straining, the partially recrystallized microstructure forms after a strain of 4 . New UFG evolve as chains separating the remainders of the initial grains with a size less than $5 \mu \mathrm{m}$. Further deformation is accompanied by grain boundary misorientation increase, transformation of $L A B$ into $H A B$ and continuous dynamic recrystallization (DRX) development. The ultra-fine grain formation takes place throughout the sample. After a total strain of 12 , the uniform equiaxed grain structure with an average grain size below $1 \mu \mathrm{m}$ develops. It should be noted that the ultra-fine grain evolution is accompanied by a gradual increase in the kernel average misorientation $\left(\theta_{\text {KAM }}\right.$ in Fig. 14) that suggests the development of large internal distortions, which can be attributed to increasing dislocation density.

The developed grain boundary misorientation distributions are typical of continuous DRX (Fig. 14). The large fraction of $L A B s$ is observed after the first ECAP pass. Then, the peak of LABs decreases and expands towards high-angle misorientations. Thus, the fraction of HABs progressively increases with straining. The boundary misorientation distributions evolved at sufficiently large strains are characterised by almost the same fractions of boundaries of different misorientations above $15^{\circ}$. Such flattype misorientation distribution has been frequently observed in various metallic materials during large strain deformation accompanied by continuous DRX irrespective of processing method [47,50,51]. Correspondingly, the average angle of boundary misorienations increases from $7^{\circ}$ to $27^{\circ}$ as strain increases from 1 to 12, although a small peak against $L A B s$ remains even in the almost completely recrystallized microstructure.

A role of the deformation microbands in the evolution of new ultra-fine grains is illustrated by TEM micrographs. Examples of the misorientation evolution within the deformation microbands are represented in Fig. 15. It is clearly seen that these defor- 


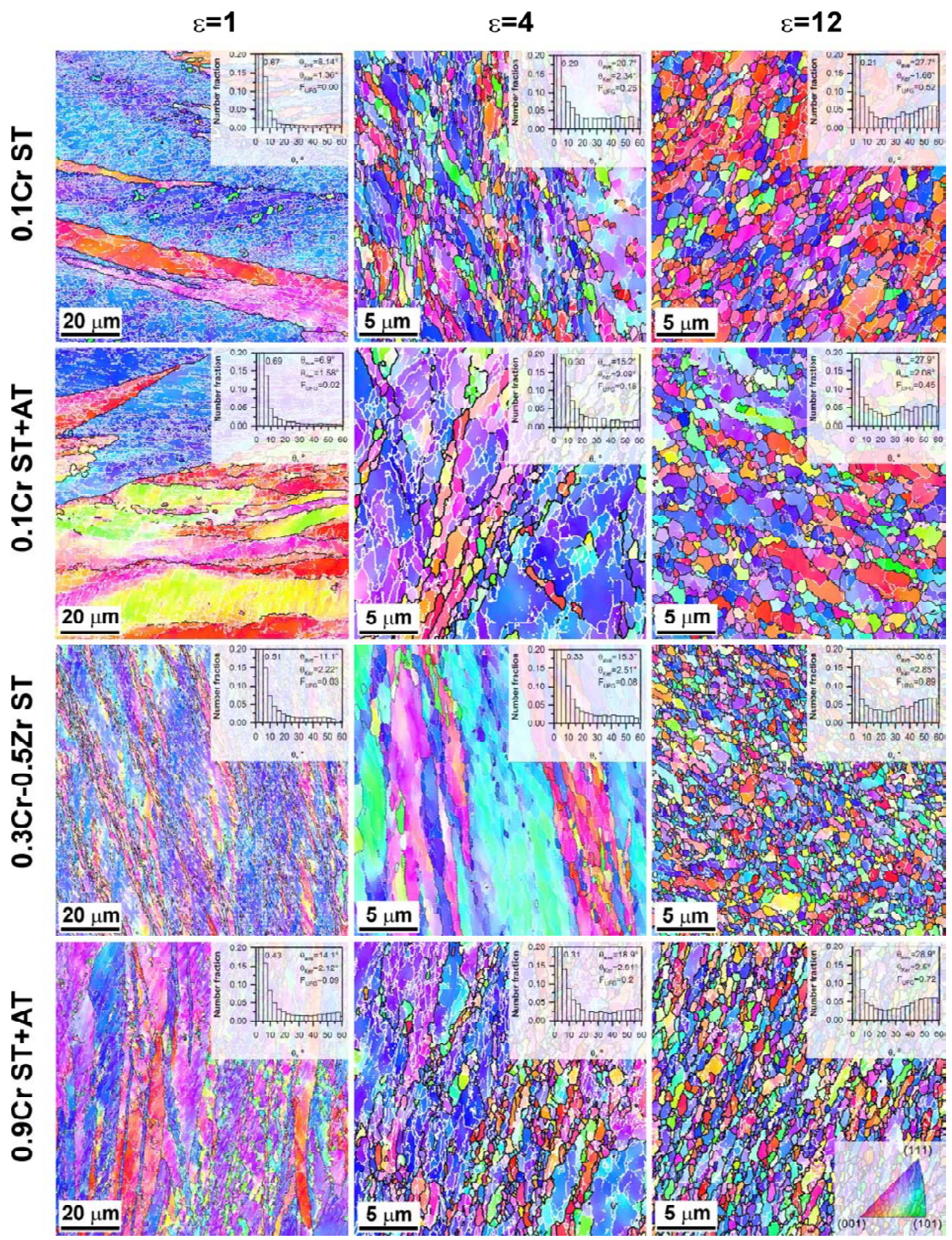

Fig. 14. Typical deformation microstructures and grain boundary misorientation distributions developed in a $0.1 \mathrm{Cr}$ alloy after ST and AT; in $0.3 \mathrm{Cr}-0.5 \mathrm{Zr}$ alloy after ST; and $0.9 \mathrm{Cr}$ alloy after ST subjected to ECAP at a temperature of $400^{\circ} \mathrm{C}$ to total strains of $1,4,12$, adapted from Refs. [47, 50-51]. The inverse pole figures are shown for pressing direction (PD). The white and black lines indicate the low-angle $\left(\theta<15^{\circ}\right)$ and high-angle $\left(\theta \geq 15^{\circ}\right)$ boundaries, respectively. 

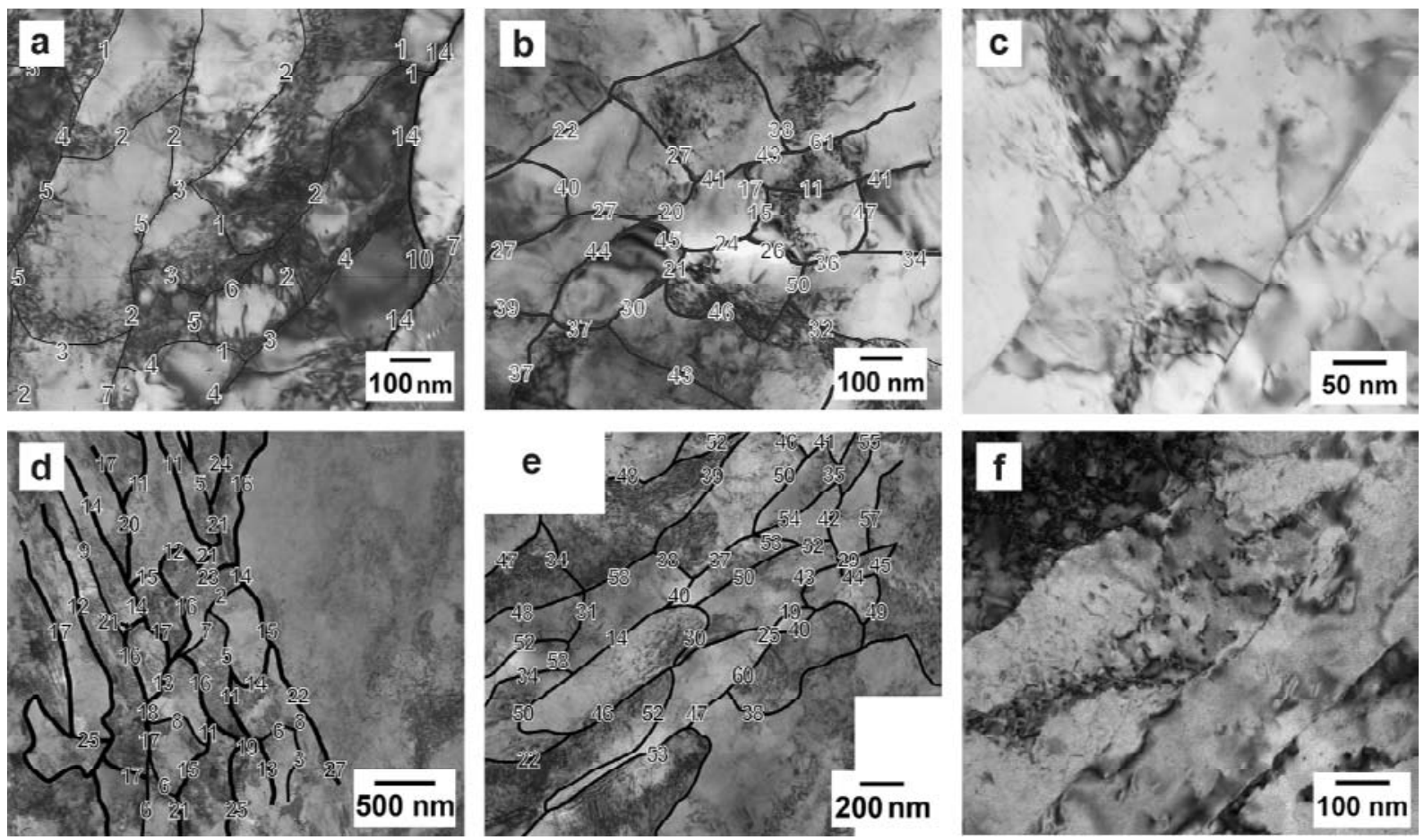

Fig. 15. Typical fine substructures of a $0.1 \mathrm{Cr}$ alloy after $\mathrm{ST}(\mathrm{a}, \mathrm{b}, \mathrm{c})$ and $0.3 \mathrm{Cr}-0.5 \mathrm{Zr}$ alloy after $\mathrm{AT}(\mathrm{b}, \mathrm{e}, \mathrm{f})$ subjected to ECAP at $400^{\circ} \mathrm{C}$ to total strains of $2(\mathrm{a}, \mathrm{b}), 4(\mathrm{e}), 8(\mathrm{~b})$, and 12 (c, f), adapted from Ref. [50]. The numbers indicate the boundary/subboundary misorientations in degrees.

mation microbands are composed of closely spaced subboundaries. It is worth noting that the misorientations of longitudinal subboundaries are larger than those of transverse subboundaries (3$8^{\circ}$ vs. $2-3^{\circ}$ in Fig. 15). The band-like character of deformation substructure remains during ECAP to rather large strains (Fig. 15). However, boundary/ subboundary misorientations significantly increase. At rather large strains, the deformation microbands consist of almost equiaxed UFGs bounded by HAB (Fig. 15).

The development of deformation bands in copper alloys has been discussed in terms of the grain boundary triple junctions. Severe plastic deformation is accompanied by significant microstructure change that is associated with an increase in the dislocation density and the development of straininduced (sub)boundaries. The new grains develop heterogeneously that is assisted with the formation of deformation bands. This process promotes the fragmentation of the initial grains, and lead to a rapid increase in the $F_{\mathrm{HAB}}$ fraction, while $F_{\mathrm{UFG}}$ does not increase remarkably at early stage of deformation (Fig. 14). The number of the deformation microbands rapidly increases during ECAP to a strain of 2 . Then, the new ultrafine grains readily develop along the microbands and the initial grain boundaries, as well as at their intersections, accelerating an increase in $F_{\mathrm{UFG}}$. The deformation microbands and the new (sub)boundaries lead to the appearance of new triple junctions formed by low-angle and/or high-angle boundaries. The number of high-angle boundaries in the triple junctions and their distribution are controlled by continuous dynamic recrystallization and grain refinement.

In general, the triple junctions in largely strained materials may consist of three low-angle boundaries (J0), one high-angle and two low-angle boundaries (J1), two high-angle and one low-angle boundary (J2), and three high-angle boundaries (J3). The developing microstructure should correspond to the specific triple junction distribution. Thus, at relativity small strain levels, a large fraction of $\mathrm{JO}$ and a small fraction of $\mathrm{J} 3$ are expected. On the other hand, the $\mathrm{J} 3$ fraction in the dynamically recrystallized ultrafine-grained microstructure after large strain deformations should be approximately 1 . If deformation strips are formed in the microstructure at early deformation, that is, long parallel high-angle boundaries, then the fraction of $\mathrm{J} 2$ must be very high. With an increase in the strain, transverse $\mathrm{HAB}$ are formed within the deformation bands and the fraction of $\mathrm{J} 3$ should increase.

The effect of total strain on the fraction of triple junctions with the different contents of high-angle boundaries in several $\mathrm{Cu}-\mathrm{Cr}-\mathrm{Zr}$ alloys with different 

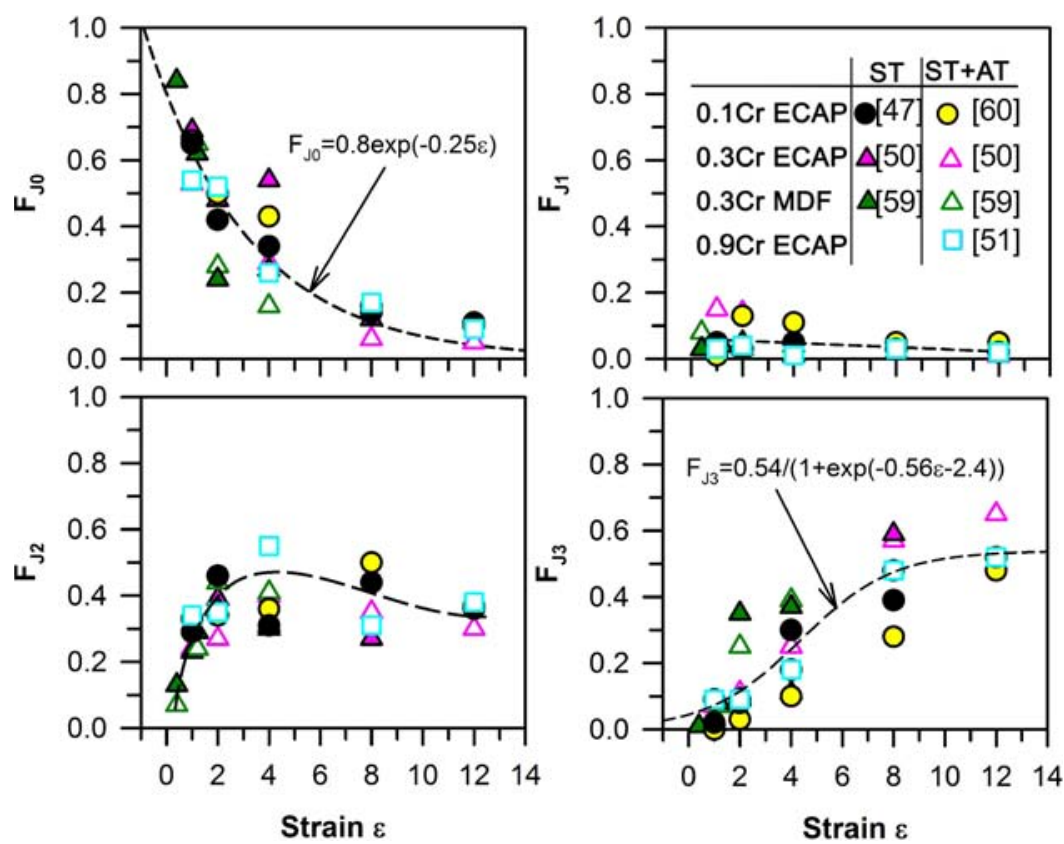

Fig. 16. The strain effect on the fraction of triple junctions with zero, one, two, or three adjacent high-angle boundaries, denoted as FJO, FJ1, FJ2, and FJ3, respectively, for $0.1 \mathrm{Cr}$ (circles [47, 60]), Cu-0.3Cr-0.5Zr $(0.3 \mathrm{Cr}$, triangles [50,59]), $0.9 \mathrm{Cr}$ (squares, [51]) alloys after solution treatment (ST) or aging (AT) subjected to ECAP or multidirectional forging (MDF) at $400^{\circ} \mathrm{C}$, adapted from Ref. [60].

chromium/zirconium contents subjected to severe plastic deformations by different methods at a temperature of $400{ }^{\circ} \mathrm{C}[60]$ is represented in Fig. 16. The large fraction of $\mathrm{J} 0$ at the relativity small strain levels corresponds to the formation of many dislocation subboundaries with low-angle misorientations. Then, the fraction of $\mathrm{J0}$ gradually decreases with straining as the new high-angle boundaries develop. It should be noted that the number of the $\mathrm{J} 1$ junctions is quite small, and does not vary remarkably during the deformation, irrespective of total strains. The J1 fraction of 0.1-0.15 is almost unchanged with straining.

In contrast, many triple junctions with two highangle boundaries rapidly appear upon the plastic deformation to a strain of 4 . Therefore, the J2 fraction quickly increases in the strain range of zero to four, followed by a slight decrease during subsequent deformation. The fraction of J3 exhibits an accelerated increase in the intermediate strain level range of two to eight, and then approaches an apparent saturation of about 0.5 at large strain levels. The strain level range of zero to four is characterized by the development of the deformation microbands. The formation of such bands leads to an increase in the $\mathrm{J} 2$ fraction and a decrease in the $\mathrm{JO}$ fraction. The change in the $\mathrm{J} 0$ fraction during large deformation of the $\mathrm{Cu}-\mathrm{Cr}-\mathrm{Zr}$ alloys with different $\mathrm{Cr}$ and $\mathrm{Zr}$ content, as shown in Fig. 16, can be related to the strain through an exponential function:

$$
F_{J 0}=0.8 \exp (-0.25 \varepsilon) \text {. }
$$

The high $\mathrm{J} 2$ and low $\mathrm{J} 0$ fractions indicate the localization of deformation in the microbands. The strain dependence of the $\mathrm{J} 2$ fraction on ECAP deformation has a peak at total strains of 4 to 6 . Further plastic deformation is accompanied by a decrease in the fraction of low-angle boundaries; thus, the $\mathrm{JO}$ fraction decreases to almost zero at sufficiently large strain levels. The transformation of the transverse low-angle boundaries into high-angle boundaries and the ultra-fine grained microstructure formation lead to an increase in the $\mathrm{J} 3$ fraction, while the $\mathrm{J} 2$ fraction decreases when the total strains are in the range of 8-12. The strain effect on the J3 fraction in the various $\mathrm{Cu}-\mathrm{Cr}-\mathrm{Zr}$ alloys is shown in Fig. 16, and can be approximated by a sigmoid law as follows:

$$
F_{J 3}=\frac{0.54}{1+\exp (-0.56 \varepsilon-2.4)} .
$$

Based on the above analysis, a model of microstructural changes in the $\mathrm{Cu}-\mathrm{Cr}$-Zr alloys has been proposed (Fig. 17). 
$\varepsilon=1$

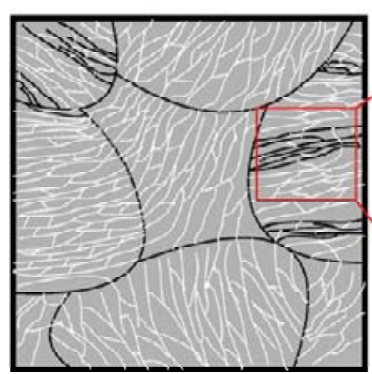

$\varepsilon=4$

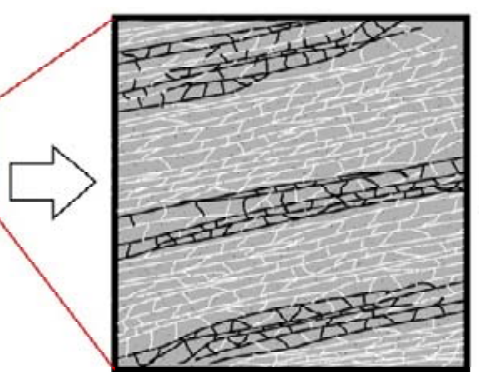

$\varepsilon=12$

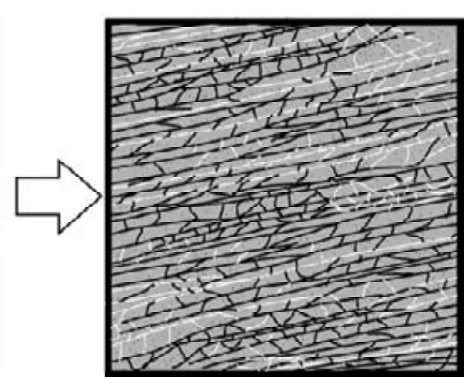

Fig. 17. Schematic illustration of the microstructural evolution in $\mathrm{Cu}-\mathrm{Cr}-\mathrm{Zr}$ alloys subjected to large plastic deformation.
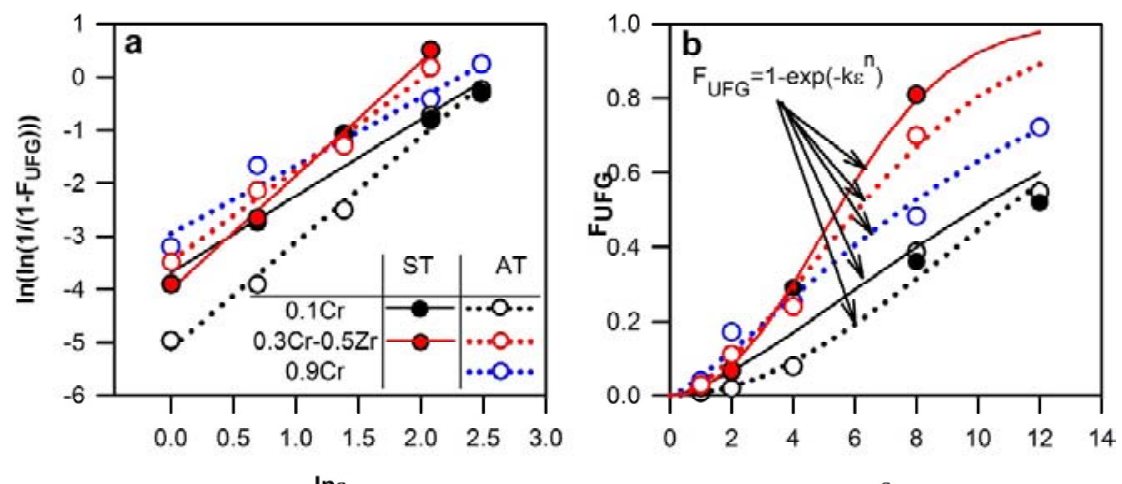

$\ln \varepsilon$

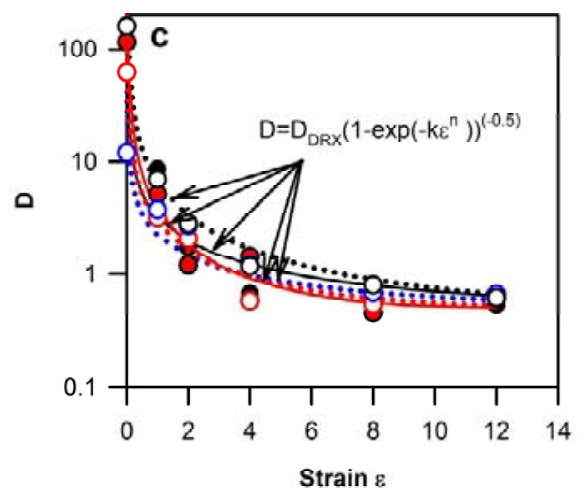

Fig. 18. Dynamic recrystallization in $\mathrm{Cu}-\mathrm{Cr}-\mathrm{Zr}$ alloys during ECAP at $400^{\circ} \mathrm{C}$; recrystallization kinetics (a), the UFG fraction (b), and the mean grain size (c), data taken from Refs. [47,50-51,60].

\subsubsection{DRX kinetics}

Continuous increase in the misorientations between the strain-induced grain/subgrain boundaries is an essential feature of the UFG formation in the present alloys during large strain deformation. This suggests that the grain refinement process in the present study can be discussed in terms of continuous dynamic recrystallisation $[51,123,152-155]$. Similar to other numerous studies on continuous dynamic recrystallisation $[79,92,156]$, the new grains developed heterogeneously, through the formation of deformation microbands. The formation of deformation microbands results in fragmentation of the initial grains leading to a rapid increase in $F_{\mathrm{HAB}}$, although $F_{\mathrm{UFG}}$ does not increase remarkably at an early stage of continuous DRX upon straining to about 4 (Fig. $15)$.

The number of deformation microbands rapidly increases upon further deformation. Then, the new ultra-fine grains readily develop along the microbands and the initial grain boundaries, as well as their intersections accelerating an increase in $F_{\mathrm{UFG}}$. It has been shown for hot working conditions that the progress in discontinuous DRX obeys normal Avrami kinetics, and the recrystallised fraction $\left(F_{\mathrm{DRX}}\right)$ can be related to a strain $(\varepsilon)$ through a modified JohnsonMehl-Avrami-Kolmogorov (JMAK) equation [157159],

$F_{D R X}=1-\exp \left(-k \varepsilon^{n}\right)$, 
where $k$ and $n$ are constants, which depend on material and processing conditions. Therefore, the plot of $\ln \left(1 /\left(1-F_{D R X}\right)\right)$ vs. $\varepsilon$ in logarithmic scale should represent a straight line. It is clearly seen in Fig. 18a that the kinetics of grain refinement in the 0.1 $\mathrm{Cr}, 0.3 \mathrm{Cr}$ and $0.9 \mathrm{Cr}$ alloys during ECAP can be expressed by a modified JMAK equation. The strain exponent in Fig. 18a is quite close to those of 2-3, which have been reported in other studies on DRX [160].

The strain effect on the recrystallised fraction is represented in Fig. 18b. The solid lines represent the $\mathrm{F}_{\mathrm{DRX}}$ calculated by modified JMAK equations, using the obtained in Fig. 18a parameters. The 0.1 $\mathrm{Cr}$ alloy is characterized by the slowest kinetics of grain refinement as compared to others. This may be caused by the coarse initial grain size. The kinetics of both discontinuous and continuous DRX can be significantly accelerated with a decrease in the initial grain size [154]. Another reason for the slow DRX kinetics is a relatively small fraction of dispersed particles. In contrast to discontinuous $\mathrm{DRX}$, when the new grains develop owing to largescale grain boundary migration, continuous (in situ) DRX does not necessary require the grain growth [152]. Instead, the stabilization of boundary network by any second phase particles may be favorable for continuous DRX [152]. Moreover, the presence of a large fraction of dispersed particles accelerates the microbanding, which, in turn, promotes the DRX development [47,51].

\subsubsection{Dynamic grain size and dislocation density}

The development of continuous DRX is accompanied by a gradual decrease in the grain size, which approaches the size of deformation subgrains at sufficiently large strains. Therefore, the mean dynamic grain size is an average of the size of nonrecrystallised initial grains and the size of ultra-fine DRX grains. A decrease in the mean dynamic grain size should correspond to an increase in the recrystallised fraction. Therefore, the average grain size can be calculated as [47]:

$D=D_{D R X}\left(1-\exp \left(-k \varepsilon^{n}\right)\right)^{-0.5}$.

The strain effect on the mean grain size is represented in Fig. 18c. It is clearly seen that the grain sizes calculated by Eq. (22) match well the experimental data. Note that the grain size depends on chemical composition. It is seen that the largest grain size is observed in the $0.1 \mathrm{Cr}$ alloy, and the smallest $0.3 \mathrm{Cr}-0.5 \mathrm{Zr}$ that can be associated with different recrystallization kinetics.

The change in the dislocation density during large strain deformation that is accompanied by continuous DRX can be considered as a superposition of $\mathrm{DRX}$ (namely, dynamic recovery in DRX grains) on work hardening [161,162]. Hence, the dislocation density is related to the recrystallized fraction as follows [162]:

$\rho=\left(1-F_{\mathrm{UFG}}\right) \rho_{\mathrm{wh}}+F_{\mathrm{UFG}} \rho_{\mathrm{rex}}$.

where $\rho_{\text {wh }}$ is the dislocation density by work hardening that can be evaluated as [162]:

$\rho_{\mathrm{wh}}=\frac{h}{r}+\left(\frac{h}{r}-\rho_{0}\right) \exp (-r \varepsilon)$

and $\rho_{\text {rex }}$ is the dislocation density by DRX [161]:

$\rho_{\text {rex }}=\frac{h}{r^{\prime}}+\left(\frac{h}{r^{\prime}}-\rho_{0}\right) \exp \left(-r\left(\varepsilon-\varepsilon_{c}\right)\right)$.

Here, $h$ is the athermal work hardening rate, $r$ is the rate of dynamic recovery in non-recrystallized grains, $r$ is the rate of dynamic recovery in DRX grains, $\rho_{0}$ is the initial dislocation density, and $\varepsilon_{\mathrm{C}}$ is the critical strain.

The best fit for dislocation density measured by TEM is obtained with $\rho_{0}=(0.03-0.1) \times 10^{14} \mathrm{~m}^{-2}, h=$ $2-5, r=0.4-0.85, r^{r}=0.42-2, \varepsilon_{\mathrm{C}}=0$ (Fig. 19) depending on the chemical composition of the alloys. The highest density of dislocations is observed in the $0.3 \mathrm{Cr}-0.5 \mathrm{Zr}$ alloy. It should be noted that the dislocation density of $0.9 \mathrm{Cr}$ and $0.1 \mathrm{Cr}$ alloys reaches saturation followed by a decrease at large strains, whereas the dislocation density in the $0.3 \mathrm{Cr}$ $0.5 \mathrm{Zr}$ alloy increases at all strains in the range studied.

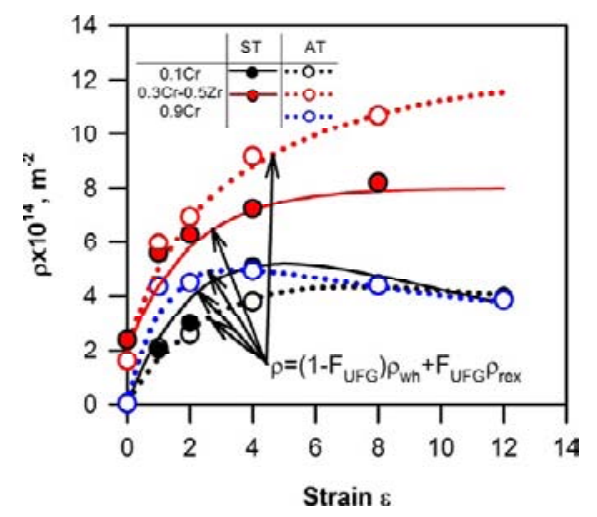

Fig. 19. Dynamic dislocation density $(\rho)$ in $\mathrm{Cu}-\mathrm{Cr}-$ $\mathrm{Zr}$ alloys during ECAP, data taken from Refs. [47, 50-51,60]. 

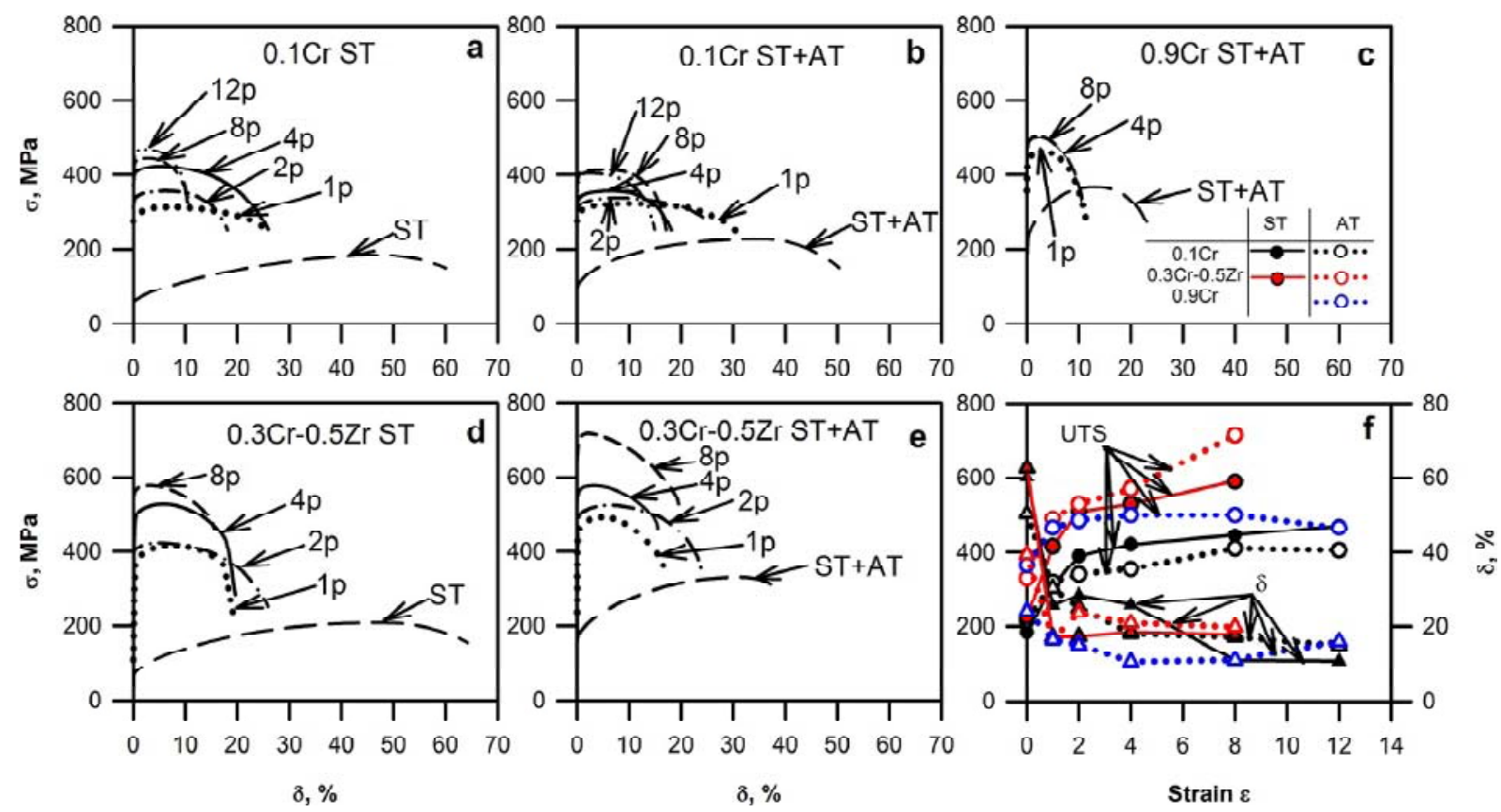

Fig. 20. Engineering stress-strain curves for $0.1 \mathrm{Cr}(\mathrm{a}, \mathrm{b}), 0.3 \mathrm{Cr}-0.5 \mathrm{Zr}(\mathrm{b}, \mathrm{e})$ and $0.9 \mathrm{Cr}$ (c) in ST (a, d) and $S T+A T(b, c, e)$ condition. Effect of deformation strain e on UTS and elongation to failure $\delta(f)$, data taken from Refs. [47,50-51,60].
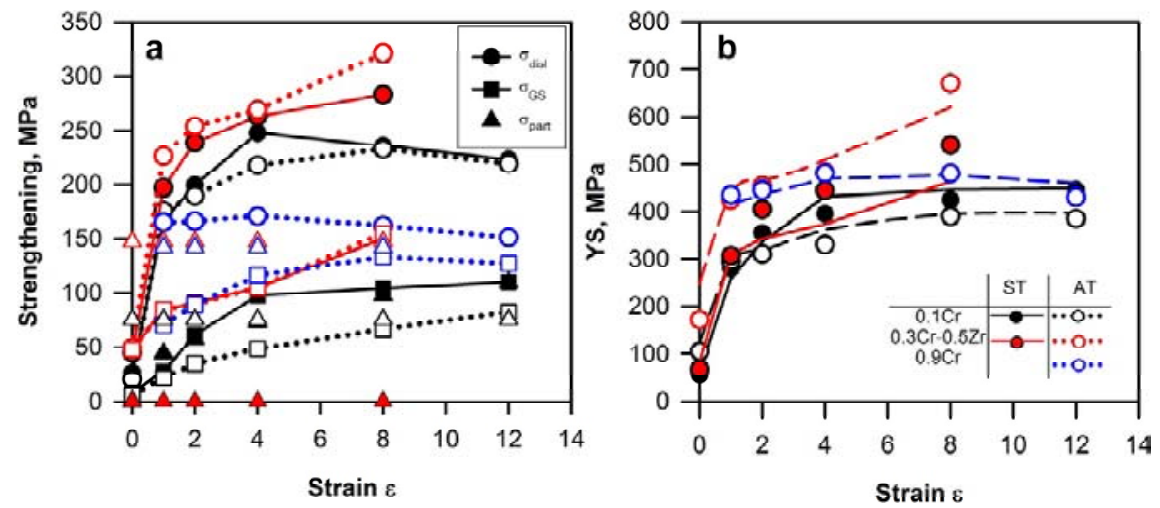

Fig. 21. Variations of the particles strengthening, $\sigma_{\text {part }}$, the grain size strengthening, $\sigma_{\mathrm{GS}}$, and the dislocation strengthening, $\sigma_{\text {disl }}$ of $\mathrm{Cu}-\mathrm{Cr}-\mathrm{Zr}$ alloys processed by ECAP at $400^{\circ} \mathrm{C}(\mathrm{a})$, and the relationship between the experimental (points) and calculated (lines) yield strengths (YS) for the alloys subjected to ECAP (b), data taken from Refs. $[47,50-51,60]$.

\subsubsection{Tensile behavior and strengthening}

Fig. 20 shows typical engineering stress-strain curves obtained by tensile tests of the initial and ECAP samples of $0.1 \mathrm{Cr}, 0.3 \mathrm{Cr}-0.5 \mathrm{Zr}$, and $0.9 \mathrm{Cr}$ alloys. The initial samples are characterized by conventional type of stress-strain curve. Namely, following a relatively low yield point at about 100 $150 \mathrm{MPa}$ the strain hardening takes place until the UTS is reached at a large engineering strain of about $35 \%-60 \%$. Then, the flow stress continuously decreases until the fracture. The ECAP processing affects significantly the shape of stress-strain curves and the mechanical properties. Commonly, YS in- creases to 300-450 MPa depending on the ECAP strain and chemical composition. In the samples subjected to 4-12 ECAP passes, the strain hardening rapidly decreases to zero at relatively small engineering strains of about $5 \%$, leading to UTS being quite close to the yield strength. Correspondingly, the total elongation rapidly decreases from $50 \%$ in the initial state to $15-20 \%$ in the samples after $4-12$ ECAP passes. The $0.3 \mathrm{Cr}-0.5 \mathrm{Zr}$ alloy exhibits the highest strength in AT condition after 8 ECAP passes (UTS $=710 \mathrm{MPa}$ ). In contrast, the 0.1 Cr alloy exhibits the lowest strength of UTS $=445$ $\mathrm{MPa}$ in AT condition.

A modified Hall-Petch analysis is elaborated to understand the reasons for the strengthening of $\mathrm{Cu}$ - 

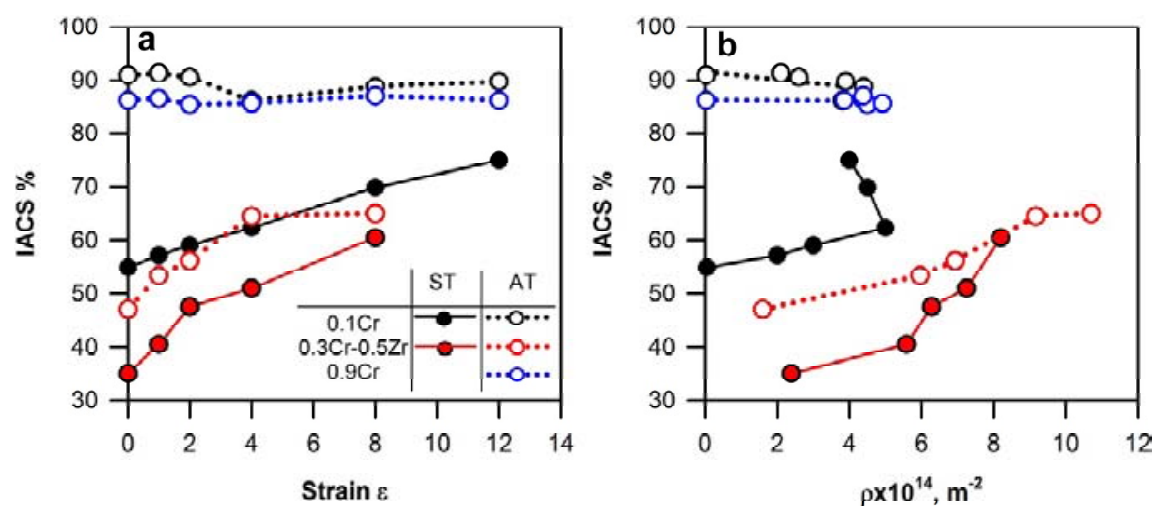

Fig. 22. Electroconductivity (IACS \%) of Cu-Cr-Zr alloys as a function of total strain by ECAP at $400{ }^{\circ} \mathrm{C}$ (a) and effect of the dislocation density $(\rho)$ on the electroconductivity of $\mathrm{Cu}-\mathrm{Cr}-\mathrm{Zr}$ alloy (b), data taken from Refs. $[47,50-51,60]$.

$\mathrm{Cr}$-Zr alloys and the effect of the chemical composition and total strain on the hardening. In the considered alloys, the strength of dislocation-free single crystal is $25 \mathrm{MPa}$ [163]. The particle strengthening after aging for $0.1 \mathrm{Cr}, 0.3 \mathrm{Cr}-0.5 \mathrm{Zr}$, and $0.9 \mathrm{Cr}$ comprises $75 \mathrm{MPa}, 175 \mathrm{MPa}$, and $142 \mathrm{MPa}$, respectively [47,50-51]. The contribution from the solid solution strengthening can be neglected because of quite low concentration of $\mathrm{Cr}$ and $\mathrm{Zr}$-atoms, which are almost insoluble in Cu matrix [84,50-51].

Fig. 21 summaries the contributions of different strengthening mechanisms to the overall strength for the $0.1 \mathrm{Cr}, 0.3 \mathrm{Cr}-0.5 \mathrm{Zr}$, and $0.8 \mathrm{Cr}$ alloys. The grain size and dislocation density for the grain size strengthening $\left(\sigma_{G S}\right)$ and the dislocation strengthening $\left(\sigma_{\text {disl }}\right)$ were calculated by Eq. (13). It is clearly seen that the dislocation strengthening $\left(\sigma_{\text {dis }}\right)$ dominates in the all examined strain range and constitutes 200-300 MPa. The lattice friction and precipitation strengthening do not influence the overall strengthening during ECAP because they are taken as constants. The contribution of grain size strengthening $\left(\sigma_{G S}\right)$ to overall strength increases with an increase in ECAP passes and comprised 100-150 $\mathrm{MPa}$. The grain size strengthening gradually increases with straining, whereas the dislocation strengthening increases significantly during the first ECAP pass followed by quite slow increase on further processing. Note that dispersed particles promote the accumulation of dislocations density. Therefore, the alloy with the maximum dispersion strengthening is characterized by maximum UTS.

\subsubsection{Electrical conductivity}

The large plastic deformation affects not only the structure and strength properties, but also the electrical conductivity. The effects of strain and disloca- tion density on electrical conductivity of $\mathrm{Cu}-\mathrm{Cr}-\mathrm{Zr}$ alloys are illustrated in Fig. 22. Cu-Cr-Zr alloy with high conductivity (i.e., $0.1 \mathrm{Cr}$ and $0.9 \mathrm{Cr}$ alloys after AT) in initial state demonstrates a decrease in electrical conductivity at early deformation followed by an increase in the conductivity after total strains of 8-12 that may be associated with a change in the dislocation density (Fig. 19a) [59].

In contrast, the alloys with low conductivity in initial state $(0.1 \mathrm{Cr}$ after ST, $0.3 \mathrm{Cr}-0.5 \mathrm{Zr}$ after either ST or AT) are characterized by monotonic increase in the electrical conductivity during large plastic deformation. This behavior can be explained by the deformation-induced decomposition of the solid solution during plastic deformation and the particle precipitation as suggested by TEM observations [50].

\subsection{Effect of deformation method on the microstructure and properties of $\mathrm{Cu}-\mathrm{Cr}-\mathrm{Zr}$ alloys}

The development of microstructure and properties of $\mathrm{Cu}-\mathrm{Cr}$-Zr alloys depends on the stress-strain state during deformation. Therefore, the deformation scheme significantly affects the microstructure evolution during plastic deformation. The influence of large plastic deformations on the kinetics of grain refinement and properties of the $0.3 \mathrm{Cr}-0.5 \mathrm{Zr}$ alloy was studied by using MDF, ECAP, and HPT (Fig. 23) [164].

The deformation microstructures evolved in a $\mathrm{Cu}-$ $\mathrm{Cr}-\mathrm{Zr}$ alloy during large plastic deformation are shown in Fig. 24. The deformation to a relatively small strain of about 1 brings about the development of a number of low-angle strain-induced subboundaries. However, the number of strain-induced high-angle boundaries is larger after ECAP and HPT than that after MDF. An increase in the 

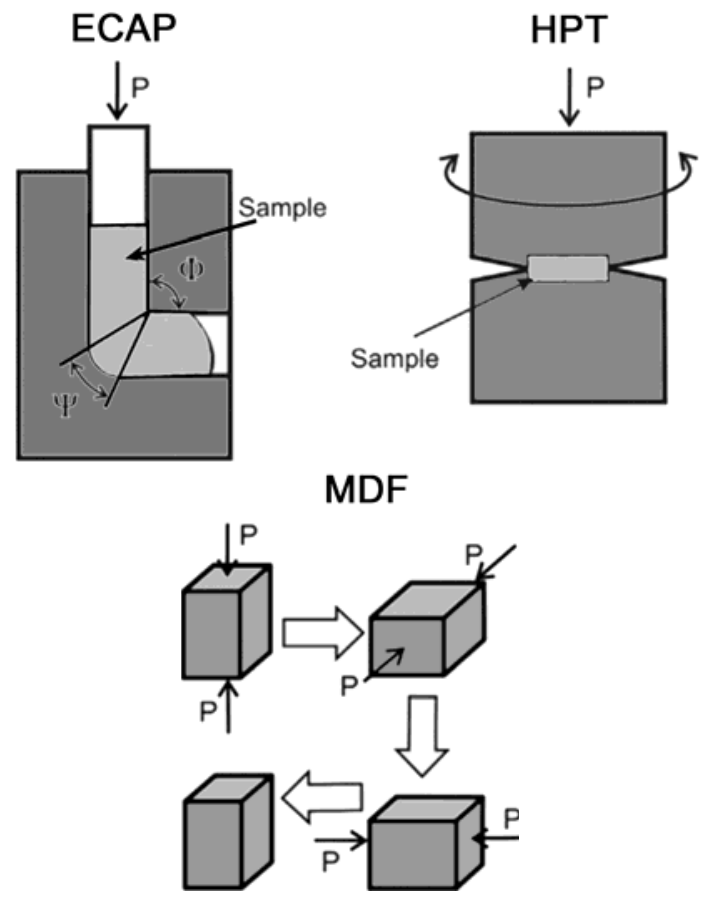

total strain to about 2 (or 1 turn in HPT) leads to the formation of new ultrafine grains. The sharp deformation microbands develop during ECAP and HPT resulting in the formation of a bimodal microstructure. An increase in the total strain to 4 by ECAP does not affect remarkably the formation of new ultrafine grains, although the average size of original grain remnants becomes less than $5 \mathrm{~mm}$. On the other hand, MDF results in the homogeneous microstructure evolution. The formation of new ultrafine grains occurs near the initial grain boundaries. Such homogeneous formation of microstructure during MDF may be associated with the changes in the forging axis from pass to pass. As a result, the MDF leads to the development of ultrafine grained structure at a strain of 4 . The new ultrafine grains are characterized by almost equiaxed shape. Besides the new ultrafine grains, the microstructure of MDF samples includes small remainders of the original grains. In HPT samples, the homogene-

Fig. 23. Principles of equal channel angular pressing (ECAP), high pressure torsion (HPT) and multidirectional forging (MDF).
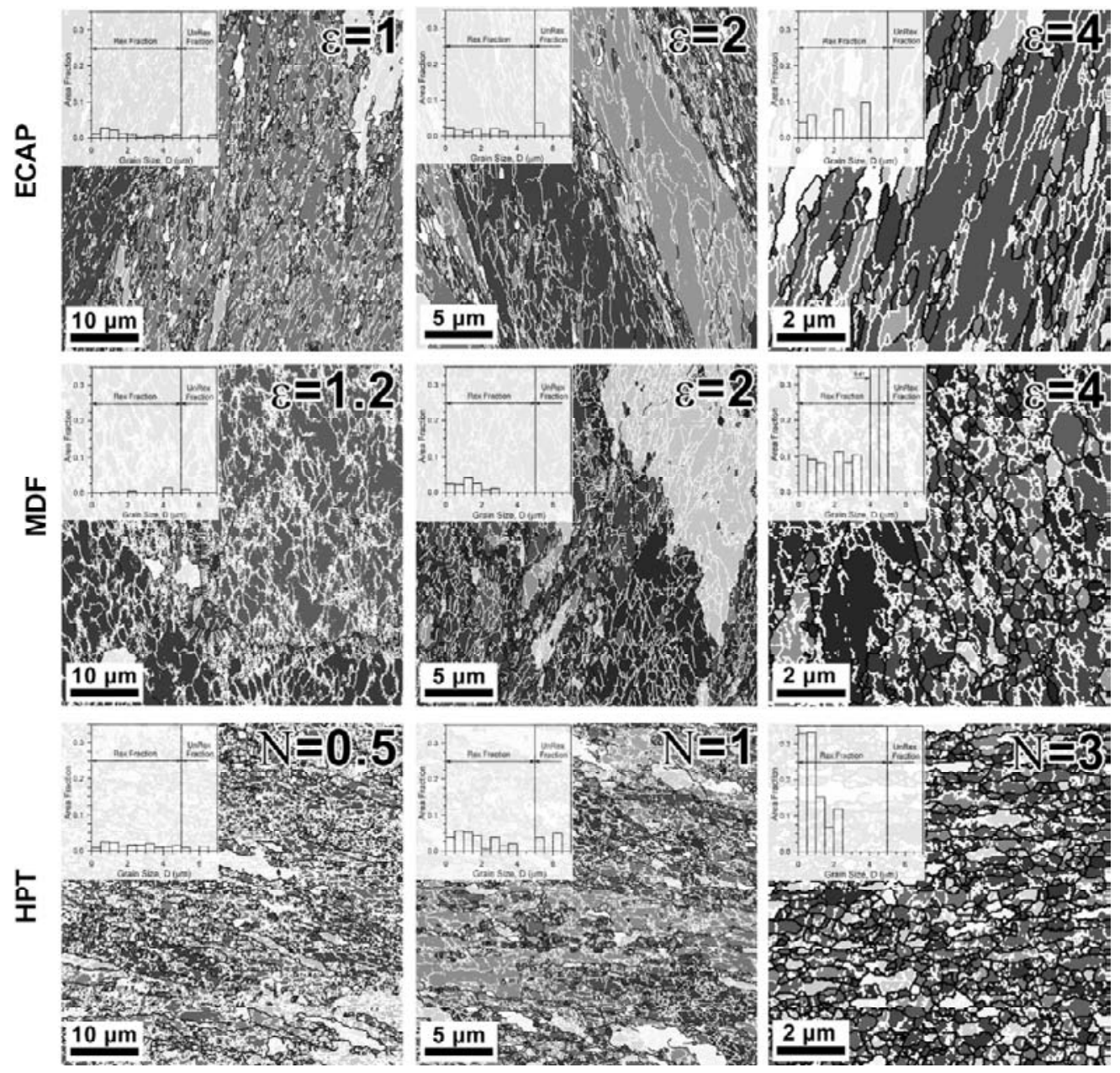

Fig. 24. Deformation microstructures and grain size distributions in a $\mathrm{Cu}-0.3 \mathrm{Cr}-0.5 \mathrm{Zr}$ alloy subjected to ECAP and MDF at $400^{\circ} \mathrm{C}$ and HPT ( 0.5 to 3 turns) at room temperature, adapted from Ref. [164]. 

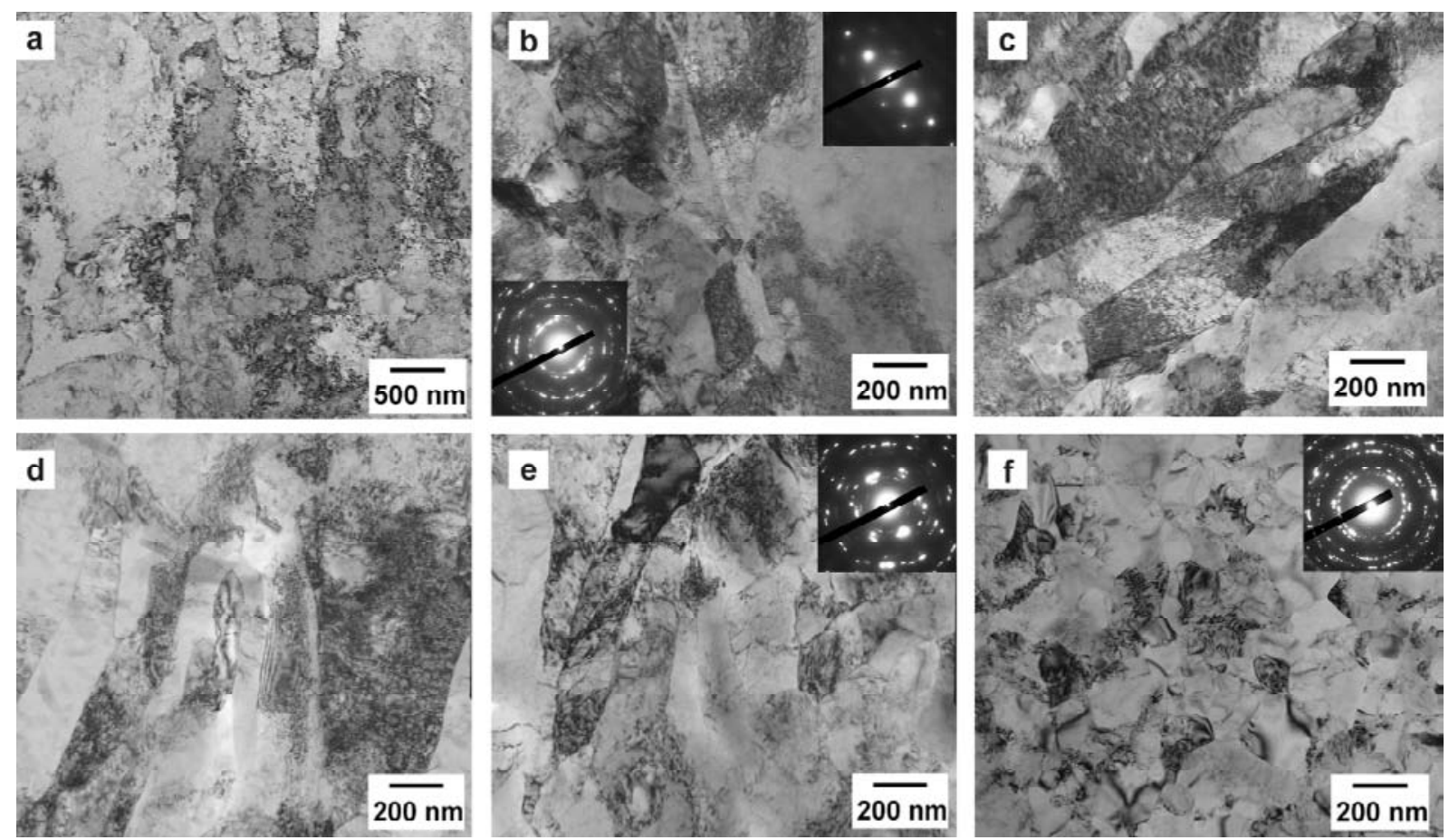

Fig. 25. Fine deformation substructure in a $\mathrm{Cu}-0.3 \mathrm{Cr}-0.5 \mathrm{Zr}$ alloy subjected to equal channel angular pressing (a-c), multidirectional forging (d-e) at temperature of $400^{\circ} \mathrm{C}$ to a total strain of 1 (a), 1.2 (d); 2 (b); 4 (c, e) and high pressure torsion at $20^{\circ} \mathrm{C}$ to 5 turns (f), adapted from Ref. [164].

ous microstructure with the lowest $L A B$ fraction and grain size is formed after 3 turns.

The fine substructures evolved during MDF, ECAP and HPT to strains of 1 to 4 and 3 turns are presented in Fig. 25. MDF to a relatively small strain of about 1.2 results in the development of a large number of strain-induced subboundaries with lowangle misorientations crossing over the original grains (Fig. 25a). Further MDF is accompanied by an increase in the subboundary misorientations leading to the formation of relatively equiaxed subgrains surrounded by moderate-to-high angle boundaries (Fig. 25b). The fine microstructure after MDF to a strain of 4 consists of largely misorientated grains/ subgrains (Fig. 25c). On the other hand, the first pass of ECAP leads to the evolution of a spatial network of the planar low-angle boundaries (Fig. 25d). After the second ECAP pass, the sharp deformation microbands, which include a large number of new ultrafine grains, appear in the deformation microstructure (Fig. 25e). The ring-like diffraction pattern that obtained from the deformation microband region indicates the high angle misorientations between grains within the microband. In contrast, the single spot diffraction pattern taken from neighboring area suggests lowangle misorientations among dislocation cell substructure (Fig. 25e). The fraction of ultrafine grained structures gradually increases upon further processing (Fig. 25f). HPT resultes in the formation of an UFG structure with a mean grain/subgrain size of $113 \mathrm{~nm}$. The structure consists of dislocations-free grains with sharp high-angle boundaries and work hardened regions with large internal distortions and low-angle dislocation subboundaries.

\subsubsection{Grain refinement kinetics}

The grain refinement kinetics in $0.3 \mathrm{Cr}-0.5 \mathrm{Zr}$ alloy subjected to large plastic deformation can be expressed by Eq. (21). Commonly, all obtained plots, irrespective of the method of large plastic deformation, show straight lines in logarithmic scale (Fig. 26a). The slope of the line depends on the method of plastic deformation. It is clearly seen that MDF is characterized by sharpest slope in comparison with other methods of large strain deformation (ECAP and HPT).

Fig. 26b represents the recrystallized fraction as a function of total strain (or number of turns for HPT). The solid lines indicate the recrystallized fraction calculated by modified JMAK equation (Eq. (21)), setting the parameters obtained in Fig. 26a. It is clearly seen in Fig. 26 that the HPT is more effective method to produce fully recrystallized microstructure in the $\mathrm{Cu}-\mathrm{Cr}-\mathrm{Zr}$ alloy in comparison with 

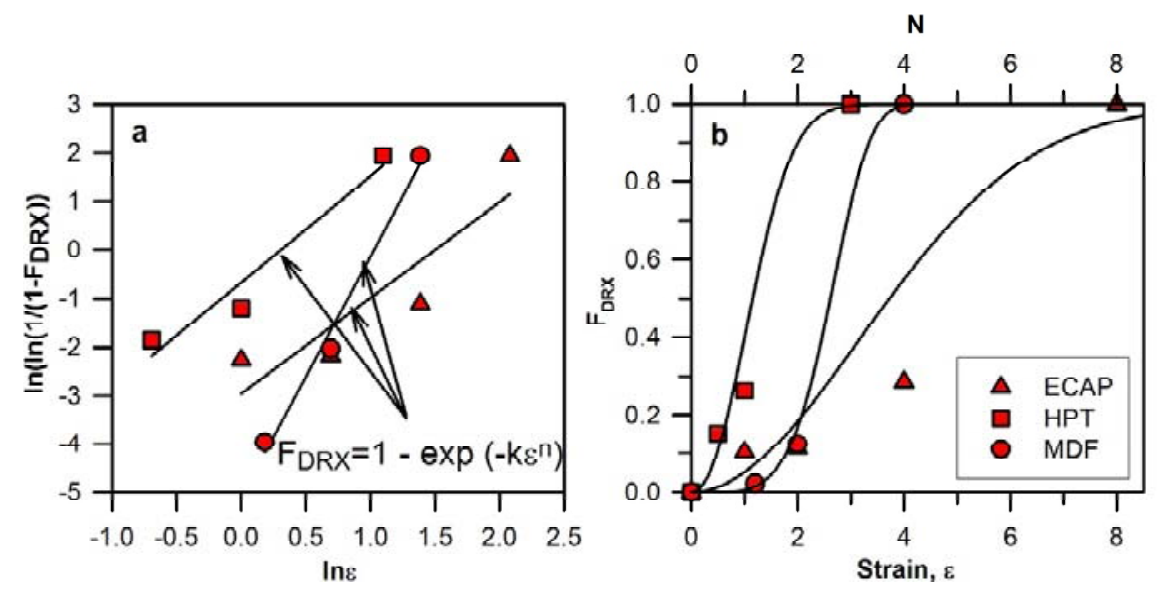

Fig. 26. Relationship between $\ln \ln (1 /(1-F D R X))$ and $\ln$ for a $\mathrm{Cu}-0.3 \mathrm{Cr}-0.5 \mathrm{Zr}$ alloy subjected to large plastic deformation (a) and an increase in the recrystallized fraction during large plastic deformation (b), adapted from Ref. [164].
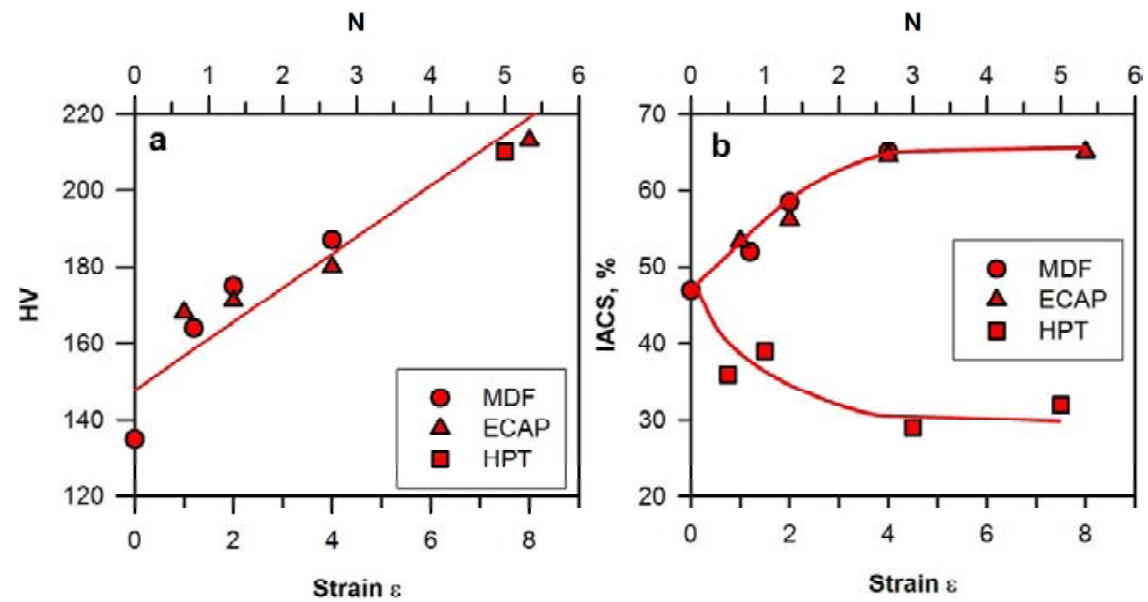

Fig. 27. Microhardness (HV) and electroconductivity (IACS, \%) of a $\mathrm{Cu}-0.3 \mathrm{Cr}-0.5 \mathrm{Zr}$ alloy as a function of total strain during large plastic deformation, data taken from Ref. [59].

ECAP and MDF. The fully recrystallized microstructure develops after 3 HPT turns. It is interesting to note that process of continuous dynamic recrystallization starts to occur at early stage of HPT processing. On the other hand, MDF is characterized by kind of incubation period which ranged from 0.4 to 2 total strains. Significant increase of the grain refinement kinetics is observed after straining to about 2. Finally, the recrystallized fraction achieves almost 1 , when the total strain increases to 4. Despite of early start of dynamic recrystallization process, the ECAP shows the slowest kinetics of grain refinement.

\subsubsection{Mechanical properties and electrical conductivity}

The change in the hardness and electrical conductivity of the $0.3 \mathrm{Cr}-0.5 \mathrm{Zr}$ alloy is shown in Fig. 27. An increase in strain is accompanied by an increase in hardness, regardless of the deformation method. Note that the hardness values after ECAP and MDF are similar despite the different mechanisms of microstructural changes during deformation. The hardness after to 5 turns by HPT is also similar to that after ECAP and MDF [69].

MDF and ECAP of the $0.3 \mathrm{Cr}-0.5 \mathrm{Zr}$ alloy are accompanied by almost the same increase in the electrical conductivity (s. Section 2.2 above). In contrast, the change in electrical conductivity during HPT is quite different. HPT leads to a decrease in the electrical conductivity to the level of a supersaturated solid solution [69], which may result from the high dislocation density and deformation-induced dissolution of the particles. Note that dispersed particles are observed in the $0.3 \mathrm{Cr}-0.5 \mathrm{Zr}$ alloy after HPT (Fig. 25), but their volume fraction is lower than in the initial AT condition. 

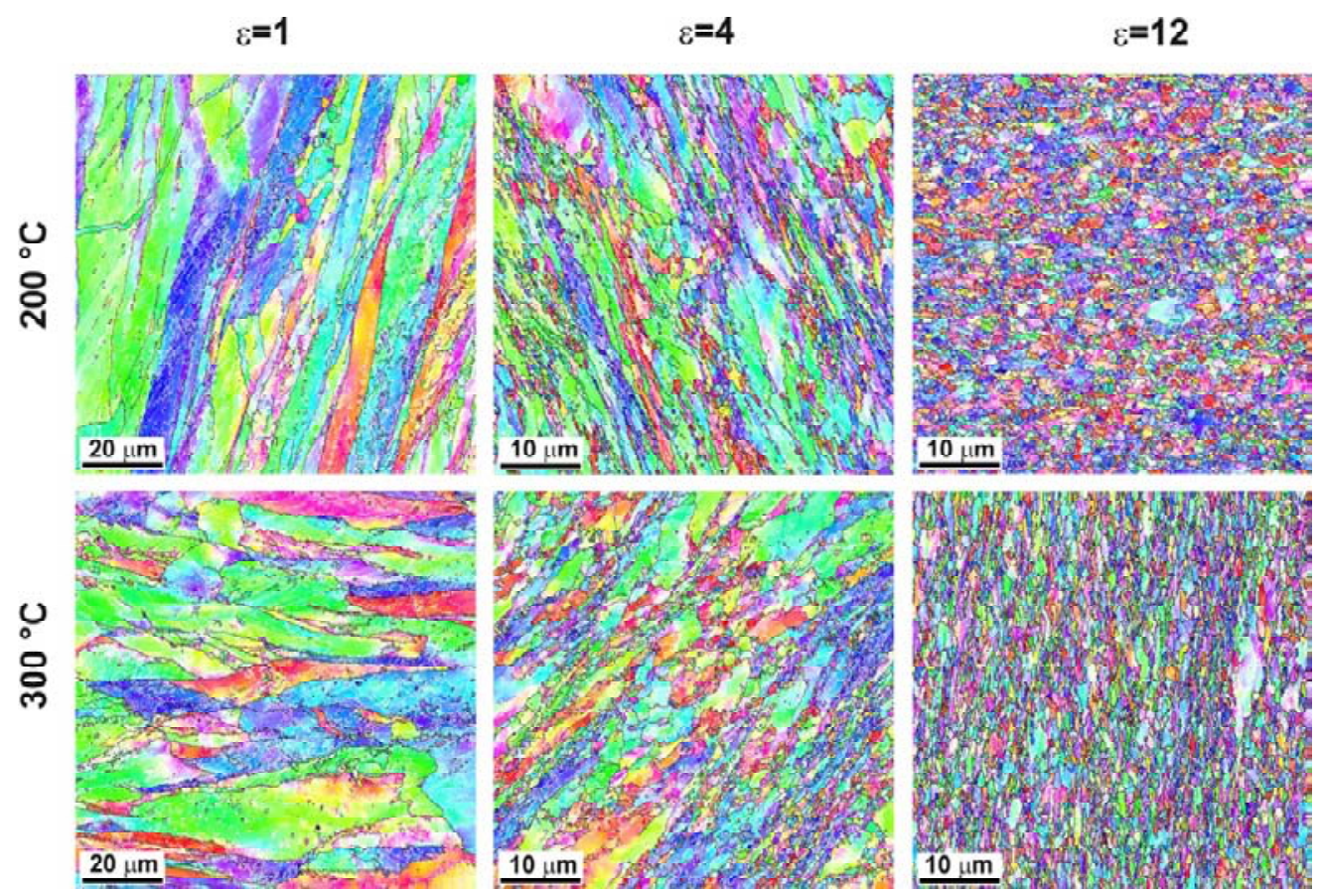

Fig. 28. Typical deformation microstructures developed in a Cu-0.9Cr alloy subjected to ECAP at $200^{\circ} \mathrm{C}$ and $300{ }^{\circ} \mathrm{C}$ to total strains, $\varepsilon$, of 1,4 and 12 , adapted from Ref. [139].
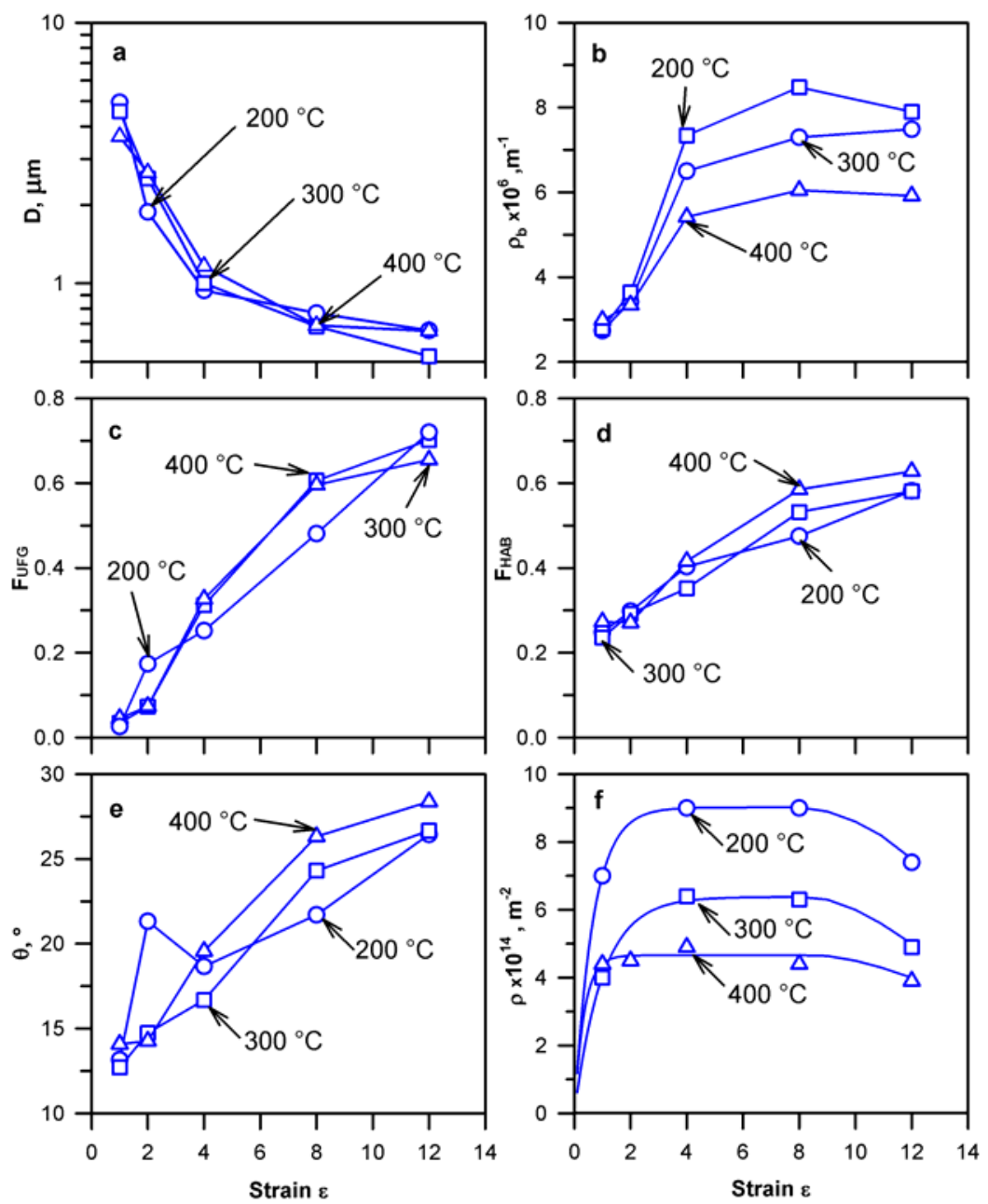

Fig. 29. ECAP temperature effect on (a) the average grain size (D), (b) the density of boundaries with misorientations of $\theta>2^{\circ}\left(\rho_{b}\right)$, (c) the fraction of HAB (FHAB), (d) the fraction of ultrafine grains (FUFG), (e) the average misorientation $(\theta)$, and (f) the dislocation density $(\rho)$ in a $\mathrm{Cu}-0.9 \mathrm{Cr}$ alloy, adapted from Ref. [51]. 


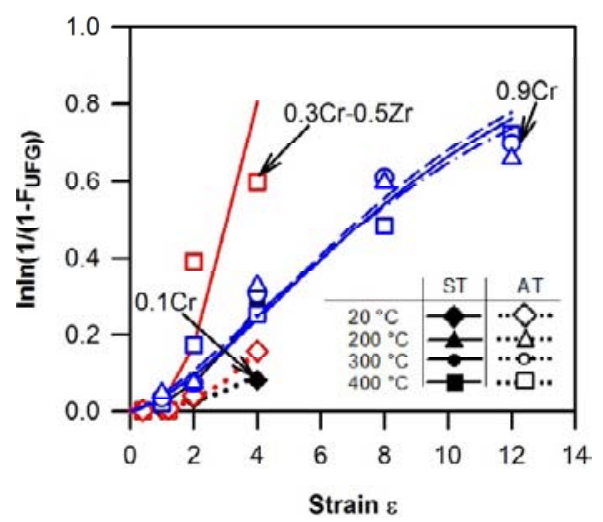

Fig. 30. The grain refinement kinetic in $\mathrm{Cu}-\mathrm{Cr}-\mathrm{Zr}$ alloys during plastic deformation at temperatures of $20-400^{\circ} \mathrm{C}$, data taken from Refs. [51,59,139,142].

\subsection{Temperature effect on deformation behavior of Cu-Cr-Zr alloys}

The deformation temperature affects the mobility of dislocations and their distribution in the copper alloys [79]. At higher temperatures, recovery processes develop more rapidly that may change the kinetics of dynamic recrystallization. The effect of deformation temperature on the microstructure and properties of $0.9 \mathrm{Cr}$ alloy was studied in ECAP at 200-400 ${ }^{\circ} \mathrm{C}[51,139]$. Figs. 14 and 28 show typical microstructure in the alloy after ECAP at temperatures of 200 and $300^{\circ} \mathrm{C}$ (Fig. 28) and $400{ }^{\circ} \mathrm{C}$ (Fig. 14).

The microstructural parameters of the $0.9 \mathrm{Cr}$ alloy processed at different temperatures are summarized in Fig. 29. The fraction of $\mathrm{HABs}\left(F_{\mathrm{HAB}}\right)$, the fraction of ultrafine grains $\left(F_{\mathrm{UFG}}\right)$ and the average boundary misorientation $(\theta)$ exhibit nearly linear increase with strain (Fig. 29). These strain dependencies do not depend remarkably on the temperature in the range of $200-400^{\circ} \mathrm{C}$. The variations of $F_{\mathrm{HAB}}, F_{\mathrm{UFG}}$, and $\theta$ with strain can be approximately expressed as $\mathrm{FHAB}=0.2+0.04 \varepsilon$, $\mathrm{FUFG}=0.07 \varepsilon$, and $\theta=12+1 \varepsilon$ for the strain range of $1<\varepsilon<8$. The number of ultrafine grains increases significantly during the straining to $4-12$, leading to an increase in the fraction of ultrafine grains above 0.5 at a total strain of 8 . Note that temperature scarcely affects the grain refinement kinetics during ECAP. Nearly the same grain size distributions are developed at the same strains, irrespective of the processing temperature. Deformation temperature clearly affects the dislocation density. An increase in the deformation temperature is accompanied by a decrease in the dislocation density.

\subsubsection{Grain refinement kinetic}

The kinetic of UFG formation or grain refinement in the copper alloys subjected to large plastic deformation can be discussed in terms of dynamic recrystallization and expressed by Eq. (21). Kinetic curves obtained with the JMAK model were constructed for the $0.1 \mathrm{Cr}$ in ST condition subjected ECAP at $400{ }^{\circ} \mathrm{C}$ and room temperature, for the $0.3 \mathrm{Cr}-0.5 \mathrm{Zr}$ in AT condition after MDF at $400^{\circ} \mathrm{C}$ and room temperature and for the $0.9 \mathrm{Cr}$ alloy. Fig. 30 shows the change in the fraction of ultra-fine grains, depending on the deformation strain for different $\mathrm{Cu}$ $\mathrm{Cr}$-Zr alloys subjected to different processing method. The slope of the kinetic lines depends on the temperature of large plastic deformation for the $\mathrm{Cu}$-Cr-Zr alloys (Fig. 30). The strain exponent in the JMAK equitation for the $0.1 \mathrm{Cr}$ and $0.3 \mathrm{Cr}-0.5 \mathrm{Zr}$ alloys increases with the deformation temperature, e.g., from 2.04 at $20^{\circ} \mathrm{C}$ to 2.84 at $400{ }^{\circ} \mathrm{C}$ for the $0.3 \mathrm{Cr}-0.5 \mathrm{Zr}$ alloy. On the other hand, the change in deformation temperature does not affect remarkably the dynamic recrystallization kinetics for the $0.9 \mathrm{Cr}$ alloy, i.e., a constant of $\mathrm{n}$ is about 2.5 irrespective of the warm deformation temperature.

\subsubsection{Mechanical properties and strengthening}

The YS, the UTS and elongation $(\delta)$ of the $0.9 \mathrm{Cr}$ alloy in the peak aged condition subjected to ECAP to strains of 1 to 12 at $200-400^{\circ} \mathrm{C}$ and $0.1 \mathrm{Cr}$ alloy after ST subjected to ECAP to strains of 1 to 4 at $20^{\circ} \mathrm{C}$ and $400^{\circ} \mathrm{C}$ are shown in Fig. 31. The strain imposed by ECAP strongly affects the strength (Fig. 31 ), although the strengthening efficiency decreases with an increase in the ECAP temperature in both alloys.

According to the modified Hall-Petch relationship (Eq. (13)), the total strengthening can be represented as a sum of the dislocation strengthening and the grain boundary strengthening. Therefore, the difference between YS and the grain boundary strengthening with particles strengthening should be linearly dependent on the dislocation strengthening. Thus, the plot of $\sigma_{\mathrm{Ys}}{ }^{-} \sigma_{\text {part }}-k_{y} D^{0.5}$ vs $M G b \rho^{0.5}$ should represent a straight line. The value of $k_{y}$ is chosen as $0.087 \mathrm{MPa} \mathrm{m}{ }^{0.5}$, which has been reported for the modified Hall-Petch relationship in copper alloys [51]. Fig. 31 clearly shows the linear dependence of $\sigma^{*}=\sigma_{\mathrm{YS}}{ }^{-} \sigma_{\text {part }}-k_{y} D^{0.5}$ vs $M G b \rho^{0.5}$ for the $0.9 \mathrm{Cr}$ and $0.1 \mathrm{Cr}$ alloys. The slop of the lines for $0.1 \mathrm{Cr}$ and $0.9 \mathrm{Cr}$ alloys is 0.24 and 0.3 , respectively, irrespective of the deformation temperature. The different 

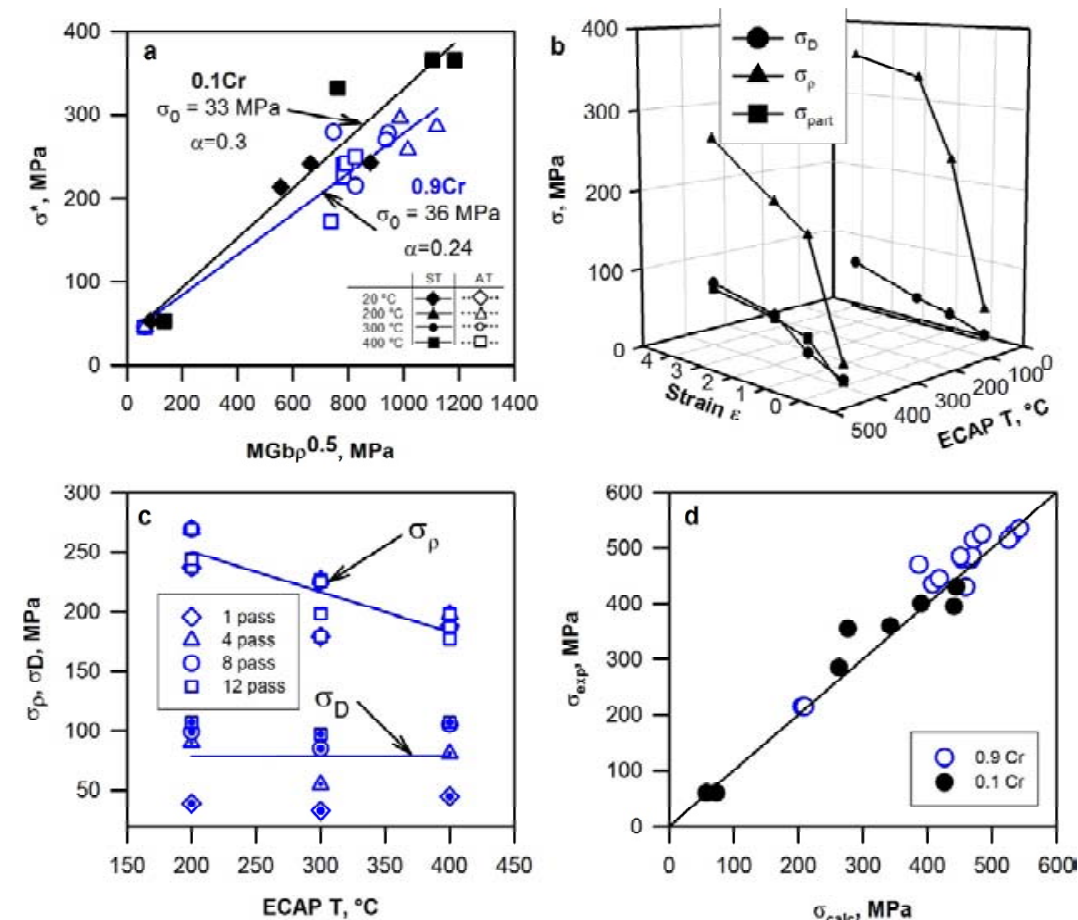

Fig. 31. Relationship between the dislocation strengthening and $\sigma^{*}\left(\sigma^{*}=\mathrm{S}_{\mathrm{YS}}-\mathrm{S}_{\text {part }}-\mathrm{k}_{\mathrm{y}} \mathrm{D}^{-0.5}\right)$ in $\mathrm{Cu}-\mathrm{Cr}-\mathrm{Zr}$ alloys processed by ECAP at $20-400^{\circ} \mathrm{C}$ and dislocation strengthening $M G b \rho^{0.5}$ (a), an influence of deformation temperature on the particle strengthening, $\sigma_{\text {part }}$, the grain size strengthening, $\sigma_{\mathrm{GS}}$, and the dislocation strengthening, $\sigma_{\hat{A}}$, in $0.9 \mathrm{Cr}$ (b) and $0.1 \mathrm{Cr}$ (c) alloys, and a relationship between the experimental $\left(\sigma_{\text {exp }}\right)$ and calculated $\left(\sigma_{\text {calc }}\right)$ yield strengths $(d)$, data taken from Refs. [51,139,142].

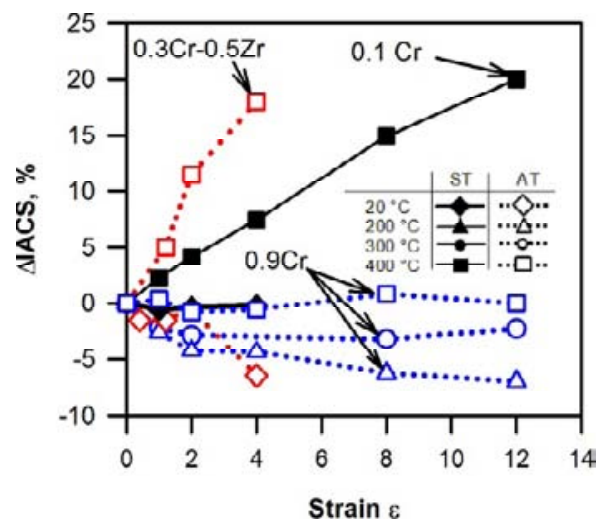

Fig. 32. Variation of electrical conductivity in Cu$\mathrm{Cr}-\mathrm{Zr}$ alloys during plastic deformation at temperatures of $20-400{ }^{\circ} \mathrm{C}$, data taken from Refs. $[51,59,139,142]$.

values of the coefficient may be associated with a difference in the rate of dislocations distribution. Note here that $\alpha$ of $0.2-0.3$ has been frequently used to evaluate the dislocation strengthening $[137,165,166]$.

Figs. $31 \mathrm{c}$ and $31 \mathrm{~d}$ show the change in the strengthening mechanism contributions during large plastic deformation in $0.1 \mathrm{Cu}$ and $0.9 \mathrm{Cr}$ alloys at different temperatures, i.e., $20^{\circ} \mathrm{C}, 200{ }^{\circ} \mathrm{C}, 300^{\circ} \mathrm{C}$, and $400^{\circ} \mathrm{C}$, as calculated by Equitation 13 . It clearly seen that the dislocation strengthening plays a major role in the overall strengthening of the copper alloys during large plastic straining. The dislocation strengthening is 2-3 times larger than the grain boundary strengthening. An increase of the ECAP temperature decreases the dislocation strengthening but does not affect the grain boundary strengthening. The dislocation strengthening increases significantly after early deformation to a total strain of 1-2 and, then, changes slowly regardless of the ECAP temperature. The dislocation strengthening constitutes $200 \mathrm{MPa}$ or $250 \mathrm{MPa}$ for $400^{\circ} \mathrm{C}$ or 200 ${ }^{\circ} \mathrm{C}$, respectively. In contrast, the grain boundary strengthening gradually increases from about 50 to $100 \mathrm{MPa}$ with straining at all temperatures within $20-400^{\circ} \mathrm{C}$. ECAP of the $0.1 \mathrm{Cr}$ in ST condition at $400^{\circ} \mathrm{C}$ is accompanied by particle precipitation resulting in a gradual increase in the dispersion strengthening from 40 to $70 \mathrm{MPa}$ during ECAP . Note that the experimental data are in good agreement with calculated YS (Fig. 31e).

\subsubsection{Electrical conductivity}

Fig. 32 summarizes the effect of temperature and strain on the electrical conductivity. In the $0.9 \mathrm{Cr}$ alloy, the electrical conductivity decreases with a decrease in deformation temperature that correlates 

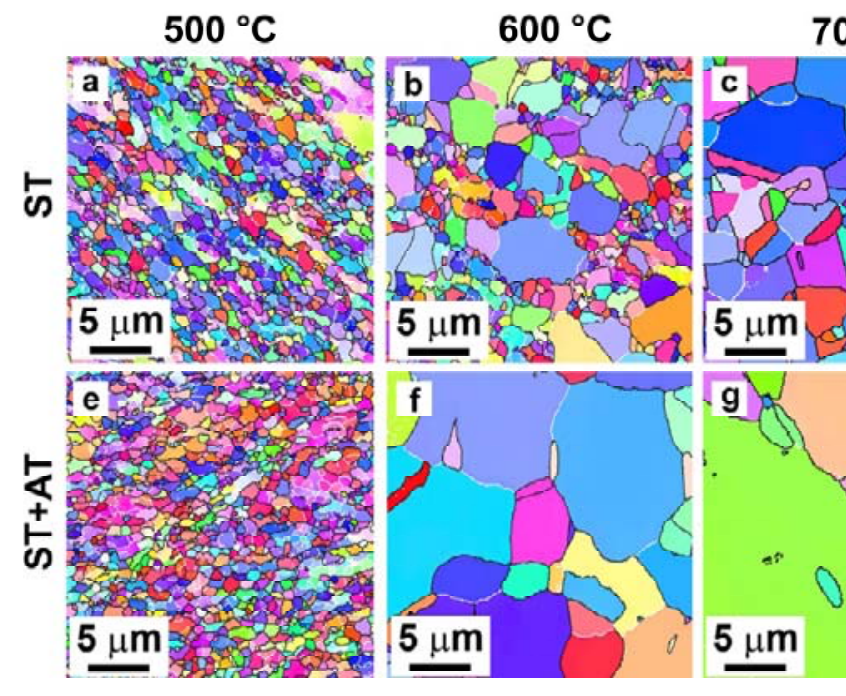

$700^{\circ} \mathrm{C}$

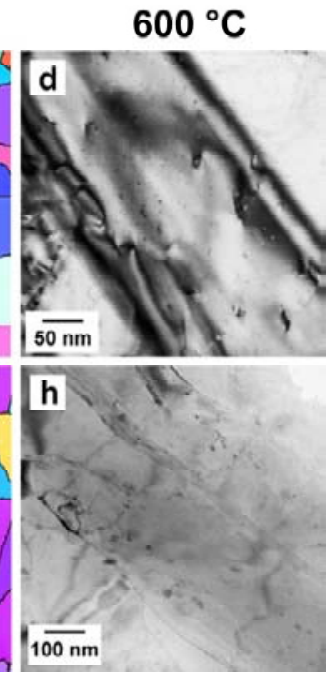

Fig. 33. Typical OIM and TEM micrographs of the fine structure in a $0.1 \mathrm{Cr}$ alloy after ECAP and annealing at 500 (b, f), 600 (c, g, TEM), $700^{\circ} \mathrm{C}(\mathrm{d}, \mathrm{e})$ in ST (a-d) and AT (e-h) samples, adapted from Ref. [167].

with an increase in the dislocation density in this alloy. In contrast, the electrical conductivity in the $0.1 \mathrm{Cr}$ and $0.3 \mathrm{Cr}-0.5 \mathrm{Zr}$ alloys depends significantly on deformation temperature. The electrical conductivity of these alloys slightly decreases during the cold deformation due to the development of substructure with high dislocation density. On the other hand, the conductivity increases considerably (by $20 \%$ ICAS) at $400{ }^{\circ} \mathrm{C}$. This growth of conductivity can be associated with the precipitation of dispersed particles and the decomposition of solid solution.

\subsection{Annealing of $\mathrm{Cu}-\mathrm{Cr}-\mathrm{Zr}$ alloys after large strain deformation}

The post-deformation annealing was studied in the $0.1 \mathrm{Cr}$ in ST and AT conditions at temperatures of $300-700^{\circ} \mathrm{C}$ with an annealing time of $1 \mathrm{~h}$ [167]. Annealing at $300-500^{\circ} \mathrm{C}$ does not lead to any remarkable changes in the microstructures developed by ECAP (Fig. 33). Similar to the deformation microstructures, the annealed microstructures consist of almost equiaxed grains below $1 \mu \mathrm{m}$ in size irrespective of the initial alloy conditions. At $600^{\circ} \mathrm{C}$, a kind of abnormal grain growth occurs in the ST samples. The coarse grains with a size of 5-7 $\mu \mathrm{m}$ are surrounded by the ultra fine grains with a size about $1 \mu \mathrm{m}$. In contrast, the large grains with an average grain size of $5 \mu \mathrm{m}$ are only observed in the AT samples. Further increase in temperature is accompanied by a disappearance of the fine grains in the ST condition and the grain growth in the AT condition. Typical annealed substructures evolved in the ECAP samples are shown in Figs. $33 \mathrm{c}$ and $33 \mathrm{f}$. It is clearly seen that the annealed substructures are charac- terized by uniform distribution of dispersed particles. The average particle size is about $5 \mathrm{~nm}$ in the ST condition and about $50 \mathrm{~nm}$ in the AT condition.

Fig. 34a shows the change in the structural parameters, i.e., average grain size $(D)$ and dislocation density $(r)$ with annealing temperature. The grain growth is observed during annealing at $600^{\circ} \mathrm{C}$. The grain size in the AT samples is larger than in the ST samples under all annealing conditions. The dislocation density decreases slowly at $300-500{ }^{\circ} \mathrm{C}$ followed by a rapid decrease at $600 \mathrm{C}$. After annealing at $700{ }^{\circ} \mathrm{C}$ the dislocation density decreases to $0.5 \times 10^{14} \mathrm{~m}^{-2}$ in both ST and AT states.

The microstructure evolution during annealing is accompanied by non monotonic variation in the hardness with increasing the annealing temperature (Fig. 34b). After annealing at $300{ }^{\circ} \mathrm{C}$ the hardness increases. Then, the hardness slightly decreases after annealing at $400-500{ }^{\circ} \mathrm{C}$ followed by significant softening at $600^{\circ} \mathrm{C}$. The softening rate depends on the previous treatment. In the range of $300-500^{\circ} \mathrm{C}$, the softening rate in the ST condition is higher than that in AT. The softening rate at $600-700^{\circ} \mathrm{C}$ increases in the both states, but hardness degradation is more pronounced in the AT condition. The annealing hardening can be associated with particle strengthening due to the fine precipitations with a size of 4-5 $\mathrm{nm}$, the volume fraction of which increases after annealing compared to deformation microstructure. Annealing at $600-700{ }^{\circ} \mathrm{C}$ is accompanied by particle coarsening leading to a particle size of 50-100 $\mathrm{nm}$, and particle strengthening decreases.

Dispersed particles can efficiently stabilize the ultrafine-grained structure. Nanosized particles impede boundary motion at elevated temperatures 


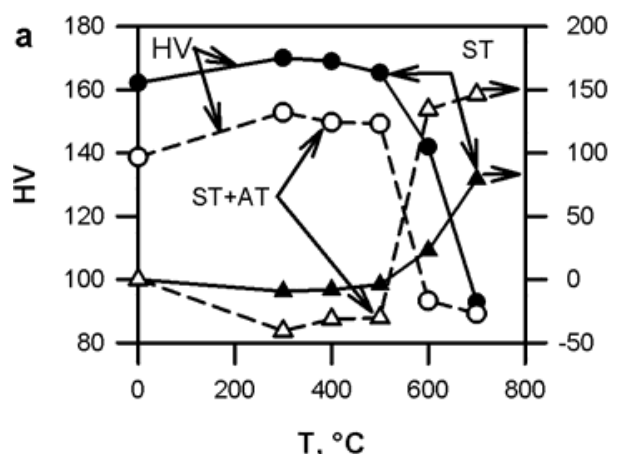

$\mathrm{T},{ }^{\circ} \mathrm{C}$
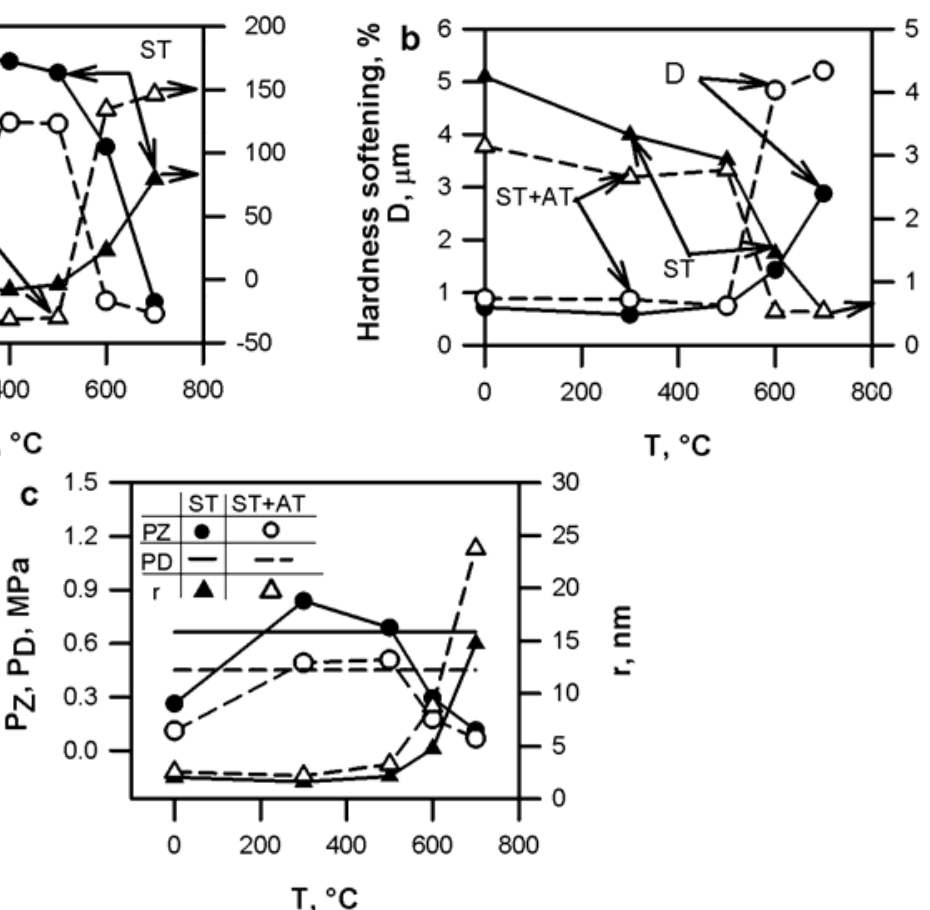

Fig. 34. Effect of annealing temperature on the grain size and the dislocation density (a), hardness and softening (b), Zener pinning pressure, $P_{Z}$, driving pressure, $P_{D}$, and particle size, $r,(\mathrm{c})$ in a low alloyed $\mathrm{Cu}$ Cr-Zr alloy after ECAP, adapted from Ref. [167].

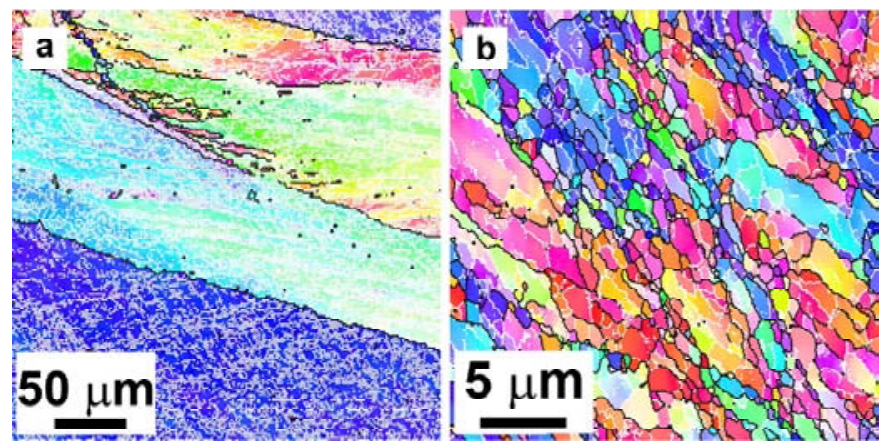

Fig. 35. Typical OIM micrographs of the fine structure in a $0.1 \mathrm{Cr}$ alloy after 1 (a) and 4 (b) ECAP passes followed by annealing at $500^{\circ} \mathrm{C}$ in the ST condition.

according to the Zener model [3,4]. The driving pressure for grain growth due to the curvature of the grain boundary is counteracted by the pinning pressure exerted by the particles on the boundary. The Zener pinning pressure $P_{Z}$ can be estimated as follows $[79,168]$ :

$$
P_{z}=\frac{3 f \gamma}{2 r},
$$

where $f$ is the volume fraction of the secondary phase, $\gamma$ is the boundary surface energy per unit area, and $r$ is the radius of particles.

The driving pressure for grain growth $P_{D}$ in materials after SPD is provided by the dislocation density [168]:

$$
P_{D}=\alpha G b \Delta \rho,
$$

where $\alpha$ is about $0.3, G$ is the shear module, $b$ is the Burgers vector, and $\rho$ is the dislocation density. Therefore, the size and volume fraction of particles control the structure stability during heating. Secondary phase particles evolve during aging or deformation at elevated temperature, as well as upon subsequent annealing. The change in the morphology of particles, their volume fraction, size and precipitation kinetics may have a significant effect on the microstructure, hardness and functional properties of the alloy. The influence of preliminary heat treatment on the microstructure and hardness of $\mathrm{Cu}-\mathrm{Cr}$-Zr alloys subjected to ECAP followed by annealing was detailed in [168].

The variations of Zener pinning pressure, $P_{Z}$, with temperature (Eq. (26)) and the driving pressure for grain growth, $P_{\mathrm{D}}$, (Eq. (27)) in the $0.1 \mathrm{Cr}$ alloy are 

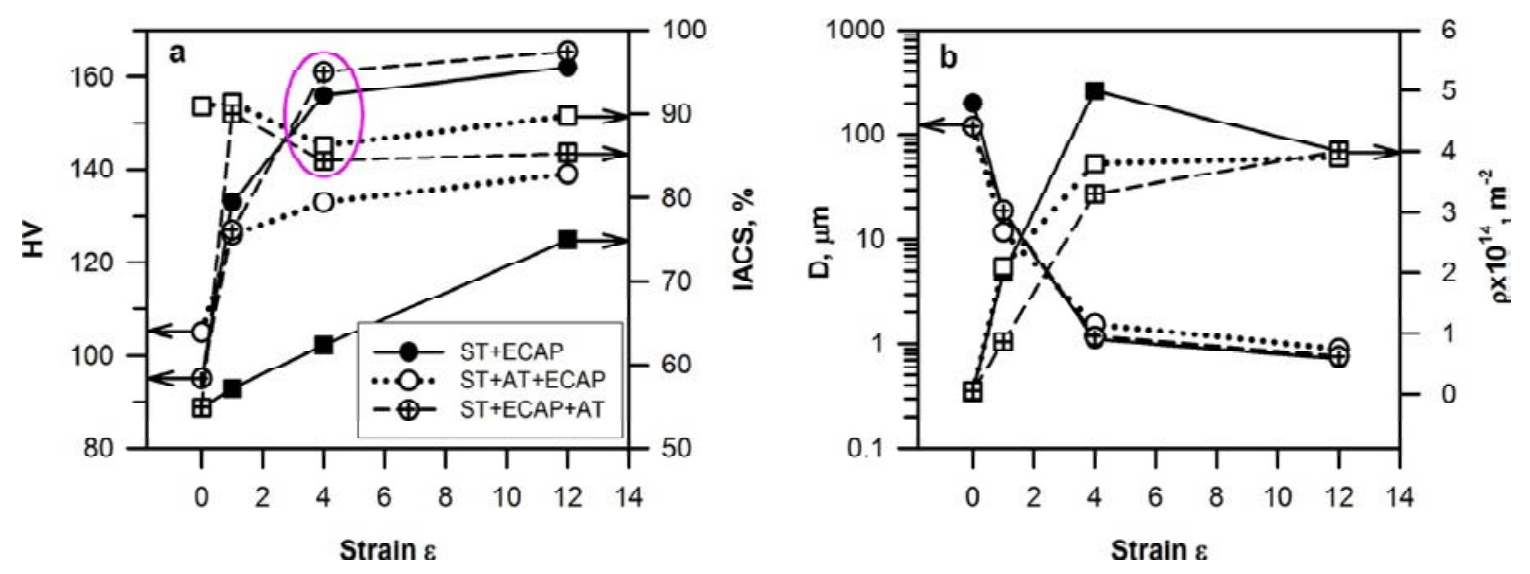

Fig. 36. Effect of processing sequence on: (a) microhardness (HV) and electroconductivity (IACS, \%), (b) grain size (D) and dislocation density $(\rho)$ in a $0.1 \mathrm{Cr}$ alloy, data taken from [167].

shown in Fig. 34c. The values of pinning pressure exceeds the driving pressure at temperatures up to $500^{\circ} \mathrm{C}$. As a result the fine particles fix grain boundaries and prevent their moving at $300-500^{\circ} \mathrm{C}$ Quick softening after annealing at $600{ }^{\circ} \mathrm{C}$ is associated with the Zener pinning pressure degradation due to particle coarsening. The coarsening kinetics at $600-$ $700{ }^{\circ} \mathrm{C}$ is faster in the AT samples than in the ST samples, so the softening is faster as well, Fig. (34b). It should be noted that the hardness of ST samples after deformation and annealing is higher than that in the AT samples.

The sequence of thermo-mechanical treatment operations can significantly affect the microstructure and the mechanical/physical properties of the material. The dissolution of particles during solid solution treatment or secondary phase precipitation during aging or warm plastic deformation can influence the mechanisms and kinetic of microstructural evolution and properties of $\mathrm{Cu}-\mathrm{Cr}-\mathrm{Zr}$ alloys. The influence of pre-deformation and post-deformation aging was investigated in the $0.1 \mathrm{Cr}$ alloy. Typical microstructures of the alloy are shown for the following types of thermo-mechanical treatments: ST and ECAP to a strain of 1, 4, 12 (Fig. 14); ST + AT and ECAP to a strain of 1, 4, 12 (Fig. 14), ST and ECAP to a strain of $1,4,12$ followed by post-deformation aging at temperature of $500^{\circ} \mathrm{C}$ for $1 \mathrm{~h}$ (Fig. 35).

Continuous dynamic recrystallization develops that is assisted by deformation microbands leading to a large number of strain-induced subboundaries, misorientation of which increase with straining regardless of the type of pre-deformation treatment (see 3.1). Plastic deformation at $400{ }^{\circ} \mathrm{C}$ leads to solid solution decomposition and particle precipitation. Aging at $500{ }^{\circ} \mathrm{C}$ promotes the solid solution decomposition. Remarkable grain refinement takes place at 1-4 strain, followed by a slight decrease in the grain size upon further straining. Recovery develops in the $0.1 \mathrm{Cr}$ alloy after aging at $500^{\circ} \mathrm{C}$ during $1 \mathrm{~h}$ leading to dramatic decrease in the dislocation density while the grain size remains stable regardless of prior strain.

Particle precipitation and high dislocation density during ECAP provide higher hardening of the ST $0.1 \mathrm{Cr}$ alloy comparing with the AT samples (Fig. 36). Post-deformation aging leads to an additional hardening due to the dispersion strengthening. Remarkable strengthening is observed after 1-4 ECAP passes. Maximum of electrical conductivity in the $0.1 \mathrm{Cr}$ is observed after pre-deformation aging. In contrast, solid solution treatment leads to a drastic decrease in the electrical conductivity. The large plastic deformation and post deformation aging restore the high level of electrical conductivity (Fig. 36).

It clearly seen in Fig. 36 that post-ECAP aging of the ST $0.1 \mathrm{Cr}$ alloy provides a beneficial combination of hardness and electrical conductivity. Note here that an increase in the ECAP strain above 4 has insignificant influence on the microstructural parameters and properties of the alloy. Thus, optimal treatment of $0.1 \mathrm{Cr}$ alloy is a solution treatment and ECAP at $400{ }^{\circ} \mathrm{C}$ to a total strain of 4 followed by an aging at $500{ }^{\circ} \mathrm{C}$ for $1 \mathrm{~h}$. Such treatment provides hardness about $165 \mathrm{HV}$ and electrical conductivity of $85 \%$ IACS.

\section{SUMMARY}

The microstructural design of high strength and high conductivity $\mathrm{Cu}-\mathrm{Cr}-\mathrm{Zr}$ alloys, their alloying concept, thermo-mechanical processing based on technique of severe plastic deformation, physical mechanisms 
responsible for high strength and electric conductivity are considered. Advanced approaches to obtain the beneficial property combination should involve complex control of all structure-property relationships including dispersed particles, grain/ subgrain sizes, dislocation densities, etc., as briefly summarized below.

The decomposition of the supersaturated solid solutions in $\mathrm{Cu}-\mathrm{Cr}$-Zr alloys may include the formation of several precipitates, like GP zones, ordered fcc $C r$-rich phase, coherent B2 phase, $\beta$ - $C r$, depending on the chemical composition. Minor Zr additions play a key role in restraining coherency for $\mathrm{Cr}$ particles that increases contribution of these particles to dispersion hardening, which may reach over 150 $\mathrm{MPa}$. The solid solution decomposition is quite important for electrical conductivity, e.g., solid solution of $0.6 \mathrm{wt} . \% \mathrm{Cr}$ and $0.1 \mathrm{wt} . \% \mathrm{Zr}$ decreases the conductivity to $40 \%$ IACS.

The outstanding mechanical and functional properties in the $\mathrm{Cu}-\mathrm{Cr}-\mathrm{Zr}$ alloys can be attained by a combination of aging treatment and large plastic deformation. The formation of the ultra-fine grained microstructure with high dislocation density by means of severe plastic deformation results in significant strengthening. Typical grain sizes after severe plastic deformation are $0.5-0.7 \mu \mathrm{m}$. Note that alloying extent promotes the kinetics of grain refinement and dislocation density increase. The dislocation strengthening dominates over other strengthening mechanisms. The dislocation strengthening is 1.5-2 times larger than the grain boundary strengthening and may attain $350 \mathrm{MPa}$, depending on the deformation conditions and chemical composition of the alloy. It is worth noting that plastic working at elevated temperatures promotes the solid solution decomposition and, therefore, concurently improves both the strength and conductivity of the alloy.

A wear resistance is another critical issue for industrial application of $\mathrm{Cu}-\mathrm{Cr}$ - Zr alloys. The wear rate depends significantly on the microstructure. Large plastic deformations leading to the ultrafine grains arranged in deformation microbands remarkably improve the wear resistance. Therefore, the grain refinement by severe plastic deformation has a beneficial effect on both the strength and wear resistance of the alloy.

Further improvement of properties of $\mathrm{Cu}-\mathrm{Cr}-\mathrm{Zr}$ alloys subjected to severe plastic deformation can be achieved by an appropriate post-deformation heat treatment. Post-deformation aging can be used for additional hardening and electrical conductivity increase owing to complete precipitation of solutes in
$\mathrm{Cu}$-Cr-Zr alloys. Therefore, optimal processing route of advanced $\mathrm{Cu}-\mathrm{Cr}-\mathrm{Zr}$ alloys should include an initial heat treatment, large plastic deformation, and final aging. The alloying content and processing conditions should be detailed in accordance with intended application of the alloys, enhancing either strength or conductivity.

The progress in the development of high-strength and high-conductivity Cu-Cr-Zr alloys is closely connected with solution of both fundamental and practical problems. The former is currently associated with more detailed investigations of precipitation reactions, which are not perfectly understood and should be clarified for both aging tretment and warm working depending on the chemical composition. From the practical viewpoint, commercial applications of thermo-mechanical treatments for $\mathrm{Cu}-\mathrm{Cr}-\mathrm{Zr}$ alloys require the development of processing technologies involving severe plastic deformation, like ECAP-Conform process, which are of high efficiency and can be used for production of sizeable semiproducts.

\section{ACKNOWLEDGEMENTS}

The financial support received from the Ministry of Science and Education, Russia, under grant No. 14.575.21.0135 (ID RFMEFI57517X0135) is gratefully acknowledged. The authors are grateful to the personnel of the Joint Research Center, "Technology and Materials", Belgorod National Research University, for their assistance with instrumental analysis.

\section{REFERENCES}

[1] O. E. Osintsev and V.N. Fedorov, Copper and copper alloys (Mechanical engineering, Moscow, 2004).

[2] V. Sedláček, Non-Ferrous Metals and Alloys (Elsevier, 1986).

[3] Y. Karaki, Y. Koike, M. Kubota and H. Ishimoto // Cryogenics 37 (1997) 171.

[4] G. Straffelini, L. Maines, M. Pellizzari and P. Scardi // Wear 259 (2005) 506.

[5] J. Lerner, Jr and C. J. McMahon // Mater. Sci. Eng. A 336 (2002) 72.

[6] L.X. Sun, N.R. Tao and K. Lu // Scr. Mater. 99 (2015) 73.

[7] Z. Zhao, Z. Xiao, Z. Li, M. Ma and J. Dai // J. Alloys Comp. 752 (2018) 191.

[8] J.W. Davis and G.M. Kalinin // J. Nucl. Mater. 258-263 (1998) 323. 
[9] A.D. Ivanov, A.K. Nikolaev, G.M. Kalinin and M.E. Rodin // J. Nucl. Mater. 307-311 (2002) 673.

[10] A. Hernandez-Perez, M. Eddahbi, M.A. Monge, A. Munoz and B. Savoini // Fusion Eng. Des. 98-99 (2015) 1978.

[11] W. Tian, L. Bi, F. Ma and J. Du // Vacuum 149 (2018) 238.

[12] A. Belyakov, M. Murayama, Y. Sakai, K. Tsuzaki, M. Okubo, M. Eto and T. Kimura // J. Electron. Mater. 35 (2006) 2000.

[13] U. Holzwarth and H. Stamm // J. Nucl. Mater. $279(2000) 31$.

[14] K. X. Wei, W. Wei, F. Wang, Q. B. Du, I. V. Alexandrov and J. Hu // Mater. Sci. Eng. A 528 (2011) 1478.

[15] S. Xu, H. Fu, Y. Wang and J. Xie // Mater. Sci. Eng. A 726 (2018) 208.

[16] N. Gao, E. Huttunen-Saarivirta, T. Tiainen and M. Hemmila // Mater. Sci. Eng. A 342 (2003) 270.

[17] W.X. Qi, J.P. Tu, F. Liu, Y.Z. Yang, N.Y. Wang, H.M. Lu, X.B. Zhang, S.Y. Guo and M.S. Liu // Mater. Sci. Eng. A 343 (2003) 89.

[18] X. Chen, F. Jiang, L. Liu, H. Huang and Z. Shic // Mater. Sci. Techn. 34 (2018) 282.

[19] M. Kulczyka, W. Pachla, J. Godek, J. Smalc-Koziorowska, J. Skiba, S. Przybysz, M. Wróblewska and M. Przybysz // Mater. Sci. Eng. A 724 (2018) 45.

[20] Y. Wang, P. Xing, P. Wang and J. Liu // J. Alloys Comp. 656 (2016) 581.

[21] G. Purcek, H. Yanar, D.V. Shangina, M. Demirtas, N.R. Bochvar and S.V. Dobatkin // J. Alloys Compd. 742 (2018) 325.

[22] D. V. Shangina, N. R. Bochvar and S. V. Dobatkin // J. Mater. Sci. 47 (2012) 7764.

[23] G. Purcek, H.Yanar, O.Saray, I.Karaman and H.J.Maier // Wear 311 (2014) 149.

[24] A. Vinogradov, Y. Suzuki, T, Ishida, K. Kitagawa and V. I. Kopylov // Mater. Trans. 45 (2004) 2187.

[25] N. Liang, J. Liu, S. Lin, Y. Wang, J. T. Wang, Y. Zhao and Y. Zhu // J. Alloys Compd. 735 (2018) 1389.

[26] S. Zhang, R. Li, H. Kang, Z. Chen, W. Wang, C. Zou and T. Wang // Mater. Sci. Eng. A 680 (2017) 108.

[27] W. B. Gauster // J. Nucl. Mater. 212 (1994) 3.

[28] K.J. Zeng and M. Hamalainen // J. Alloys Comp. 220 (1995) 53.
[29] K. Zeng and M. Hamalainen // Calphad 19 (1995) 93.

[30] N. Wang, C. Li, Z. Du, F. Wang and W. Zhang // Computer Coupling of Phase Diagrams and Thermochemistry 30 (2006) 461.

[31] Y. Liu, P. Zhou, S. Liu and Y. Du // CALPHAD: Computer Coupling of Phase Diagrams and Thermochemistry 59 (2017) 1.

[32] Y. Liu, S. Liu, C. Zhang, Y. Du, J. Wang and Y. Li // J. Phase Equilib. Diffus. 38 (2017) 121.

[33] N. Bochvar, Chromium-Copper-Zirconium (Springer, Berlin, 2007).

[34] Z. Zhang, J. Guo, G. Dehm and R. Pippan // Acta Mater. 138 (2017) 42.

[35] A. Chbihi, X. Sauvage and D. Blavette // Acta Mater. 60 (2012) 4575.

[36] A. Korneva, B. Straumal, A. Kilmametov, R. Chulist, P. Straumal and P. Zięba // Mater. Char. 114 (2016) 151.

[37] J. Guo, J. M. Rosalie, R. Pippan and Zaoli Zhang // Mater. Sci. Eng. A 695 (2017) 350.

[38] P. Liu, B.X. Kang, X.G. Cao, J.L. Huang, B. Yen and H.C. Gu // Mater. Sci. Eng.: A 265 (1999) 262.

[39] F. Lopez, J. Reyes, B. Campillo, G. Aguilar-Sahagun and J.A. Juarez-Islas // J. Mater. Eng. Perform. 6 (1997) 611.

[40] J. Stobrawa, L. Ciura and Z. Rdzawski // Scr. Mater. 34 (1996) 1759.

[41] X. Wang, J. Zhao and J. He // Mater. Sci. Eng. A 460-461 (2007) 69.

[42] D. V. Shangina, V. F. Terent'ev, D. V. Prosvirnin, O. V. Antonova, N. R. Bochvar, M. V. Gorshenkov and S. V. Dobatkin // Adv. Eng. Mater. 20 (2018) 1700536.

[43] D. V. Shangina, N. R. Bochvar and S. V. Dobatkin // Inorg. Mater.: Applied Research 7 (2016) 465.

[44] S. V. Dobatkin, D. V. Shangina, N. R. Bochvar and M. Janeček // Mater. Sci. Eng. A 598 (2014) 288.

[45] D. V. Shangina, J. Gubicza, E. Dodony, N. R. Bochvar, P. B. Straumal, N. Y. Tabachkova and S. V. Dobatkin // J. Mater. Sci. 49 (2014) 6674.

[46] D. Shangina, Y. Maksimenkova, N. Bochvar, V. Serebryany, G. Raab, A. Vinogradov and S. Dobatkin // Advanced Materials Research 922 (2014) 651.

[47] A. Morozova and R. Kaibyshev // Philosophical Magazine 97 (2017) 2053. 
[48] A.Kauffmann, D.Geissler and J.Freudenberger // Mater. Sci. Eng. A651 (2016) 567.

[49] S. Chenna Krishna, G. Sudarsana Rao, Abhay K. Jha, Bhanu Pant and P.V. Venkitakrishnan // Mater. Sci. Eng. A 674 (2016) 164.

[50] A. P. Zhilyaev, I. Shakhova, A. Morozova, A. Belyakov and R. Kaibyshev // Mater. Sci. Eng. A 654 (2016) 131.

[51] R. Mishnev, I. Shakhova, A. Belyakov and R. Kaibyshev // Mater. Sci. Eng. A 629 (2015) 29.

[52] S. C. Krishna, N. K. Karthick, G. S. Rao, A. K. Jha, B. Pant and R. M. Cherian // J. Mater. Eng. Perform. 27 (2018) 787.

[53] K.V. León, M.A. Munoz-Morris and D.G. Morris // Mater. Sci. Eng. A 536 (2012) 181.

[54] N. Takata, Y. Ohtake, K. Kita, K. Kitagawa and N. Tsuji // Scripta Mater. 60 (2009) 590.

[55] C.Z. Xu, Q.J. Wang, M.S. Zheng, J.W. Zhua, J.D. Li, M.Q. Huang, Q.M. Jia and Z.Z. Duc// Mater. Sci. Eng. A 459 (2007) 303.

[56] H.T. Zhou, J.W. Zhong, X. Zhou, Z.K. Zhao and Q.B. Li // Mater. Sci. Eng. A 498 (2008) 225.

[57] A. Vinogradov, V. Patlan, Y. Suzuki, K. Kitagawa and V. I. Kopylov // Acta Mater. 50 (2002) 1639.

[58] Q. Liu, X. Zhang, Y. Ge, J. Wang and J. Z. Cui // Metall. Mater. Trans. A 37 (2006) 3233.

[59] I. Shakhova, Z. Yanushkevich, I. Fedorova, A. Belyakov and R. Kaibyshev // Mater. Sci. Eng. A 606 (2014) 380.

[60] A. Morozova, E. Borodin, V. Bratov, S. Zherebtsov, A. Belyakov and R. Kaibyshev // Materials 10 (2017) 1394.

[61] V. I. Zel'dovich, S. V. Dobatkin, N. Y. Frolova, I. V. Khomskaya, A. E. Kheifets, E. V. Shorokhov and P. A. Nasonov // Phys. Metal. Metall. 117 (2016) 74.

[62] I. V. Khomskaya, V. I. Zel'dovich, E. V. Shorokhov, N. Yu. Frolova, A. E. Kheifets and V. P. Dyakina // Russian Metallurgy (Metally) 10 (2017) 851.

[63] S. V. Dobatkin, J. Gubicza, D. V. Shangina, N. R. Bochvar and N. Y. Tabachkova // Mater. Lett. 153 (2015) 5.

[64] D. Shangina, Y. Maksimenkova, N. Bochvar, V. Serebryany, G. Raab, A. Vinogradov, W. Skrotzki and S. Dobatkin // J. Mater. Sci. 51 (2016) 5493.

[65] D.V. Shangina, N.R. Bochvar, M.V. Gorshenkov, H. Yanar, G. Purcek and S.V. Dobatkin // Mater. Sci. Eng. A 650 (2016) 63.
[66] D. V. Shangina, N. R. Bochvar and S. V. Dobatkin // Russian Metallurgy (Metally) 11 (2010) 1046.

[67] D. V. Shangina, Yu. M. Maksimenkova, N. R. Bochvar and S. V. Dobatkin // Russian Metallurgy (Metally) 11 (2011) 1069.

[68] G. Purcek, H.Yanar, M.Demirtas, Y.Alemdag, D.V.Shangina and S.V.Dobatkin // Mater. Sci. Eng. A 649 (2016) 114.

[69] D. V. Shangina, N. R. Bochvar, A. I. Morozova, A. N. Belyakov, R. O. Kaibyshev and S. V. Dobatkin // Mater. Lett. 199 (2017) 46.

[70] P.K. Jayakumara, K. Balasubramaniana and G. Rabindranath Tagore // Mater. Sci. Eng. A 538 (2012) 7.

[71] G.V. Zel'dovich, N.Y.Frolova, I.V.Khomskaya, A.E.Kheifets, E.V.Shorokhov and P.A.Nasonov // Phys.Met.Metallogr. 115 (2014) 465.

[72] R. K. Islamgaliev, K. M. Nesterov, J. Bourgon, Y. Champion and R. Z. Valiev // J. Appl. Phys. 115 (2014) 194301.

[73] Y.Estrin and A.Vinogradov // Acta Mater. 61 (2013) 782.

[74] F. Dalla Torre, R. Lapovok, J. Sandlin, P.F. Thomson, C.H.J. Davies and E.V. Pereloma // Acta Mater. 52 (2004) 4819.

[75] A.P. Zhilyaev, I. Shakhova, A. Belyakov, R. Kaibyshev and T.G.Langdon // Wear 305 (2013) 89.

[76] M. Saitoh, M. Kajihara, Y. Tomioka and J. Miyake // Mater. Sci. Eng. A 318 (2001) 87.

[77] V. I. Zel'dovich, N. Yu. Frolova, I. V. Khomskaya and A. E. Kheifets // Phys. Metal. Metall. 117 (2016) 710.

[78] V. I. Zel'dovich, I. V. Khomskaya, N. Yu. Frolova, A. E. Kheifets, E. V. Shorokhov and P. A. Nasonov // Phys. Met. Metall. 114 (2013) 411.

[79] F. Huang, J. Ma, H. Ning, Z. Geng, C. Lu, S. Guo, X. Yu, T. Wang, H. Li and H. Lou // Scripta Mater. 48 (2003) 97.

[80] J.Y.Cheng, F.X.Yu and B.Shen // Mater. Lett. 115 (2014) 201.

[81] L. Peng, H. Xie, G. Huang, G. Xu, X. Yin, X. Feng, X. Mi, Z. Yang // J. Alloys Comp. 708 (2017) 1096.

[82] J.Y. Cheng, B. Shen and F.X. Yu // Mater. Charact. 81 (2013) 68.

[83] N.Y. Tang, D.M. Taplin and G.L. Dunlop // Mater. Sci. Technol. 1 (1985) 270. 
[84] I.S. Batra, G.K. Dey, U.D. Kulkarni and S. Banerjee // J. Nucl. Mater. 299 (2001) 91.

[85] I.S. Batra, G.K. Dey, U.D. Kulkarni and S. Banerjee // Mater. Sci. Eng. A 356 (2002) 32

[86] S. H. Huh, H. K. Kim, J. W. Park and G. H. Lee // Phys. Rev. 62 (2000) 2937.

[87] A. Bachmaier, G.B. Rathmayr, M. Bartosik, D. Apel, Z. Zhang and R. Pippan // Acta Mater. 69 (2014) 301.

[88] C. Xia, W. Zhang , Z. Kang, Y. Jia, Y. Wu, R. Zhang, G. Xu and M. Wang // Mater. Sci. Eng. A 538 (2012) 295.

[89] T. Fujii, H. Nakazawa, M. Kato and U. Dahmen // Acta Mater. 48 (2000) 1033.

[90] Y. Jin, K. Adachi, T. Takeuchi and H.G. Suzuki // J. Mater. Sci. 33 (1998) 1333.

[91] D.A. Porter, K.E. Easterling and M. Sherif, Phase Transformations in Metals and Alloys, third ed. (CRC Press, 2009).

[92] L. Peng, H. Xie, G. Huang, Y. Li, X. Yin and X. Feng // Mater. Sci. Eng. A 633 (2015) 28.

[93] Y. Ye, X. Yang, J. Wang, X. Zhang, Z. Zhang and T. Sakai // J. Alloys and Compd. 615 (2014) 249.

[94] H. Wang, L. Gong, J. Liao, H. Chen, W. Xie and B. Yang // J. Alloys Compd. 749 (2018) 140.

[95] Y. Zhang, A. A. Volinsky, H. T. Tran, Z. Chai, P. Liu, B. Tian and Y. Liu // Mater. Sci. Eng. A650 (2016) 248.

[96] H. Fu, S. Xu, W. Li, J. Xie, H. Zhao and Z. Pan // Mater. Sci. Eng. A 700 (2017) 107.

[97] Ch. Watanabe, R. Monzen and K. Tazaki // J Mater Sci 43 (2008) 813.

[98] M. Hatakeyama, T. Toyama, Y. Nagai, M. Hasegawa, M. Eldrup and B. N. Singh // Mater. Trans. 49 (2008) 518.

[99] J. H. Su, Q. M. Dong, P. Liu, H. J. Li and

B. X. Kang // Mater. Sci. Eng. A 392 (2005) 422.

[100] K. Abib, F.H. Larbi, L. Rabahi, B. Alili, D. Bradai // Trans. Nonferrous Met. Soc. China 25 (2015) 838.

[101] M.A. Turchanin // Powder Metall. Met. C 45 (2006) 457.

[102] S. Sheibani, S. Heshmati-Manesh, A. Ataie, A. Caballero and J. M. // J. Alloys Compd. 587 (2014) 670.

[103] P. R. Subramanian and D. E. Laughlin // Bulletin of Alloy Phase Diagrams 9 (1988) 51.
[104] Z. Shijie, Z. Bingjun, Z. Zhen and J. Xin // Journal of Rare Earths 24 (2006) 385.

[105] Z. W. Du, Z. M. Sun, B. L. Shao and A. S. Liu // Mater. Sci. Forum 610 (2009) 591.

[106] D. Hull and D. J. Bacon, Introduction to dislocation (Butterworth-Heinemann, Oxford, 1984).

[107] D. Lu. and C.P. Wong, Materials for Advanced Packaging (Springer, New York, 2009).

[108] H.J. Frost and M.F. Ashby, Deformation mechanism maps: the plasticity and creep of metals and ceramics (Pergamon, Oxford, 1982).

[109] L. M. Brown and R. K. Ham, Dislocationparticle interactions (Appl. Sci. Publ. LTD, London, 1971).

[110] L. M. Brown and R. K. Ham, Strengthening methods in crystals (Applied Science, London, 1971).

[111] K.C. Russell and L.M. Brown // Acta Metall. Mater. 20 (1972) 969.

[112] A.J.E. Foreman and M.J. Makin // Philos. Mag. 14 (1966) 911.

[113] T. J. Harrell, T. D. Topping, H. Wen, T. Hu, J. M. Schoenung and E. J. Lavernia // Metall. Mater. Trans. A 45 (2014) 6329.

[114] T.J. Koopenaal and D. Kuhlmann-Wilsdorf // Appl. Phys. Lett. 4 (1964) 59.

[115] I. Holzer and E. Kozeschnik // Mater. Sci. Eng. A 527 (2010) 3546.

[116] E. O. Hall // Proc. Phys. Soc. B 64 (1951) 747753.

[117] N. J. Petch // J. Iron Steel Inst. 174 (1953) 2528.

[118] M. Kato // Mater. Trans. 55 (2014) 19.

[119] S. Malopheyev, V. Kulitskiy and R. Kaibyshev // J. Alloys Compd. 698 (2017) 957.

[120] N. Kamikawa, X. Huang, N. Tsuji and N. Hansen // Acta Mater. 57 (2009) 4198.

[121] N. Hansen // Mater. Sci. Eng. A 409 (2005) 39.

[122] N. Hansen // Scr. Mater. 51 (2004) 801.

[123] D.A. Hughes and N. Hansen // Acta Mater. $48(2000) 2985$.

[124] J. Li // Trans. Metall. Soc. AIME 277 (1963), pp. 239-247.

[125] S. Malopheyev and R. Kaibyshev // Mater. Sci. Eng. A 620 (2015) 246.

[126] P. S. Kusakin and R. O. Kaibyshev // Rev. Adv. Mater. Sci 44 (2016) 326. 
[127] Z. Yanushkevich, A. Mogucheva, M. Tikhonova, A. Belyakov and R. Kaibyshev // Mater. Char. 62 (2011) 432.

[128] M. Odnobokova, A. Belyakov and R. Kaibyshev // Metals 5 (2015) 656.

[129] P. Kusakin, K. Tsuzaki, D. A. Molodov, R. Kaibyshev and A. Belyakov // Metall. Mater. Trans. A 47 (2016) 5704.

[130] M. Yu. Murashkin, I. Sabirov, X. Sauvage and R. Z. Valiev // J. Mater. Sci. 51 (2016) 33.

[131] X. Chen, F. Jiang, J. Jiang, P. Xu, M. Tong and Z. Tang // Metals 8 (2018) 227.

[132] P. Liu, B. X. Kang, X. G. Cao, J. L. Huang and H. C. Gu // J. Mater. Sci. 35 (2000) 1691.

[133] O. Saray // Mater. Sci. Eng. A 656 (2016) 120.

[134] I. Faizov, G. Raab and D. Aksenov // Key Engineering Materials 743 (2017) 743.

[135] J. Zhou, D. Zhu, L. Tang, X. Jiang, S. Chen, X. Peng and C. Hu // Vacuum 131 (2016) 156.

[136] Y. Liu, Z. Li, Y. Jiang, Y. Zhang, Z. Zhou and Q. Lei // J. Mater. Res. 32 (2017) 1324.

[137] T. Akita, K. Kitagawa, K. Kita, M. Gotoh, Y. Hirose and N. Tsuji // Journal of Physics: Conference Series 240 (2010) 012119.

[138] K. Rodak, A. Brzezińska and R. Molak // Mater. Sci. Eng. A 724 (2018) 112.

[139] R. Mishnev, I. Shakhova, A. Belyakov and R. Kaibyshev // IOP Conference Series: Mater. Sci. Eng. A 63 (2014) 012094.

[140] J. Cizek, I. Prochazka, M. Cieslar, R. Kuzel, J. Kuriplach, F. Chmelik, I. Stulikova, F. Becvar, O. Melikhova and R. K. Islamgaliev // Phys. Rev. B65 (2002) 094106.

[141] A. Morozova, A. Belyakov and R. Kaibyshev // Mater. Sci. Forum 879 (2017) 1332.

[142] A. Morozova, Y. Olkhovikova, E. Tkachev, A. Belyakov and R. Kaibyshev // Mater. Sci. For., in Press.

[143] A.A. Luhvich, Influence of defects on the electrical properties of metals (Science and Technology, Minsk, 1976).

[144] K.M. Nesterov, Strength and electroconductivity of ultrafine grained $\mathrm{Cu}$ Cr-Zr alloy (Doctoral dissertation, 2017, ProQuest Dissertations and Theses database UMI No. 01008712230).

[145] R. Chembarisova, I. Alexandrov and W. Wei // Mater. Sci. Forum, in Press.
[146] S. G. Mu, F. A. Guo, Y. Q. Tang, X. M. Cao and M. T. Tang // Mater. Sci. Eng., A 475 (2008) 235.

[147] J.B. Correia, H.A. Davies and C.M. Sellars // Acta Mater. 45 (1997) 177.

[148] G. Ghosh, J. Miyake and M. E. Fine // JOM 49 (1997) 56.

[149] J.F. Archard // J. Appl. Phys. 24 (1953) 981.

[150] J.F. Archard and W. Hirst // Proc. Royal. Soc. A 236 (1956) 397.

[151] A. P. Zhilyaev, A. Morozova, J. M. Cabrera, R. Kaibyshev and T. G. Langdon // J. Mater. Sci. 52 (2017) 305.

[152] G.J. Raab, R.Z. Valiev, T.C. Lowe and Y.T. Zhu // Mater. Sci. Eng. A 382 (2004) 30.

[153] S. Gourdet and F. Montheillet // Acta Mater. 51 (2003) 2685.

[154] F.J. Humphreys, P.B. Prangnell, J.R. Bowen, A. Gholinia and C. Harris // Philos. Trans. Roy. Soc. A: Math. Phys. Eng. Sci. 357 (1999) 1663.

[155] T. Sakai, A. Belyakov, R. Kaibyshev, H. Miura and J.J. Jonas // Prog. Mater. Sci. 60 (2014) 130-207.

[156] F.X. Lin, Y.B. Zhang, N. Tao, W. Pantleon and D. Juul Jensen // Acta Mater. 72 (2014) 252.

[157] A. Kolmogorov // Izv. Acad. Sci. USSR, Math. Ser. 1 (1937) 355.

[158] W.A. Johnson. R.F. Mehl // Trans. Am. Inst. Min. Metall. Pet. Eng. 135 (1939) 396.

[159] M. Avrami // J. Chem. Phys. 7 (1939) 1103.

[160] A. Belyakov, S. Zherebtsov, M. Tikhonova and G. Salishchev // Mater. Phys. Mech. 24 (2015) 224.

[161] X. Quelennec and J.J. Jonas // ISIJ Int. 52 (2012) 1145.

[162] J. J. Jonas, X. Quelennec, L. Jiang and É. Martin // Acta Mater. 57 (2009) 2748.

[163] W.F. Smith and J. Hashemi, Foundations of Materials Science and Engineering (McGraw-Hill, New York, 2003).

[164] I. Shakhova, A. Belyakov and R. Kaibyshev / I Mater. Sci. Forum 879 (2017) 1749.

[165] M. Sauzay and L.P. Kubin // Prog. Mater. Sci. 56 (2011) 725.

[166] F.F. Lavrentev // Mater. Sci. Eng. 46 (1980) 191.

[167] A. Morozova, A. Belyakov, R. Kaibyshev // AIP Conf. Proc. 1909 (2017) 020142.

[168] P. A. Manohar, M. Ferry and T. Chandra // ISIJ Int. 38 (1998) 913. 